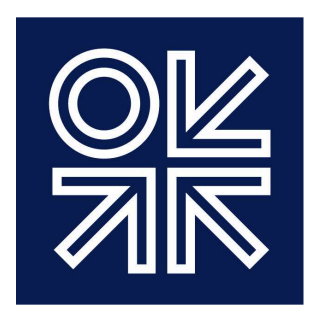

THE OXFORD

INSTITUTE

FOR ENERGY

STUDIES

\title{
The Offshore Discovery in the Republic of Cyprus
}

Monetisation Prospects and Challenges

Anastasios Giamouridis

NG 65

July 2012 
The contents of this paper are the author's sole responsibility. They do not necessarily represent the views of the Oxford Institute for Energy Studies, of any of the Institute's members, and/or of the author's other affiliations.

Copyright $\mathbb{C} 2012$

Oxford Institute for Energy Studies

(Registered Charity, No. 286084)

This publication may be reproduced in part for educational or non-profit purposes without special permission from the copyright holder, provided acknowledgment of the source is made. No use of this publication may be made for resale or for any other commercial purpose whatsoever without prior permission in writing from the Oxford Institute for Energy Studies.

ISBN

$978-1-907555-55-8$ 


\section{Preface}

The discovery of a significant gas field offshore Cyprus in December 2011 by Noble Energy, came close on the heels of the major discoveries in adjacent offshore Israel, further astounding the international upstream exploration and production community who had largely overlooked the prospectivity of this area. For the Republic of Cyprus, whose economy is dominated by tourism and the service sector, and whose prospects appear overshadowed by Eurozone economic malaise, this discovery offers a path to lower domestic energy costs and substantial export revenues. However, as is often the case with unexpected fortune, decisions on how best to develop such a resource for the benefit of a country with a history of inter-ethnic tensions are not straightforward and further complicated by Cyprus' geographic and geopolitical setting.

In this working paper, Anastasios Giamouridis describes the status of the Aphrodite discovery, applications for the 2nd licensing round, and options for the development of the field and the export strategy for gas produced in excess of Cyprus' modest current and future consumption needs. He juxtaposes the logical process of progressively defining field development and export options by the operator facing the customary field size uncertainty ahead of further appraisal drilling, with the rising expectations not just of the Cypriot government; but also neighbouring countries with either aspirations to share in this source of hydrocarbon wealth, or openly disputing Cyprus' sovereign hydrocarbon ownership rights. Into this already complex array of issues, Anastasios introduces the pros and cons of future unitisation and joint development with Israel with the potential of alienating potentially valuable IOC participants. In addition, he examines the institutional capability of the Cypriot government to successfully guide the optimal monetisation of this resource given the intricate negotiations necessary not only with upstream participants but also possible transit country governments; and this at a time when Cypriot authorities are focussed on Cyprus's EU Presidency in the second half of 2012 .

This paper, as well as presenting a detailed and comprehensive account of the challenges facing Cyprus in the monetisation of its hydrocarbon resource, exemplifies the OIES Natural Gas Programme's desire to integrate the more tangible aspects of the natural gas industry with the interlinking social and geopolitical considerations, in an independent and objective manner.

Howard V Rogers 


\section{Table of Contents}

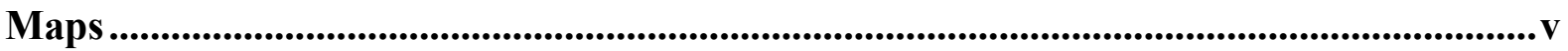

Figures......................................................................................................................................vi

Acknowledgments ..............................................................................................................................vii

1. Background ......................................................................................................................1

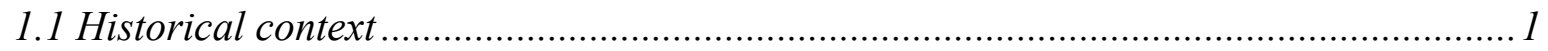

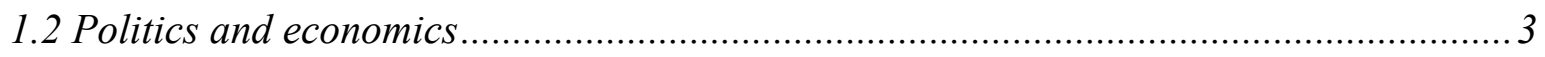

2. Local energy market and gasification prospects .............................................................6

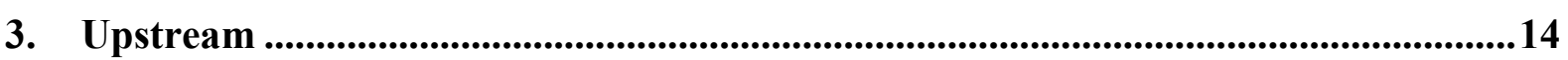

3.1 Exclusive economic zones and unitisation agreements............................................ 14

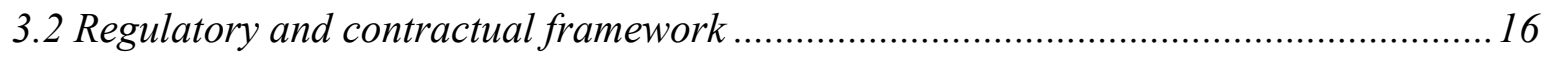

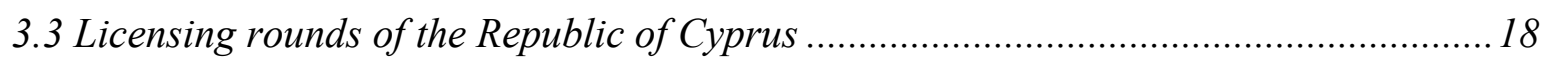

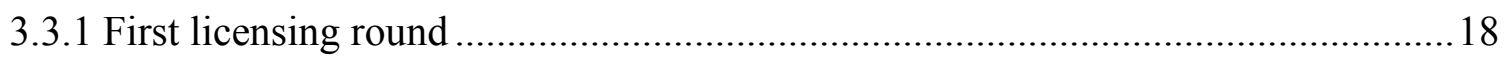

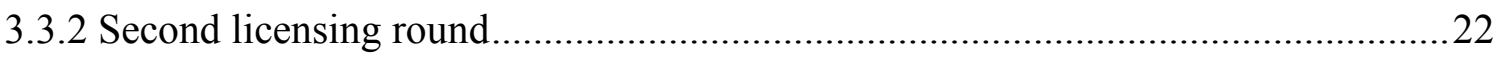

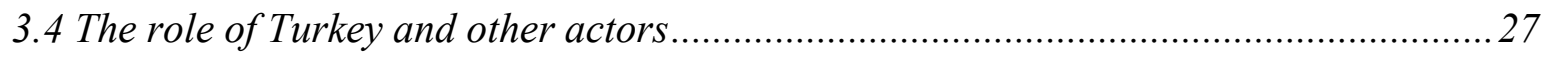

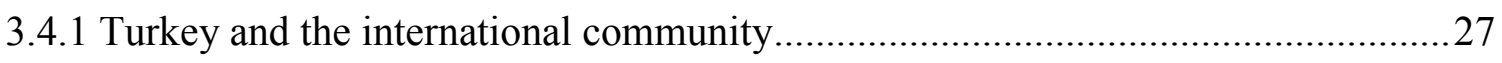

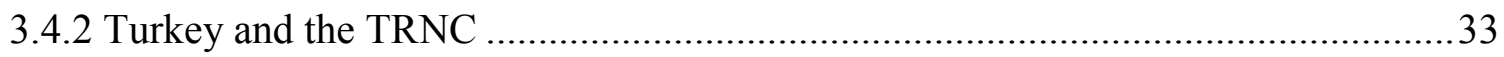

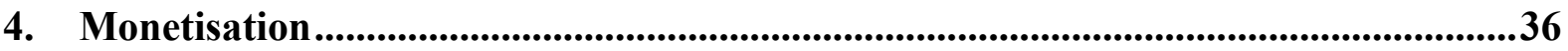

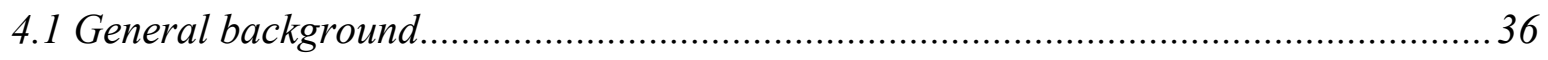

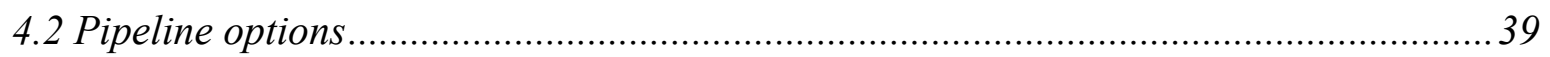

4.2.1 Pipeline to Greece.......................................................................................

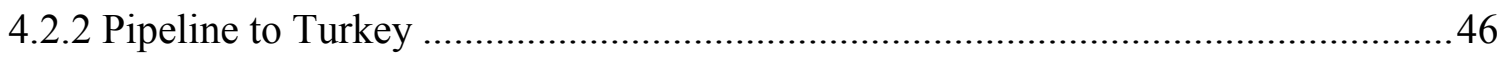

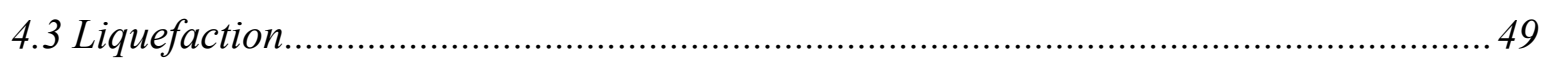

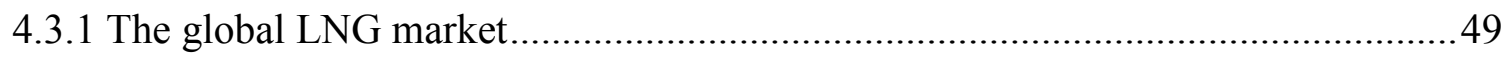

4.3.2 Contextualisation of East Mediterranean LNG …………………….................52

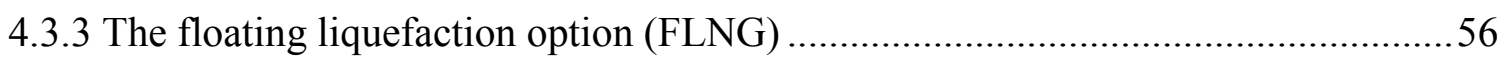

4.3.4 Cooperation with Israel and Noble Energy ……………....................................57

5. National hydrocarbons strategy and institutional capacity........................................63

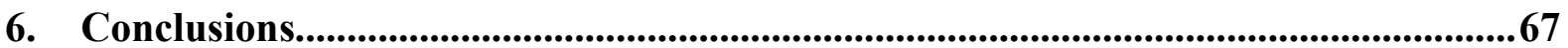

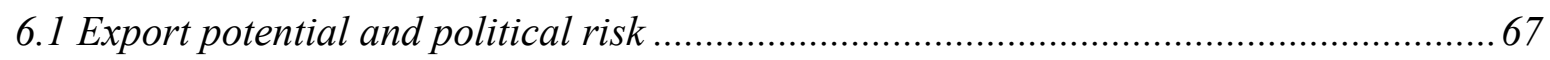

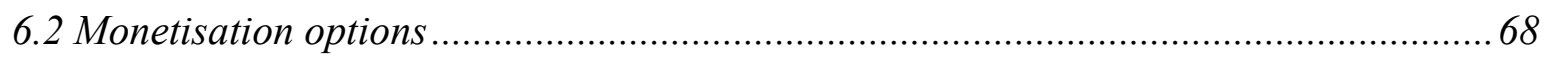

6.3 Co-operation with Israel and Noble Energy.......................................................... 71

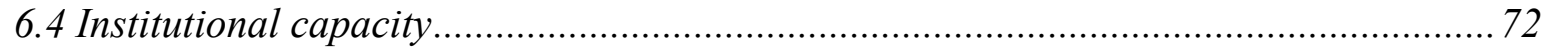

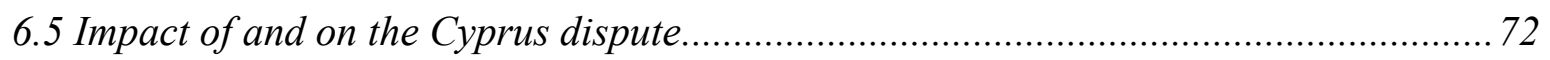

References...................................................................................................................................73 


\section{Maps}

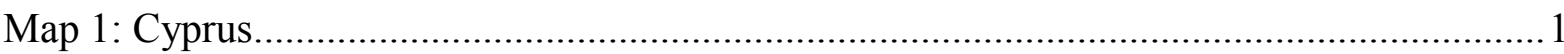

Map 2: Maritime boundaries of the Republic of Cyprus ........................................................ 16

Map 3: Exploration blocks in the Republic of Cyprus ……………………………….........26

Map 4: Request for Proposals by TPAO for Iskenderun Basin .................................................28

Map 5: Turkish claims on offshore blocks of the Republic of Cyprus ....................................31

Map 6: Contextualisation of E\&P blocks "licensed to TPAO by TRNC" ...............................35

Map 7: Potential route for connection of Block 12 with Cyprus ...............................................38

Map 8: Potential route of proposed East Med - Greece gas pipeline.........................................39

Map 9: Synergies with planned infrastructure in SE Europe.................................................42

Map 10: Proximity of Cyprus to Turkey ..........................................................................4

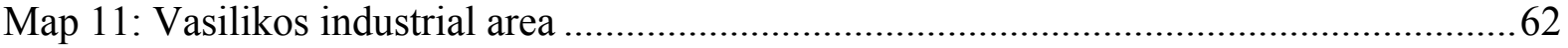




\section{Figures}

Figure 1: Basic economic indicators in the Republic of Cyprus .........................................5

Figure 2: Oil product consumption in Cyprus (million tonnes)............................................6

Figure 3: Installed power capacity and production in Cyprus (MW/MWh)..........................

Figure 4: Gasoil use in the Republic of Cyprus in 2010 by type ........................................ 7

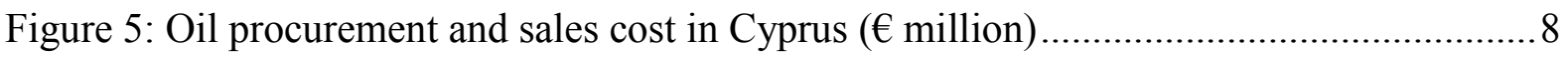

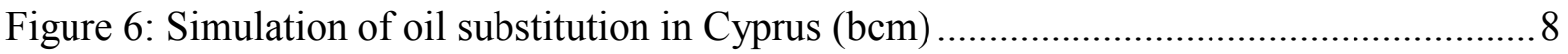

Figure 7: Cost benefit of substitution of oil in Cyprus ( $€$ million $)$ - no gas excise................. 10

Figure 8: Cost benefit of substitution of oil in Cyprus ( $€$ million $)-$ NL gas excise .............. 10

Figure 9: Cyprus historical oil demand and natural gas demand scenario ........................... 13

Figure 10: Timeline and background of E\&P activities in Cyprus....................................21

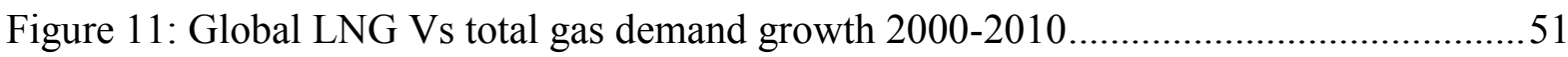

Figure 12: Global LNG demand Vs liquefaction growth 2000-2010 ................................51

Figure 13: Egyptian LNG exports in 2011 by country and region ......................................52

Figure 14: Snapshot of LNG landed prices, freight rates, and Egyptian netback...................53

Figure 15: Historical import price differentials in European and Asian markets* .................55 


\section{Acknowledgments}

I would like to thank Howard Rogers for his active interest in this research project and the numerous exchanges we had in the course of its development, which allowed me to benefit from his experience. I am also very much indebted to Spiros Paleoyannis, Andrew Dunn, and John Elkins for taking the time to read and to comment on an earlier draft; and to Kate Teasdale for preparing it for publication. I would also like to acknowledge the very kind contribution of everyone who offered their views on Cypriot natural gas and helped me in my research including: Antonis Ellinas, Petros Fiakkas, Graham Freedman, Solon Kassinis, Gary Lakes, David Ledesma, Yanos Michopoulos, Ionas Nicolaou, Panos Papanastasiou, Elizabeth Rigolet, George Shammas, Christos Skolidis, George Teriakidis, Nikos Tsafos, Tassos Tzionis, and Andrea Qualiano; and also those who would prefer to remain anonymous. My grateful thanks also go to George \& Evi Giamouridis and Demetra Kazantzidou for their support. I alone am responsible for views expressed in this paper and any mistakes are solely mine. 


\section{Background}

\subsection{Historical context ${ }^{1}$}

Cyprus is a former British island colony in the Eastern Mediterranean which gained its independence in 1960, after years of armed resistance (two sovereign UK bases remain). Inter-ethnic tensions including violence between the majority Greek Cypriot and the minority Turkish Cypriot communities followed almost immediately, with the UN deploying peacekeepers there as early as 1964. Ten years later, in 1974, Turkey invaded Cyprus in response to a coup d'état sponsored by the then ruling military regime in Athens, which was aimed at uniting the island with Greece. The Turkish armed forces have not withdrawn since and continue to occupy roughly one third of the island in northern Cyprus (see Map 1 below).

\section{Map 1: Cyprus}

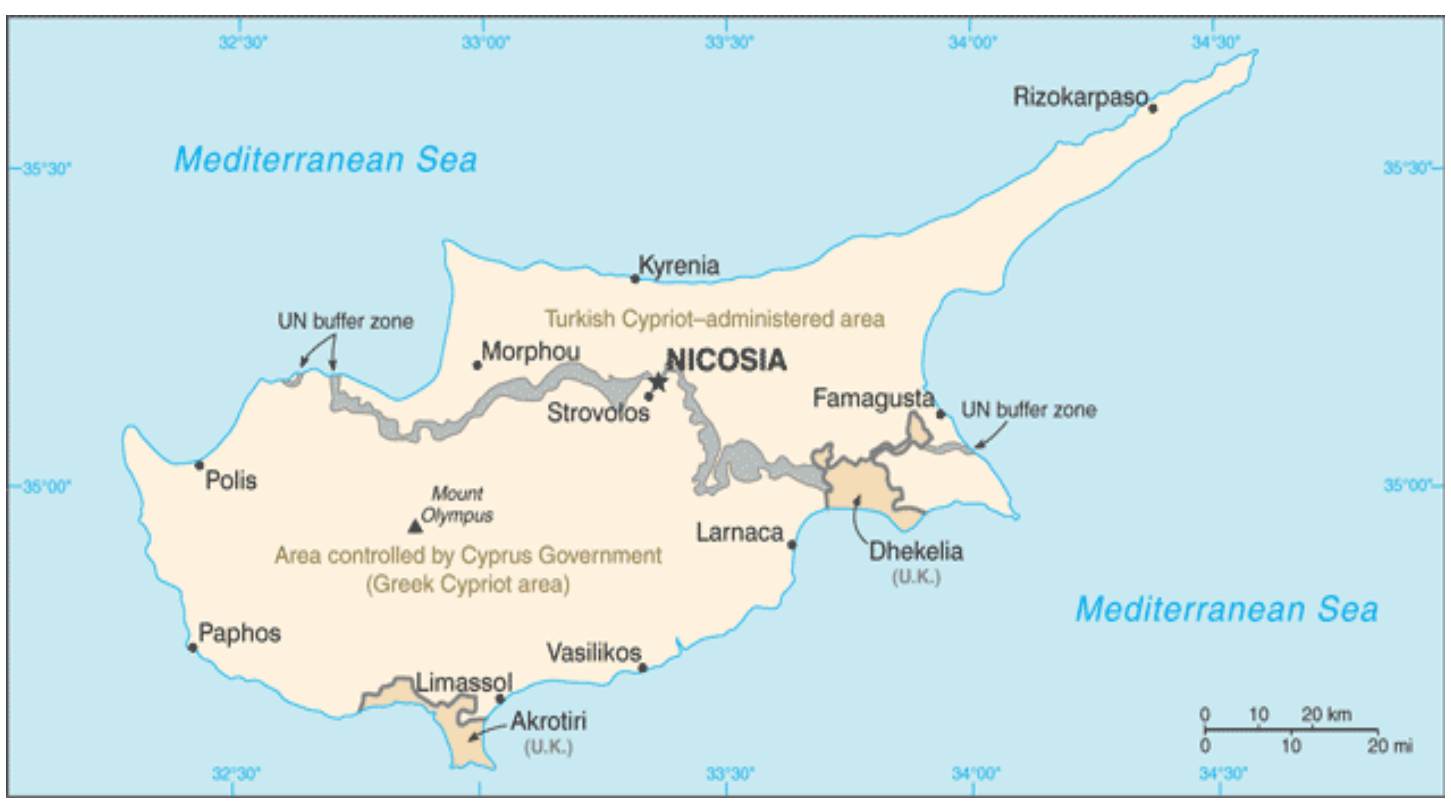

Source: Central Intelligence Agency

Following a number of failed negotiation rounds after 1974, in 1983 the Turkish Cypriot area unilaterally declared independence as the "Turkish Republic of Northern Cyprus" (TRNC). However, TRNC has remained unrecognised by the international community except Turkey; while Ankara still does not recognise the (Greek Cypriot-controlled) Republic of Cyprus.

\footnotetext{
${ }^{1}$ Information from Cyprus country profiles in the CIA World Factbook, www.cia.gov and the BBC, www.bbc.co.uk
} 
The Republic of Cyprus is the only sovereign on the island that is internationally recognised. ${ }^{2}$ A number of initiatives at reunification in the years that followed have failed to achieve any progress, as they stumbled on thorny issues such as power sharing and representation; compensation and property rights for the Greek Cypriots displaced by the invasion in 1974; the role in the new state of non-Cypriot settlers from Turkey who came to Cyprus after 1974; and security guarantees for the Turkish Cypriots and the withdrawal of Turkish armed forces.

In 2004 Cyprus joined Malta and 8 post-communist nations from Central and Eastern Europe in becoming a full member of the European Union (EU), albeit the acquis communautaire remains suspended in territories in northern Cyprus (i.e. in the areas of the so-called TRNC), which since 1974 are outside effective control by the government of the Republic of Cyprus. Still, individual Turkish Cypriots who can prove eligibility for Republic of Cyprus citizenship can apply for a passport and are afforded the same rights accorded to other EU citizens.

Furthermore, the Cyprus problem has complicated Turkey's own bid for accession to the EU. Formal negotiations between the EU and the Republic of Turkey commenced officially in October 2005, after continuous Turkish efforts to that end which date back to the 1960s. However, due to Turkey's failure to apply the Additional Protocol to the Ankara Agreement extending Turkey's customs union deal with the EU to its 10 new members including Cyprus, the European Council decided in December 2006 eight "relevant chapters will not be opened and no chapter will be provisionally closed until Turkey has fulfilled its commitment". 3

This impasse has caused problems in diplomatic relations between various involved parties, including serious complications in the EU-Turkey and the Greece-Turkey relationships. Moreover, the difficult relations between Ankara and Nicosia have spilled over, through the use of consecutive vetoes, and have undermined co-operation between the EU, where Cyprus is a member but Turkey is not, and the North Atlantic Treaty Organisation (NATO), where the opposite holds true. ${ }^{4}$

\footnotetext{
2 “Cyprus" and, synecdochically, "Nicosia" will refer in this paper to the internationally-recognised "Republic of Cyprus".

${ }^{3}$ These chapters are Free Movement of Goods; Right of Establishment and Freedom to Provide Services; Financial Services; Agriculture and Rural Development; Fisheries; Transport Policy; Customs Union; and External Relations. For more see European Commission, EU-Turkey relations, http://ec.europa.eu/index_en.htm, accessed 2 February 2012.

${ }^{4}$ See Today's Zaman, Rasmussen visits Ankara to mark 60th year of Turkey's NATO membership, 16 January 2012,

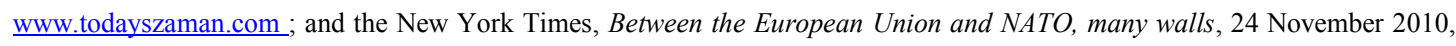
www.nytimes.com.
} 
In addition, Turkey has repeatedly said it will not cooperate with Cyprus's EU Presidency in the second half of 2012, while Turkish EU Affairs Minister Egemen Bağış went as far as to say TRNC could be annexed to Turkey if ongoing talks between Turkish and Greek Cypriots aimed at the island's reunification fail to produce a solution. ${ }^{5}$

\subsection{Politics and economics}

The island's current combined population is estimated at 1.1 million, of which more than 0.8 million are Greek Cypriots and the remainder Turkish Cypriots and other minorities. The President of the Republic of Cyprus is elected directly by means of common suffrage for a five-year term. He/she serves as both the chief of state, as well as the head of government. Members of an independent unicameral parliament, the House of Representatives, are similarly elected for a five-year period by common suffrage taking place through a separate election which does not coincide with the country's presidential election. In practical terms, this means that the presidency and the majority in the Cypriot parliament are often held by opposing parties with diverse political agendas.

Indeed, pro-unification leader of the nominally communist AKEL party Demetris Christofias is currently the President of the Republic of Cyprus, but as of May 2011 his party has lost the majority it had enjoyed in the House of Representatives to the centre-right DISY party. Furthermore, in August 2011 junior government partner DIKO withdrew its support and resigned from the governing coalition, calling for a national unity government with DISY. The next presidential election is scheduled for February 2013, while the next parliamentary election will take place in $2014 .^{6,7}$

\footnotetext{
${ }^{5}$ See Today's Zaman, Turkish Cyprus might be annexed to Turkey, minister says, 4 March 2012, www.todayszaman.com ; and ANSA Med, EU-Turkey: Ankara will ignore Cyprus as EU president, Bagis, 2 March 2012, www.ansamed.info

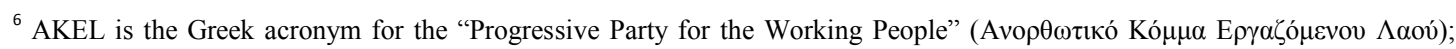

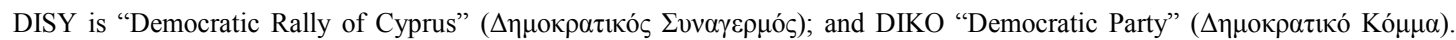
Their respective websites are www.akel.org.cy, www.disy.org.cy, www.diko.org.cy.

${ }^{7}$ In northern Cyprus, the leader of the nationalist pro-independence UBP party Derviş Eroğlu is the so-called president of TRNC, taking over in April 2010 from pro-unification leader Mehmet Ali Talat and restoring Turkish Cypriot nationalists to their previously held dominant position, which they had lost in the parliamentary election of 2003 and presidential elections of 2005 (elections and other activities in the TRNC are unrecognised by the Republic of Cyprus and the international community). Negotiations on reunification of the divided island continue to take place, under UN auspices. Still, there has been no significant recent progress reported (UPB stands for "National Unity Party” Ulusal Birlik Partisi - http://www.ulusalbirlikpartisi.com).
} 
The service sector is predominant in the Cypriot economy and contributes four-fifths to its Gross Domestic Product (GDP), primarily through tourism, financial services, and real estate. Between 2005 and 2008, Cyprus followed a successful adjustment programme aimed at meeting Euro accession criteria, which it adopted as its national currency on $1^{\text {st }}$ January 2008. GDP grew 3.8\% year-on-year on average from 2000 until the eruption of the financial crisis in 2008. Accordingly, GDP per capita exceeded the threshold of 30,000 US Dollars (USD) in 2008 , standing at $\sim 75 \%$ of average levels seen in the richest EU-15 members at the time (Figure 1). ${ }^{8}$

Problems emerged in the immediate aftermath of the global economic crisis though, which hit the Cyprus construction, tourist and financial sectors, and resulted in negative growth in 2009. Concerns heightened in 2011 due the significant exposure of the local banking sector to Greek sovereign debt, with the Cypriot government pledging to implement necessary reforms. Nonetheless, in March 2012 Finance Minister Kazamias resigned invoking health reasons, two days after the relegation of Cypriot sovereign bonds and three banks to junk status by rating agency Moody's (and also a similar decision by Standard and Poor's in January 2012). Furthermore, the deepening of the economic recession in Greece, combined with speculation about a potential exit of the country from the Eurozone due to growing political instability and an uncertain Greek election in June, resulted in negative implications for Cyprus too. ${ }^{9}$

Rating agency Fitch accordingly downgraded Cypriot debt to junk status in the same month; and the Cypriot government was forced to submit a request for assistance to the European Financial Stability Fund (EFSF) and the European Stability Mechanism (ESM), a few days before assuming for the first time the EU's rotating presidency on July $1^{\text {st }}$. Nicosia's request has already been accepted, but the specifics of its adjustment programme will be agreed later. Furthermore, Cyprus is seeking to secure an additional loan of Euros 5 billion from Moscow, the second one from Russia in the course of less than a year. Arguably, Nicosia's intention is to use the Russian loan as leverage in order to avoid some of the most stringent conditionality (in the form of tough austerity) imposed on some of the other Eurozone countries, upon their

\footnotetext{
${ }^{8}$ The economy of the self-styled TRNC is suffering from serious structural weaknesses and remains dependent on Turkey, which finances about one third of its budget. Direct transfers from Turkey have exceeded USD 400 million per annum over the course of the past few years. The global crisis affected heavily tourist flows and spending from Turkey and Britain which, coupled with structural inefficiencies resulted in negative growth. GDP per capita is roughly half of that in the Republic of Cyprus.

${ }^{9}$ More information on this is available in Financial Times, Cypriot finance minister resigns, 16 March 2012, www.ft.com ; CNBC News, Moody's downgrades Cyprus to junk status, 13 March 2012, www.cnbc.com; as well as in Kathimerini Cyprus,

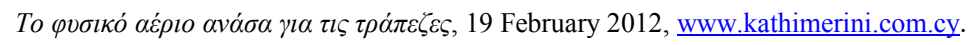


entry into European rescue mechanisms. Moscow is currently assessing the Cypriot request for financial support and has not replied; though it seems to be positively inclined. ${ }^{10}$

Against this background, Exploration \& Production (E\&P) is, among other benefits, seen as a potentially powerful means of boosting the long-term sustainability of the national economy; as its ability to substitute domestically produced gas for expensive imported oil products (thus reducing the local energy bill) and to achieve significant export revenues is now beginning to be appreciated in Cyprus. The relevant development phase with its large offshore and onshore construction activity would also have a major positive impact on the Cypriot economy. Pressures on the economy could to some extent thus be relieved and a degree of optimism on GDP growth injected, provided of course disorderly defaults are avoided in the Eurozone.

Figure 1 presents historical and forecast GDP per capita and also contextualises them with the old (and richer) $15 \mathrm{EU}$ member states.

\section{Figure 1: Basic economic indicators in the Republic of Cyprus}
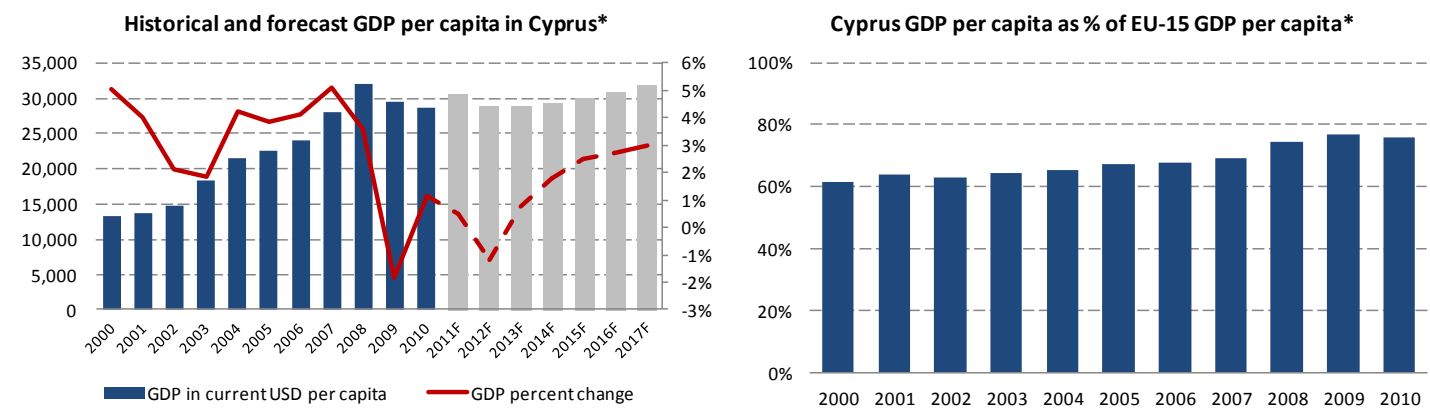

Source: Author from International Monetary Fund (World Economic Outlook, April 2012) and Eurostat

*data refer to the Republic of Cyprus

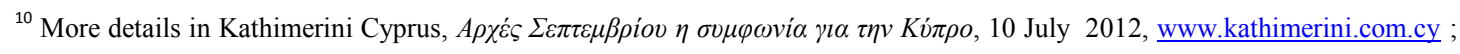

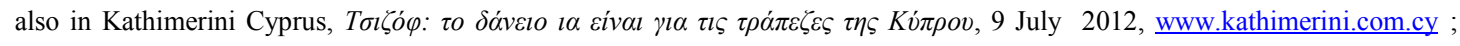

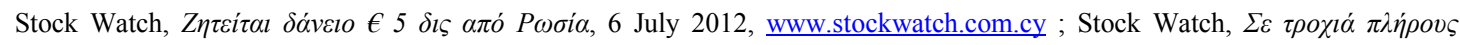

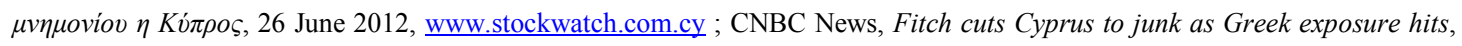
25 June 2012, www.cnbc.com ; Reuters, Cyprus not talking to EFSF on aid, cannot exclude, 6 June 2012, www.reuters.com.
} 


\section{Local energy market and gasification prospects}

Domestic oil products consumption in recent years has been just above 2 million tonnes/year. In fact, oil is the only fuel available for power generation and other stationary use; with the latter accounting for some 1.4 million tonnes, or $60 \%$ of the total oil products use (Figure 2). This dependency clearly incentivises gasification as a means of enhancing fuel diversification and security of supply, as well as reducing exposure to high oil product prices. The rationale for gasification is made stronger if gas is to be supplied by local fields.

\section{Figure 2: Oil product consumption in Cyprus (million tonnes)}
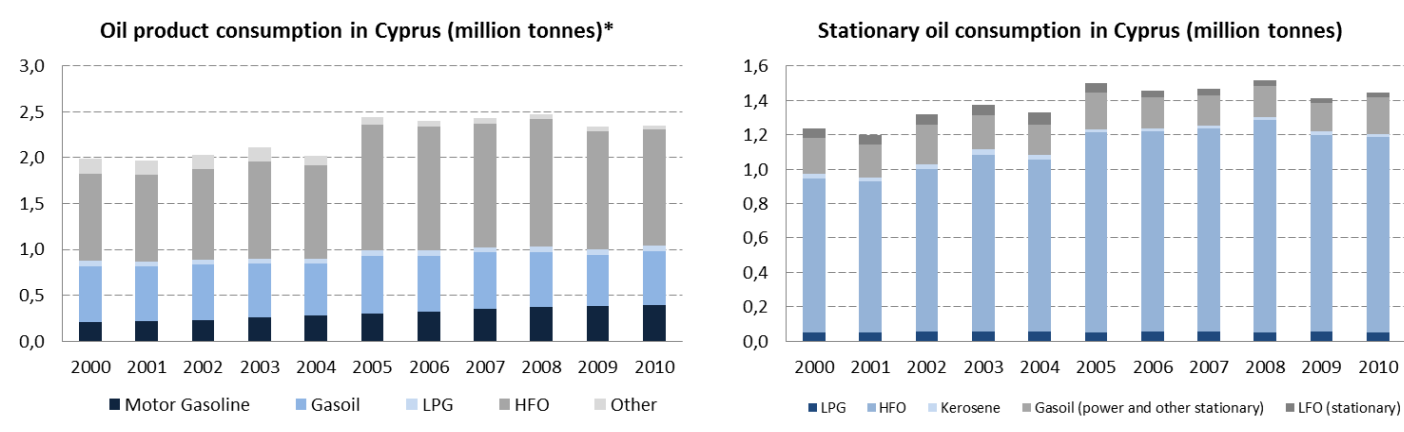

* Includes bunker fuel

Source: Interpreted by author from Eurostat and Statistical Service of the Republic of Cyprus (Industrial Statistics 2010)

The state-owned monopoly Electricity Authority of Cyprus (EAC) is by far the largest user of oil products on the island, as it continues to rely on Heavy Fuel Oil (HFO) and gasoil for the growing needs of power generation. Installed power generation capacity in Cyprus, which for the moment remains almost exclusively oil-fired, increased 46\% between 2000 and 2010, and by as much as $211 \%$ between 1990 and 2010; from 471 Megawatt (MW) to $1465 \mathrm{MW}$.

By the same token, electricity production increased by some 57\% between 2000 and 2010; and almost 170\% between 1990 and 2010 (Figure 3); hence aggravating this oil dependency, whilst, at the same time highlighting the penetration potential for natural gas in these sectors. Renewables exist and are on the rise; however, production still stood below $1.5 \%$ in 2010. HFO is also used by the local cement industry, but the fuel faces regulatory restrictions on environmental grounds with regard to its penetration to the commercial and other sectors. 
Figure 3: Installed power capacity and production in Cyprus (MW/MWh)
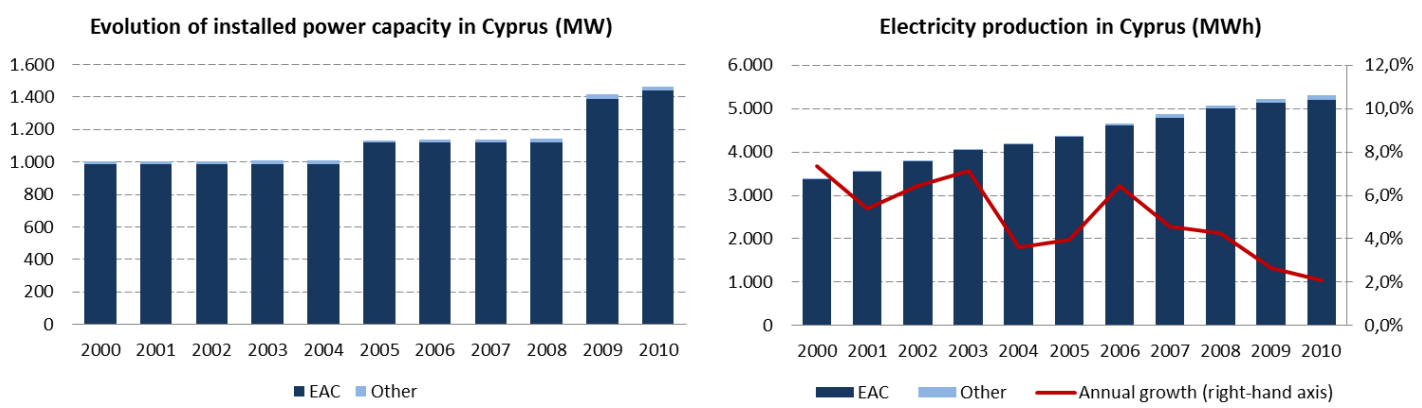

Source: Author from Statistical Service of the Republic of Cyprus (Industrial Statistics 2010)

Other industrial/commercial and heating needs are met primarily by gasoil, with close to 150,000 tonnes in 2010 (motor diesel accounted for another 330,000 tonnes in the same year); by Liquefied Petroleum Gas (LPG), with 50,000 tonnes in 2010; and Light Fuel Oil (LFO), which sold a little more than 30,000 tonnes in the same year. Kerosene makes only a small contribution to these sectors, with total 2010 use of this fuel standing close to 14,000 tonnes. Finally, some gasoil and LFO volumes are diverted to the declining local bunkering sector (for a breakdown of national gasoil usage see Figure 4).

Figure 4: Gasoil use in the Republic of Cyprus in 2010 by type

Gasoil use in the Republic of Cyprus in 2010 by type

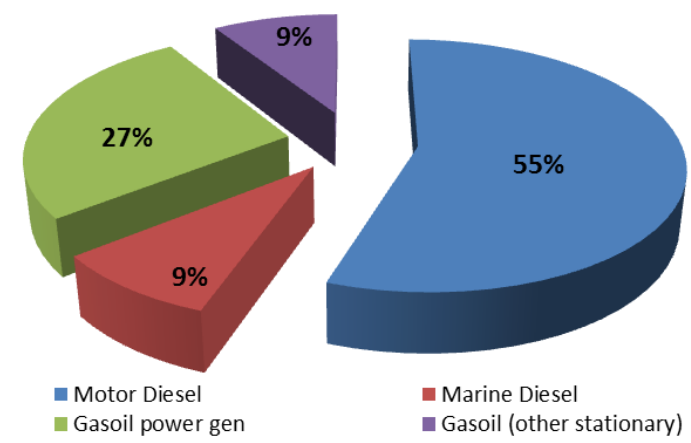

Source: Interpreted by author from Eurostat and Statistical Service of the Republic of Cyprus (Industrial Statistics 2010)

This dependence on imported oil products creates a substantial budget drain in Cyprus which, similar to other Eurozone countries, has decreasing tolerance levels for avoidable expenditure. In 2010, Cyprus imported oil products worth a combined 1.3 billion Euros, with final consumers on the Mediterranean island having to pay more than 1.5 billion Euros - even excluding Value Added Tax (VAT) charges - to use them. More than $90 \%$ of this expenditure 
referred to motor gasoline, gasoil and HFO purchases. Some 710 million or $46 \%$ of all expenditure was related to stationary use, for the most part HFO and gasoil (Figure 5).

Figure 5: Oil procurement and sales cost in Cyprus (€ million)
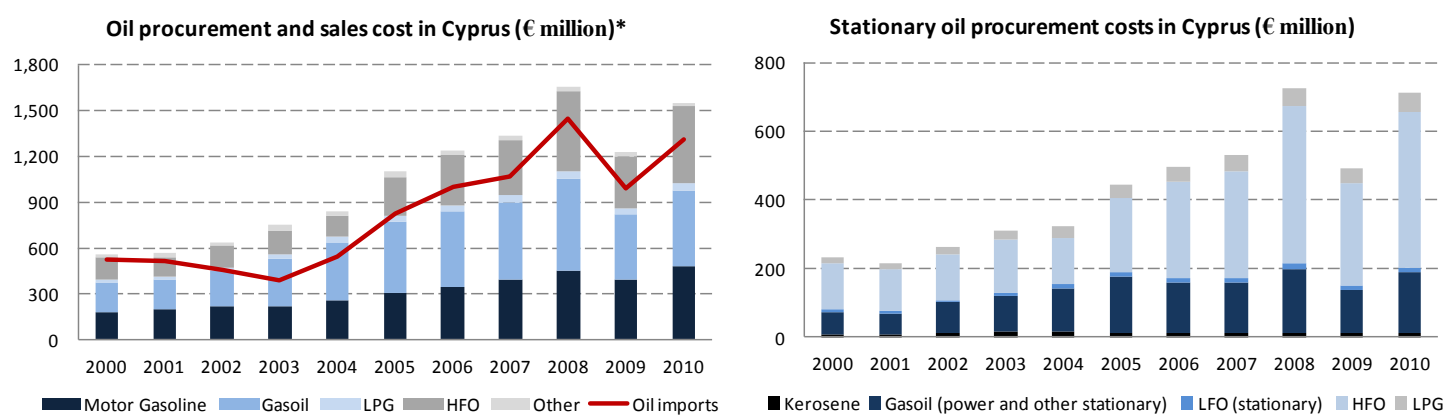

* Includes bunker fuel

Source: Interpreted by author from Eurostat and Statistical Service of the Republic of Cyprus (Industrial Statistics 2010)

If Cyprus had used gas instead of oil across all sectors of its economy except bunker in 2010, the domestic market would have been $\sim 2.3$ billion cubic metres $(\mathrm{bcm}){ }^{11}$ By the same token, the local stationary sector would have consumed approximately $1.1 \mathrm{bcm}$; with almost 900 million cubic metres $(\mathrm{mmcm})$ of this gas demand coming directly from EAC, for its power generation needs (Figure 6).

Figure 6: Simulation of oil substitution in Cyprus (bcm)

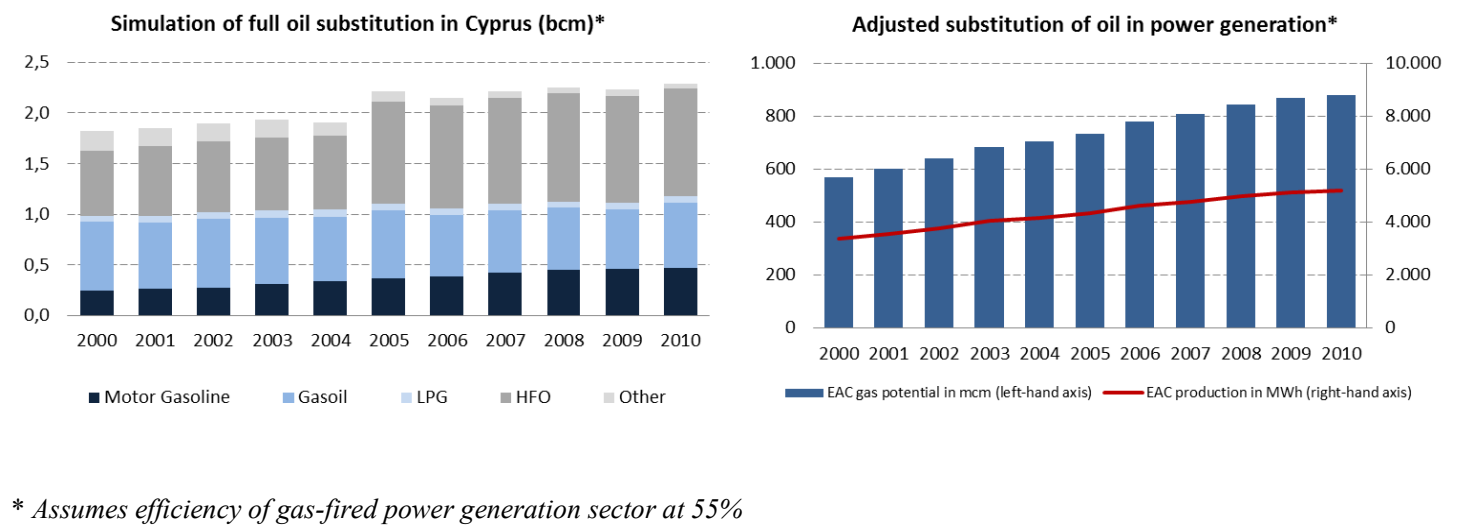

Source: Interpreted by author from data from Statistical Service of the Republic of Cyprus (Industrial Statistics 2010)

\footnotetext{
${ }^{11}$ Assuming efficiency gains from the substitution of HFO with natural gas in power generation (with an efficiency rate of 55\%) but making no other adjustments or factoring in potential efficiency gains / losses in other economic sectors.
} 
Even if Cyprus were importing this gas at average European prices of roughly USD 4/mmbtu between 2000-2005; and as high as an average of some USD 8/mmbtu between 2005-2010, rather than procuring domestic gas with some discount, as is often the case internationally, this could still generate substantial savings for domestic energy consumers. In 2010 alone, these could have reached Euros 1.1 billion, compared to a GDP of approximately 17 billion. There would be substantial savings even if penetration were limited to the stationary sector almost 500 million Euros - or even just in the most basic of candidates in this framework i.e. power generation, where relevant savings would have stood at above 400 million in $2010 .^{12}$ Depending on actual substitution levels and efficiency gains, consumers in Cyprus could have been spared the expenditure of between 1.5 and 7.4 billion Euros over the past decade.

These benefits for end consumers would be somewhat diluted - but still very significant - if an excise tax was imposed on the consumption of such domestically-procured natural gas. Even assuming excise at a relatively high Euros 4.74 per gigajoule, which is the level currently imposed by the Netherlands, on all market segments except power generation and the cement industry (which are not liable for oil excise either in the Republic of Cyprus), then the consumers of these volumes could have saved approximately Euros 970 million in $2010 .{ }^{13}$ Stationary sector savings would stand at almost Euros 470 million, or $66 \%$ below the Euros 710 million paid by Cypriot consumers for stationary oil usage in the same year.

Figures 7 and 8 give an indication of the cost benefit of substitution of oil products by gas in Cyprus, based on consumption patterns and prices between 2000 and 2010; across the board, in the stationary sector (including in power generation), and for power generation alone. Figure 7 assumes the imposition of no excise tax surcharges on locally procured natural gas; while Figure 8 uses Euros 4.74/gigajoule (as in the Netherlands) as the basis of calculation.

\footnotetext{
${ }^{12}$ EAC has been procuring HFO for its power generation units priced off Free On Board (FOB) Med Italy 1\% sulphur HFO Platts indices, with the addition of an adjustment factor to account for costs associated with transportation to Dhekelia or Moni storage tanks; and applicable duties including import duties in the Republic of Cyprus in accordance with European Community legislation and set out in the Integrated Tariff of the Community (TARIC). See for example related provisions in Tender 90/2011, Supply and delivery of heavy fuel oil for the period 1 December 2011 to 31 January 2013, www.eac.com.cy

${ }^{13}$ See European Commission, Excise duty tables, DG Taxation and Customs Unions, January 2012, www.ec.europa.eu.
} 
Figure 7: Cost benefit of substitution of oil in Cyprus ( $€$ million $)$ - no gas excise

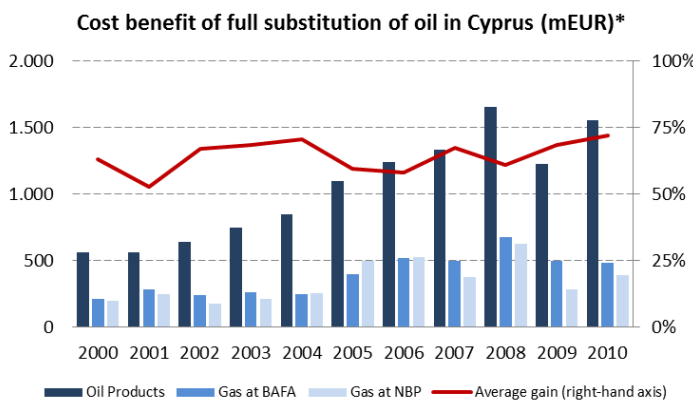

Cost benefit of substitution in stationary sector (mEUR)*

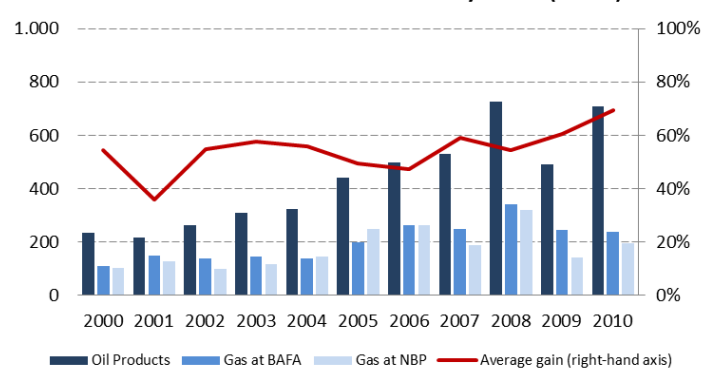

Cost benefit of substitution in power sector (mEUR)*

Cost benefit of oil substitution in Cyprus (mEUR)
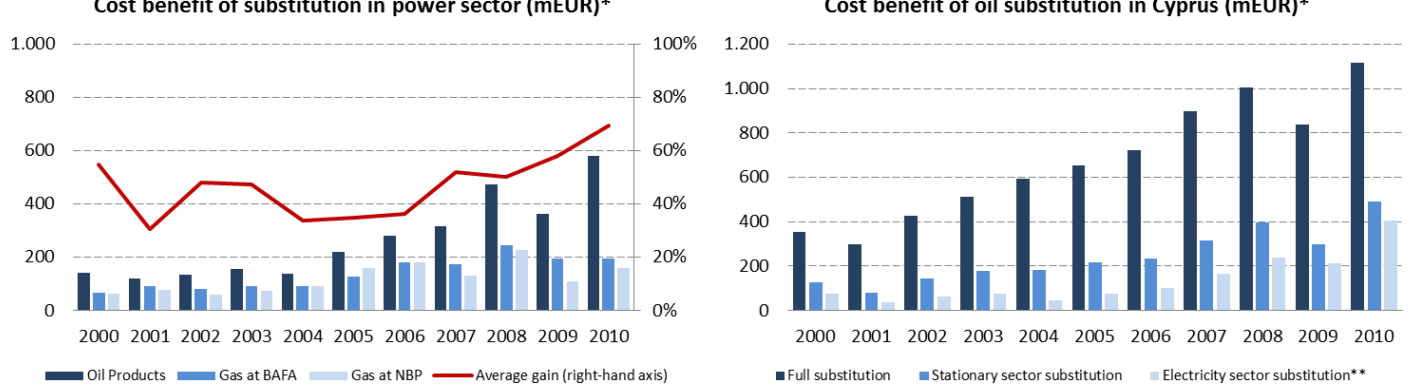

Figure 8: Cost benefit of substitution of oil in Cyprus ( $€$ million) - NL gas excise
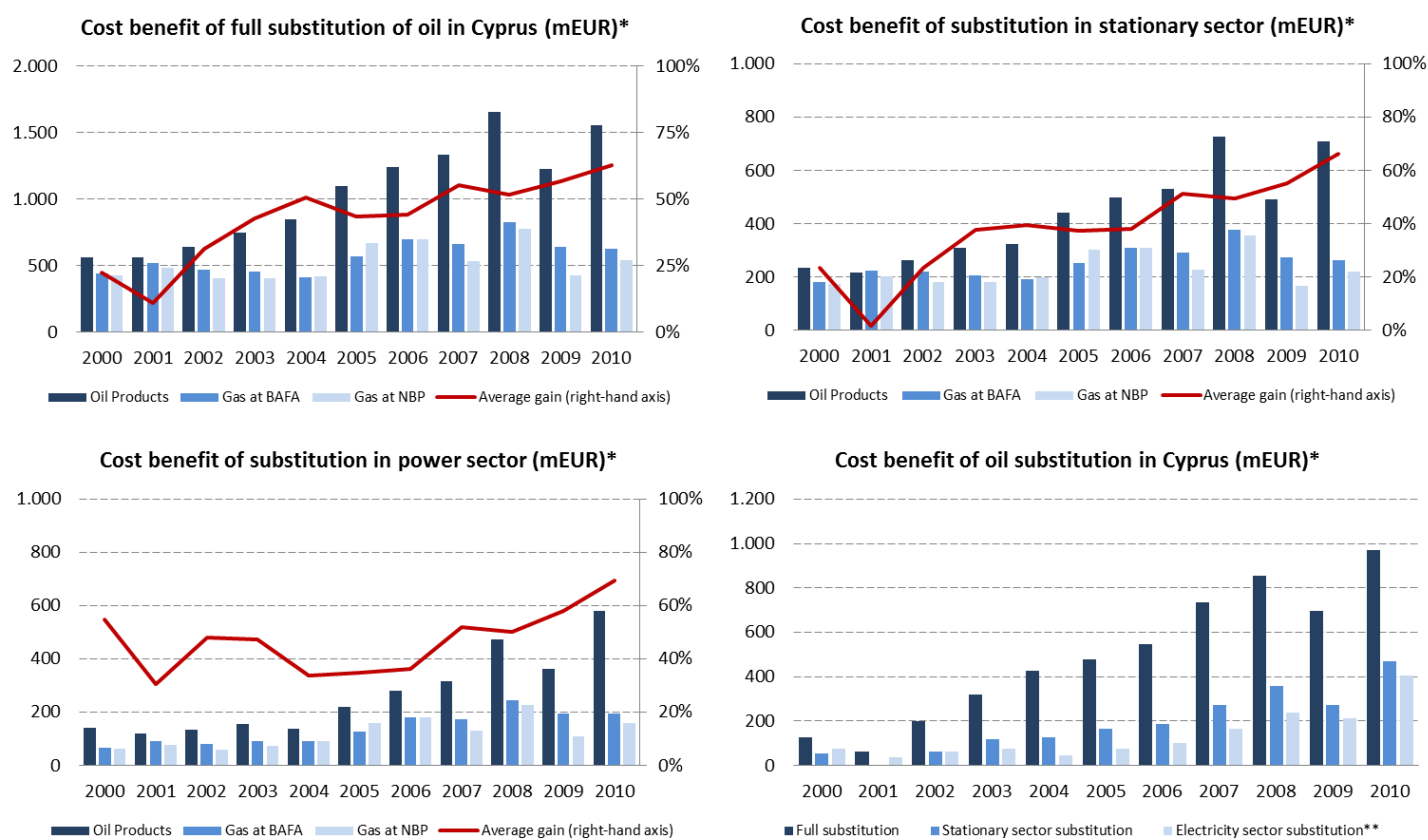

\footnotetext{
* based on retail prices including excise tax but not VAT / power generation at 55\% efficiency

** Stationary sector substitution savings include those from substitution in the electricity generation sector

Source: Author calculations on data from Statistical Service of the Republic of Cyprus and BP Statistical Review
} 
Mindful of such economic benefits, EAC had called for the gasification of local power generation as early as 2001. Cyprus sought to develop a regasification terminal aimed at allowing LNG imports from 2014 and even came close to signing a 20-year supply contract with supermajor Shell to that end. However, these plans were finally dropped in mid-2011, following opposition from a number of sources due to the island's own upstream potential and drilling scheduled for later that year, including from the influential Director of the Energy Service of the Ministry of Commerce, Industry, and Tourism, Solon Kassinis. ${ }^{14}$

EAC now targets switching to natural gas by mid-decade, provided supplies become available in Cyprus by then. The Vasilikos Power Station, which suffered serious damage in July 2011 in an accidental ammunition explosion with human casualties in the adjacent Evangelos Florakis Naval Base, already has a 220 MW Combined Cycle Gas Turbine CCGT (Unit IV) with two gas turbines and a steam turbogenerator temporarily using diesel, as a result of the unavailability of gas. Moreover, an additional identical 220 MW CCGT (Unit V) was almost committed to at that time. Vasilikos also includes three steam turbogenerators, $130 \mathrm{MW}$ each. Units I and II have been planned to be converted to gas-fired in the ongoing repair process, which is set to be completed by the summer of 2013 (all other units by the end of 2012). ${ }^{15}$

The other power stations at Dhekelia and Moni include both some steam turbogenerators as well as a number of diesel-fired gas turbines, which serve as peak shaving and back-up units. The combined installed capacity of the Dhekelia and Moni power stations is some $700 \mathrm{MW}$; while $\sim 100 \mathrm{MW}$ at Dhekelia and an extra $150 \mathrm{MW}$ at Moni could be easily converted to gas. Cyprus has already proceeded with preliminary planning and also secured Euros 10 million from the EU for the development of gas pipeline links from Vasilikos to Dhekelia and Moni (before branching off also to other industrial and residential gas areas). Cypriot authorities expect construction of this natural gas pipeline infrastructure to take three years to complete, at an estimated total cost of Euros 80 million. Besides the economic benefits described above,

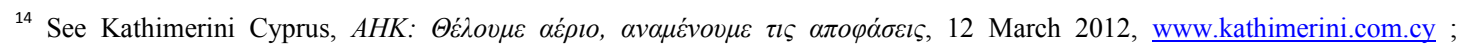

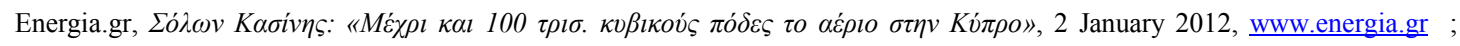
Zawya, Cyprus drops LNG regasification plan amid power crisis, 25 July 2011, www.zawya.com ; Reuters, Shell has best offer for Cyprus LNG supply, 6 January 2011, www.reuters.com.

${ }^{15}$ More details in Middle East Economic Survey, EAC makes progress on Vasilikos power plant reconstruction, Vol. LV No 19,

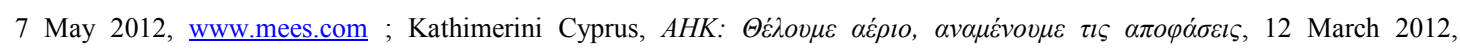

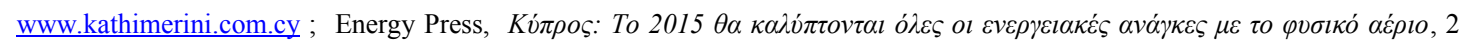
January 2012, www.energypress.gr ; Euro2day, Kv́
} 
oil products substitution in the local power generation would also save EAC an estimated 11 million Euros due to lower emissions. ${ }^{16}$

Assuming full substitution of oil products in the power and other stationary sectors, as well as a continuation of recent trends with regard to Cypriot energy demand growth in these sectors, which are the first that local gas will likely penetrate, in 2025 Cyprus could have a domestic requirement of up to $1.7 \mathrm{bcm} / \mathrm{annum}$ (bcma). The bulk of this demand would come from power generation with an expanding share, albeit this probably represents the upper bound for such projections. The ultimate level of demand will be constrained by the potential inability of gas to penetrate fully these sectors in the envisaged time frame, the downward influence from planned renewables penetration, and the impact of the economic crisis. For example, even a fairly modest penetration of relatively mature renewable energy sources such as wind and photovoltaics in the order of 400 MW by 2025 into the energy mix of Cyprus, could radically reduce the gas input required into its power generation sector; although gas fired generation capacity would be required as back-up to these intermittent power sources.

Working in the opposite direction, any subsequent gasification of the transportation sector could add an extra 1.2 bcma of demand (Figure 9). However, penetration there will depend on fleet conversion costs and gas availability, and it would be expected to proceed at a much slower pace compared to stationary sectors, probably extending into the 2020 s and beyond.

Besides the benefits associated with the planned gasification of the power generation sector, availability of competitively-priced fuel in the form of domestic gas could facilitate the emergence of a chemical industry and other industrial activity (methanol plant, fertilisers etc.) contributing to the diversification of the economy from its present dependence on services. ${ }^{17}$ Nevertheless, additional competitive advantages may be necessary for success in this context, given the substantial similar investments of recent years - and ensuing strong competition from natural gas-rich counties in the adjacent Middle East and North Africa (MENA) region.

\footnotetext{
${ }^{16}$ Harry Thrasou, the Chairman of EAC, estimates savings from use of local gas instead of oil in power generation up to $35 \%$.

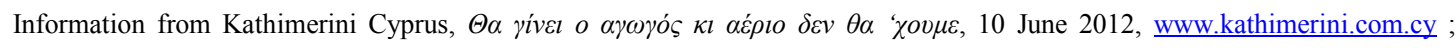

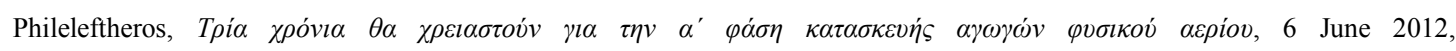

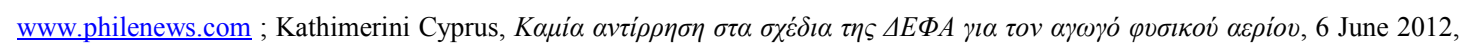

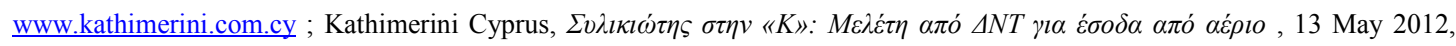
www.kathimerini.com.cy ; and Middle East Economic Survey, EAC makes progress on Vasilikos power plant reconstruction, Vol. LV No 19, 7 May 2012, www.mees.com;

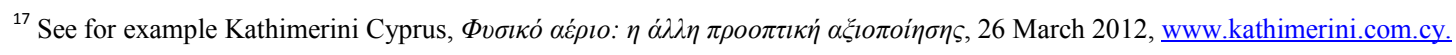


In other words, the competitive advantage of Cyprus in this framework is far from obvious; while needed advantages may thus include tax breaks and/or the existence of cheap feedstock, as a result of either real low breakeven prices for local gas; or an agreement for below-cost supply; albeit this would have to be in compliance with EU/international competition rules. Moreover, Cyprus will need to balance such industrial activity with environmental protection, both in its own right but also in order not to undermine its profitable tourist industry.

The growth pattern and size of the local natural gas market is thus contingent on realised economic growth; on the potential contribution of renewable energy sources; on the actual success of domestic market gas penetration; on the competitiveness of locally-procured gas; on the establishment of new demand centres including chemicals and other industrial outlets; and on the efficiency of natural gas usage across the various sectors that it penetrates.

Chapter 3 looks into upstream developments and complications including the Exclusive Economic Zone (EEZ) context and also applicable regulatory and contractual arrangements; from the first licensing round of 2007 and Noble Energy's Aphrodite find in 2011 until today; and a preliminary assessment of bidders in the recently completed second licensing round.

\section{Figure 9: Cyprus historical oil demand and natural gas demand scenario}
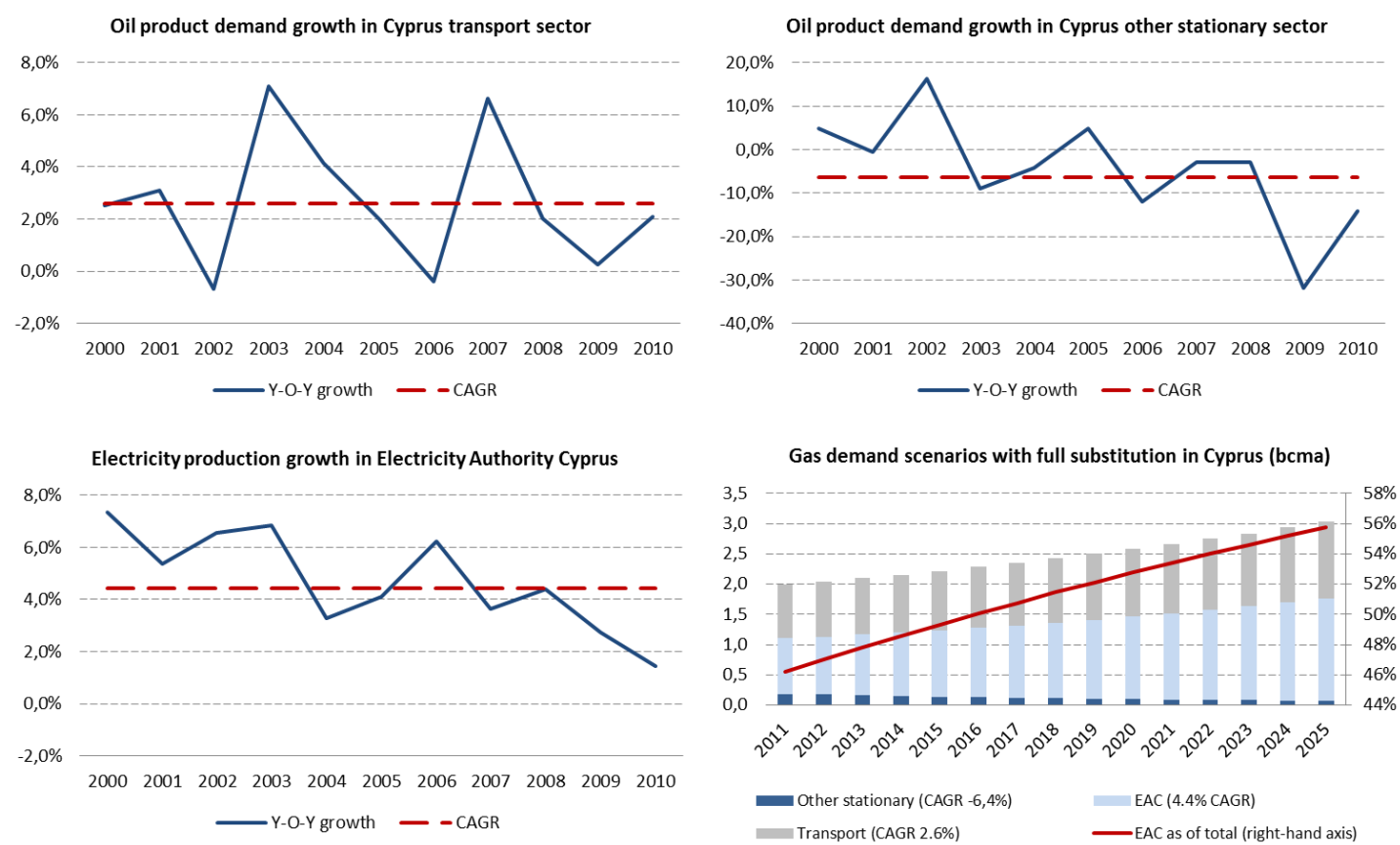

Source: Author calculations on data from Eurostat and Statistical Service of the Republic of Cyprus 


\section{Upstream}

\subsection{Exclusive economic zones and unitisation agreements}

In 1988, Cyprus ratified the United Nations Convention on the Law of the Sea (UNCLOS) which includes provisions on marine natural resources and Exclusive Economic Zones (EEZ). It followed up on this ratification more than 15 years later with Law 64 (I) of 2004, under the self-explanatory full title of "Law to provide for the Proclamation of the Exclusive Economic Zone by the Republic of Cyprus" (the "EEZ Law"). The Law was enforced retroactively with an effective date of March 2003 to allow delimitation of its EEZ with Egypt - the first such delimitation agreement in the Eastern Mediterranean - which had been signed at the time. Nicosia has also been successful in signing EEZ agreements with Lebanon and Israel in January 2007 and December 2010 respectively (despite Israel not having signed UNCLOS). In contrast, and for different sets of reasons in each case, it has not made progress towards signing such EEZ agreements with Greece, Turkey, and Syria (see Map 2); and presently it looks unlikely that there can be any significant progress to that end in the near to the medium term, due to a combination of core strategic positioning and political instability. ${ }^{18}$

The EEZ agreements of Cyprus with both Egypt and Israel have been ratified and are already in force. In contrast, there have been difficulties and delays in the case of Lebanon, which has proved unwilling to proceed with this ratification due to EEZ grievances it has against Israel. It is unclear whether this is indeed the full extent of Lebanese foreign policy considerations in this framework, or whether there are other variables creeping into this equation (e.g. Turkey); and decision-making may be inhibited by difficult domestic politics and institutional failures. Nonetheless, Lebanese authorities accept the EEZ demarcation with Cyprus to the west as per the 2007 agreement between the two countries, thus reducing risk for investors in that regard. Furthermore, the governments of Lebanon and Israel have reportedly started negotiations on this matter; while the assumption of the rotating 6-month EU presidency by Cyprus in July

\footnotetext{
${ }^{18}$ Ashurst, Energy briefing: the oil and gas regime in the Republic of Cyprus, March 2012, www.ashurst.com ; Office of the Law Commissioner of the Republic of Cyprus, The Exclusive Economic Zone Law 2004, January 2010, www.olc.gov.cy; Solon Kassinis, The status of hydrocarbon exploration in Cyprus, Presented at the Israel Business Conference, Tel Aviv, Israel, 12 December 2011, available online at www.mcit.gov.cy
} 
2012 could offer new momentum towards a solution, which would remove this uncertainty. ${ }^{19}$ This is very important for Nicosia as such an agreement between its neighbours would also clarify with whom it should sign related joint development and field unitisation agreements, should it discover hydrocarbons reserves crossing the median line in its offshore blocks. ${ }^{20}$

Cypriot authorities are also pushing forward with agreements which in practical terms are complementary to recent EEZ delimitations, aimed at facilitating their energy co-operation with neighbouring states, while at the same time also providing clarity to upstream investors. In May 2006, Cyprus and Egypt signed a Framework and a Confidentiality Agreement on the development of cross-median line hydrocarbon resources. This was ratified in January 2012 by the Cypriot parliament, but cannot come in force until Egyptian ratification is completed. ${ }^{21}$

According to local sources, Cyprus is now working together with Israel towards signing a similar joint development agreement, which it hopes that it can seal by the end of 2012 . Besides this proposed agreement and the successful EEZ delimitation, in early 2012 the two countries also signed a number of pertinent agreements comprising defence cooperation and protection, classified information exchanges, and search \& rescue agreements; primarily with a view to increasing safety in their planned offshore upstream activities in the future. Additionally, the Cypriot government is aiming at concluding similar agreements with all neighbouring EEZs and also wider regional partners as soon as possible - and ideally before the commencement of relevant E\&P operations, which could complicate negotiations. ${ }^{22}$

\footnotetext{
${ }^{19}$ See for example the recent relevant statements of Gebran Bassil, the Energy and Water Minister of Lebanon, at the 2nd Gulf Intelligence Levant Energy Forum, which was held in Nicosia in June 2012. Bassil openly called for the government of Cyprus

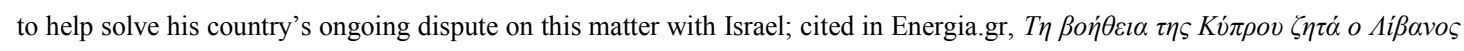

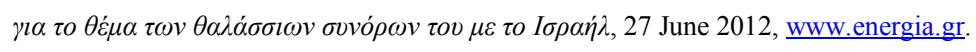

${ }^{20}$ There has in fact been speculation that there might be significant reserves in these blocks but this has yet to be confirmed. Information from author's discussions with regional government and industry officials, April and June 2012; and also from Cyprus Mail, Lebanon has no EEZ quibble with Cyprus, 17 March 2012, www.cyprus-mail.com; and Kathimerini Cyprus,

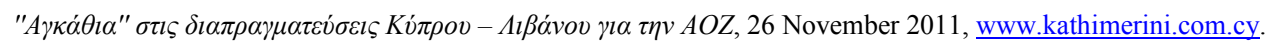

${ }^{21}$ Author's discussions with regional government and industry officials, April and June 2012; see also International Crisis Group, Aphrodite's gift: can Cypriot gas power a new dialogue, Europe Report No 216, 2 April 2012, www.crisisgroup.org ; Energy

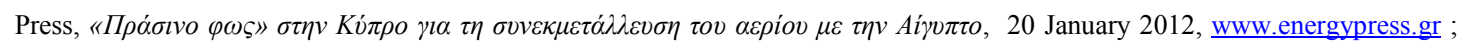
and Solon Kassinis, The status of hydrocarbon exploration in Cyprus, Presented at the Israel Business Conference, Tel Aviv, Israel, 12 December 2011, www.mcit.gov.cy.

${ }^{22}$ Ibid.
} 


\section{Map 2: Maritime boundaries of the Republic of Cyprus}

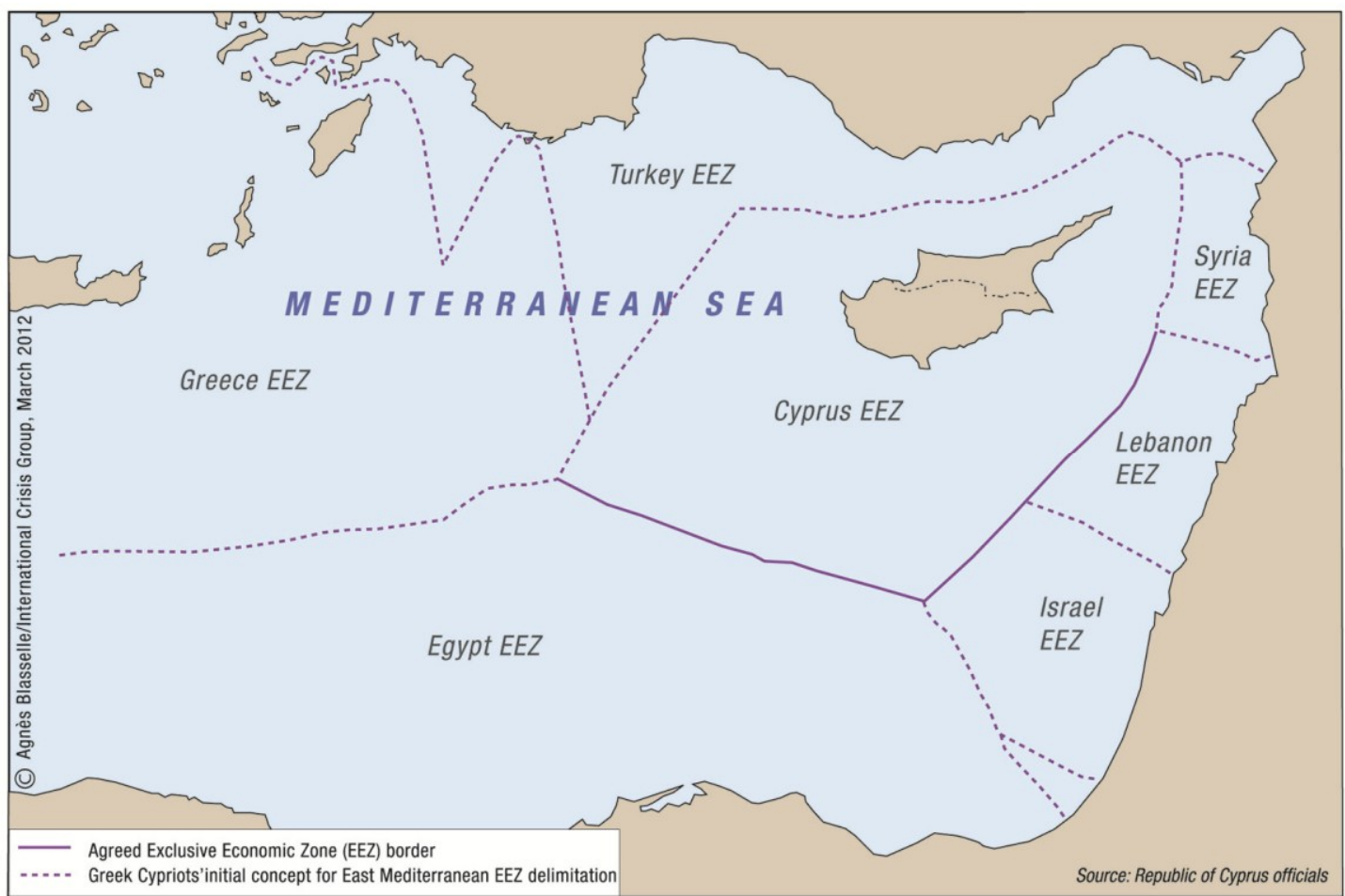

Source: International Crisis Group

\subsection{Regulatory and contractual framework}

Oil and gas activities in the Republic of Cyprus are governed by relevant EU legislation, notably the "Directive on the Conditions for Granting and Using Authorisations for the Exploration and Production of Hydrocarbons" (Directive 94/22/EC dated 30 ${ }^{\text {th }}$ May 1994). Whilst allowing for national security and other considerations, Directive 94/22/EC guarantees a minimum degree of non-discriminatory access to hydrocarbons prospecting, exploration and production, in accordance with international law and the applicable EU rules and regulations. This Directive 94/22/EC was transposed into Cypriot national law with the Hydrocarbons (Prospecting, Exploration and Exploitation) Law of 2007; and also with the Hydrocarbons (Prospecting, Exploration and Exploitation) Regulations of 2007 and 2009 respectively. Certain provisions of the Law of 2007 were amended in early 2012 (see Chapter 5 below). ${ }^{23}$

According to Cypriot officials and a Model Exploration and Production Sharing Contract (PSC) published by the Ministry of Commerce, Industry, and Tourism in February 2012,

\footnotetext{
${ }^{23}$ See Ashurst, Energy briefing: the oil and gas regime in the Republic of Cyprus, March 2012, www.ashurst.com .
} 
Hydrocarbon Exploration Licenses are granted for a 3-year period and include the possibility (with some flexibility) of up to two renewals of 2 years each, thereby offering 7 years in total to the contractor for completion of exploration activities undertaken in a given contract area. Upon each of these renewals, at least $25 \%$ of the original contract area has to be relinquished.

Any discoveries of hydrocarbons in the contract area can, at the contractor's own discretion, be followed up with an appraisal work programme, aimed at determining their commerciality. If the contractor declares a discovery to be commercial, it then has a contractual obligation to submit to the Cypriot authorities a development and production plan within a 4-month period, including a description and a map of the estimated extent of the respective exploitation area. Upon approval of its development and production plan, the contractor applies for upgrade of its Hydrocarbon Exploration to a Hydrocarbon Exploitation License in the exploitation area. This is granted initially for a 25 -year period, but may be renewed for an additional 10 years. ${ }^{24}$

In addition, production is incentivised through the recovery of applicable hydrocarbons costs and a production sharing mechanism, which improves the share of "Profit Hydrocarbons" for the contractor, when the latter incurs high capital expenditures compared to its net revenues. In other words, the scheme increases the contractor's share of the "Available Hydrocarbons", which are hydrocarbons that have been produced in the contract area and not used in related "Hydrocarbons Operations", minus the "Cost Hydrocarbons" taken by the contractor, pursuant to related provisions in the PSC. There are also signature and production bonuses of an undisclosed level payable by the contractor and not included in the "Cost Hydrocarbons". The existing PSC with Noble from the first licensing round reportedly splits the ownership of "Profit Hydrocarbons" 65/35 under normal conditions in favour of the Cypriot government. Importantly, there is no taxation imposed on the contractor's revenues from exploitation. ${ }^{25}$

Finally, the Model PSC places an obligation on the contractor to sell to the government upon request a part of its "Profit Hydrocarbons" at a price that is to be agreed between the parties; and also a separate obligation for the contractor not to sell (again upon government request)

\footnotetext{
${ }^{24}$ Ministry of Commerce, Industry, and Tourism, Model Exploration and Production Sharing Contract, Nicosia, February 2012, www.mcit.gov.cy; Ashurst, Energy briefing: the oil and gas regime in the Republic of Cyprus, March 2012, www.ashurst.com ; Solon Kassinis, The status of hydrocarbon exploration in Cyprus, Presented at the Israel Business Conference, Tel Aviv, Israel, 12 December 2011, available online at www.mcit.gov.cy; Petrostrategies, The World Energy Weekly, p.5, 10 October 2011.

${ }^{25}$ Ibid.; and also author's discussions with regional government and industry officials, April and June 2012.
} 
any hydrocarbons that are produced in the contract area "to an entity that is effectively controlled by countries declared hostile to Cyprus, or nationals of such countries". ${ }^{26}$

\subsection{Licensing rounds of the Republic of Cyprus}

\subsubsection{First licensing round}

The Republic of Cyprus proceeded with its first licensing round on 15 February 2007 for a total of eleven offshore blocks, but attracted only three bids for them. Against this backdrop, it awarded only one Hydrocarbon Exploration License on 24 October 2008 to medium-sized (but regionally quite active) US upstream independent Noble Energy for offshore Block 12, which covers roughly $100 \mathrm{~km}^{2}$ south of Cyprus. ${ }^{27}$ Following necessary preparatory work and data assessment carried out by Noble Energy on this license (including 2D and 3D seismic), the company proceeded with drilling its first exploratory well in Block 12 in September 2011. Upon expiration of the initial three-year exploration period in October of the same year, Noble successfully secured an Exploration License Renewal from the government of Cyprus; as mentioned above this included an obligatory partial relinquishment of $25 \%{ }^{28}$

Additionally, in December 2011 Noble Energy sought and successfully obtained an approval to transfer $30 \%$ of its rights to Israel's Delek Group. This included 15\% each to Delek Group

\footnotetext{
${ }^{26}$ The above is a direct and unambiguous reference to the unrecognised breakaway territories in northern Cyprus (the TRNC), which remain outside the effective control of the government of the Republic of Cyprus. It is unclear whether such provisions could block hydrocarbon sales also to Turkey, assuming the government of the Republic of Cyprus would in fact wish to do so. Indeed, it is more likely that the Republic of Cyprus would perceive sales to Turkey as an opportunity if it was presented with it, given it would probably result in de facto recognition by Ankara of both its EEZ rights and statehood.

${ }^{27}$ Noble Energy now has a market capitalisation of approximately USD 15 billion and operating assets in the US, West Africa, and the East Mediterranean. Its production stands at around 210,000 boe per day and consists of liquids (oil and condensate), US gas, and international gas in almost equal proportions. For more information see John Tomich, Noble Energy: Cyprus gas discovery, Presented at the $1^{\text {st }}$ Cyprus Energy Symposium, 26 January 2012, www.iene.gr

${ }^{28}$ Information from Ashurst, Energy briefing: the oil and gas regime in the Republic of Cyprus, March 2012, www.ashurst.com ; John Tomich, Noble Energy: Cyprus gas discovery, Presented at the $1^{\text {st }}$ Cyprus Energy Symposium, 26 January 2012, www.iene.gr ; and Petrostrategies, The World Energy Weekly, p.5, 10 October 2011.
} 
subsidiaries Delek Drilling and Avner Oil \& Gas. Noble has remained as the sole operator of Block 12 though and its obligations are accordingly left unchanged. ${ }^{29}$

In the same month - December 2011- the company announced a significant gas discovery in Block 12 ("Aphrodite"), with its exploratory well encountering 94.5 metres of net pay in multiple high-quality Miocene Sand intervals after drilling to 5,850 metres, in water depths of nearly 1,700 metres. The results from drilling, formation logs and initial evaluation indicate a gross resource range of between 5 trillion cubic feet (tcf) at a $75 \%$ probability of being exceeded, and 8 tcf at a $25 \%$ probability of being exceeded; with an intermediary estimate of $7 \mathrm{tcf}$ at a $60 \%$ probability of being exceeded. Some temporary upheaval was caused in March 2012, when independent reserve reporting company Netherland, Sewell \& Associates (NSAI) gave a best estimate of $5.1 \mathrm{tcf}$ at $50 \%$ probability for these reserves after using a deterministic methodology (compared to the probabilistic model previously employed by Noble Energy). The NSAI announcement immediately both grabbed the attention of, and also alarmed investors, putting downward pressures on Delek's shares at the Tel Aviv Stock Exchange. ${ }^{30}$

Such uncertainty (perfectly normal at this early stage on the basis of one exploration well), with regard to actual quantities and the commerciality of Block 12 reserves is set to be substantially reduced, as Noble Energy proceeds with appraisal drilling. This is expected to commence and possibly complete by the end of 2012/early 2013. Other sources of uncertainty include how large a share of Aphrodite falls within Israel's EEZ, how a unitisation agreement would be structured, and whether Aphrodite contains any liquids. The latter is of particular importance, as potential availability of condensate yields and/or of oil in a deeper reservoir in Block 12 could radically improve project economics and, thereby, allow rapid development of production and export facilities, without the need to be dependent on Israeli natural gas reserves and/or to wait to prove-up reserves in other blocks under the second licensing round, as might otherwise be required to achieve needed economies of scale (see 4.3 .4 below). ${ }^{31}$

\footnotetext{
29 Solon Kassinis, The status of hydrocarbon exploration in Cyprus, Presented at the Israel Business Conference, Tel Aviv, Israel, 12 December 2011, www.mcit.gov.cy ; Upstream Online, Cyprus OKs Noble Delek rights swap, 12 November 2011, www.upstreamonline.com

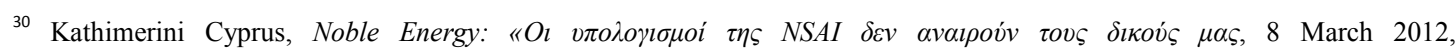
www.kathimerini.com.cy; Globes, Block 12 estimate lowered, 6 March 2012, www.globes.co.il ; John Tomich, Noble Energy: Cyprus gas discovery, Presented at the $1^{\text {st }}$ Cyprus Energy Symposium, 26 January 2012, www.iene.gr ; and Noble Energy, Noble Energy announces significant natural gas discovery offshore Republic of Cyprus, 28 December 2011, www.nobleenergyinc.com

${ }^{31}$ Natural gas fields in the immediate region are generally considered to be very dry and have failed to yield encouraging results. For example, the condensate content of the adjacent Leviathan and Tamar are as low as 4.5 barrels per million cubic feet.
} 
Operator Noble Energy has so far not shared any views on the above issues, except through its Cyprus country manager John Tomich, who said he considers Aphrodite to be large enough to offset the inevitably high costs that are to be incurred due to the significant operating depth. No announcement has been made by Noble as to breakeven costs though, and the only available guide remains a long-term contract which was signed in March 2012 with the aim of supplying the Israel Electric Corporation (IEC) with gas volumes from the adjacent Tamar field, which is also operated by Noble Energy and located in the Israeli EEZ. The sales price in that contract is estimated at USD 5.2/mmbtu in its initial phase. ${ }^{32}$

Figure 10 below offers a graphic representation and summary of the upstream regulatory framework and licensing in Cyprus from early 2003 until the end of 2011.

However, there seems to be deep oil potential in this region and operator Noble Energy is currently assessing this in Leviathan; whilst, there is a reported $25 \%$ probability of substantial oil reserves lying in deeper geological formations in the Aphrodite field. For more details on this matter see Upstream, New floater to kick-start Leviathan development, 1 June 2012, Vol. 17, Week 22; Oil \& Gas Journal, Noble halts Leviathan deepening in gas formation, 3 May 2012, www.ogj.com ; and Panos Papanastasiou, The prospects for gas and oil exploration and exploitation in Cyprus, Presented at the $1^{\text {st }}$ Academy of Athens Hydrocarbons Conference, 20 April 2012, www.academyofathens.gr.

${ }^{32}$ Noble Energy, Noble Energy announces execution of gas sales agreement with Israel Electric Corporation, 28 December 2011, www.nobleenergyinc.com ; Globes, IEC signs gas contract with Tamar, 14 March 2012, www.globes.co.il ; Kathimerini

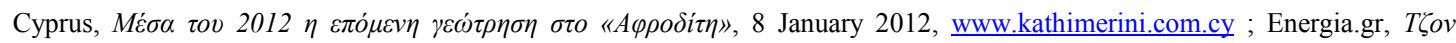

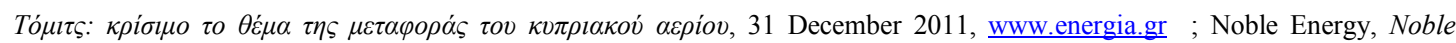
Energy announces significant natural gas discovery offshore Republic of Cyprus, 28 December 2011, www.nobleenergyinc.com

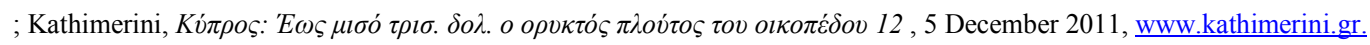


Figure 10: Timeline and background of E\&P activities in Cyprus

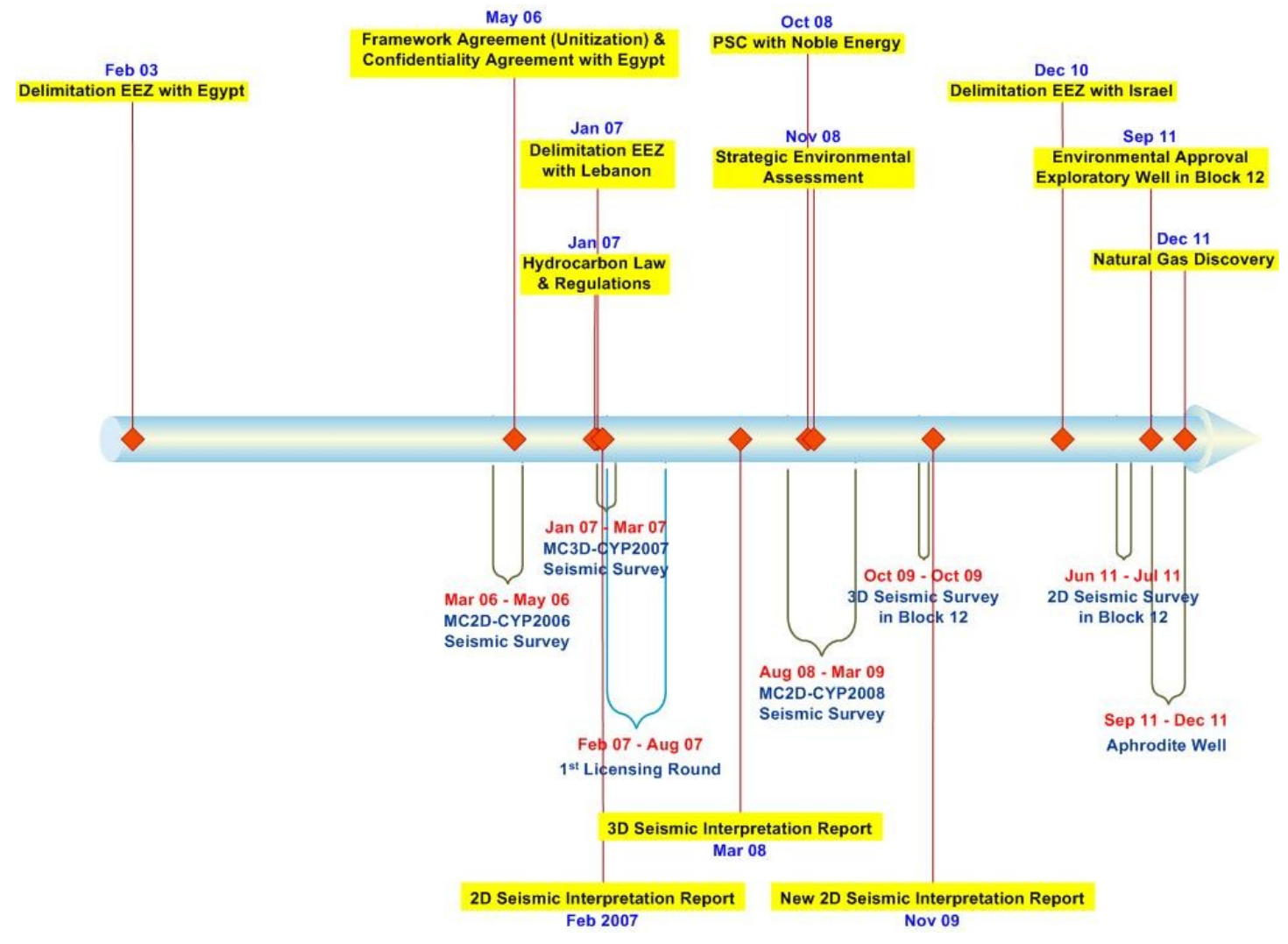

Source: Ministry of Commerce, Industry, and Tourism of the Republic of Cyprus 


\subsubsection{Second licensing round}

The Director of the Energy Service of the Ministry of Commerce, Industry, and Tourism, Solon Kassinis, has asserted that hydrocarbon resources in Cyprus - i.e. resources included in but not limited to the thirteen blocks which have so far been demarcated in the exploration area - stand at between 80 tcf and 100 tcf of gas, and may also contain some oil deposits. ${ }^{33}$ Even though such estimates remain only indicative for the time being, they draw attention to the considerable potential of the Cypriot upstream sector, beyond Block 12 .

On $11^{\text {th }}$ February 2012, the Republic of Cyprus published an invitation in the country's Official Gazette, as well as in the EU's Official Journal, calling for the submission of applications for new Hydrocarbon Exploration Licenses - including the possibility to upgrade them to Hydrocarbon Exploitation Licenses in line with the applicable contractual terms with regard to the remaining 12 exploration blocks in its EEZ, specifically for blocks 1-11 and block 13. With this second licensing round, Cyprus aimed at licensing offshore blocks bordering all three countries with which it has already signed EEZ delimitation agreements, i.e. Lebanon, Israel, and Egypt (Map 3), for which there are high hopes as to their potential. ${ }^{34}$

Thanks to significant recent discoveries in adjacent Israeli offshore territory, notably Leviathan and Tamar, but also Noble Energy's very encouraging results from its exploratory well in Block 12, there were great expectations this round would be much more successful than the last one. In the run up to the deadline for submitting bids in May, media reported interest from various International Oil Companies (IOCs) including both supermajors as well as key Asian players. For example, in March 2012 local and international media cited Cypriot officials, who confirmed there had been some interest from the China National Offshore Oil Corporation (CNOOC) in the development of Cypriot upstream and liquefaction. ${ }^{35}$

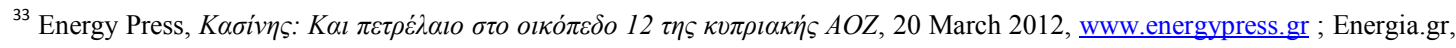

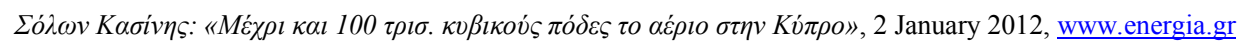

${ }^{34}$ Author's discussions with regional government and industry officials, April and June 2012; and also Natural Gas Europe, Cyprus gas findings prompts international interest, 4 January 2012, www.naturalgaseurope.com.

${ }^{35}$ More in Bloomberg, CNOOC offers to build liquefaction plant, Cyprus Mail says, 6 March 2012, www.bloomberg.com ; Rigzone, Cyprus official: CNOOC interested in gas prospecting, Cyprus Mail says, 5 March 2012, www.rigzone.com ;

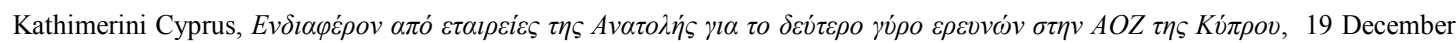

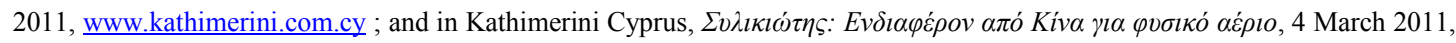
www.kathimerini.com.cy.
} 
Additionally, there was speculation regarding French majors GDF Suez and Total; while in February 2012 President Demetris Christofias expressed publicly his hopes that Russian companies would decide to participate in the second upstream licensing round of Cyprus. These comments by President Christofias, combined with a separate agreement that had been signed in December 2011 between Moscow and Nicosia for a sovereign loan of Euros 2.5 billion (and with the first Euros 590 million tranche arriving in the same month), gave rise to heavy conjecture that Gazprom was indeed interested and was accordingly preparing a bid. However, the company denied it had plans to participate, referring to high production costs. ${ }^{36}$ In contrast, in April 2012 the Russian independent Novatek, which purportedly enjoys good links with the Kremlin and sponsors (along with Total) the Yamal LNG project in Siberia, confirmed it would be interested in Cypriot energy projects without offering any other details; while Gazprom once more grabbed local headlines. ${ }^{37}$

All this speculation finally came to an end on May $11^{\text {th }} 2012$, the deadline for submitting bids, when the government publicised the full list of upstream bidders. This included a total of 15 companies and consortia, predominantly from the EU and Israel, but also important players from North America, Australia, Asia, and the Russian Federation; and comprised integrated IOCs, upstream independents, buyers / traders, and regional players.

The full list is as follows: ${ }^{38}$

\section{Petra Petroleum}

2. ATP East Med // Naphtha Israel Petroleum // DOR Chemicals // Modiin Energy

3. Total

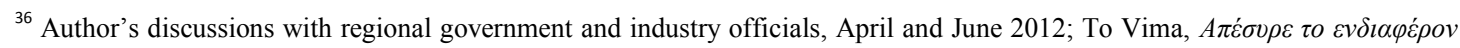

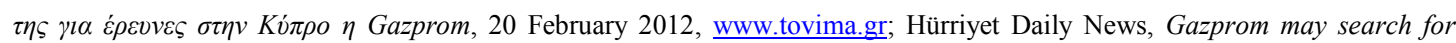

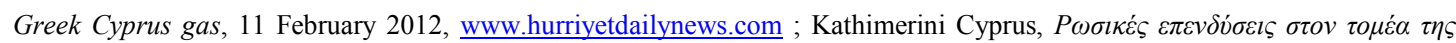

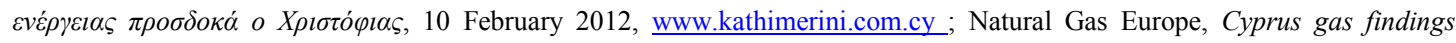
prompts international interest, 4 January 2012, www.kathimerini.com.cy ; Bloomberg, Cyprus, Russia Sign 2.5 Billion-Euro Loan Deal in Moscow, 23 December 2011, www.bloomberg.com.

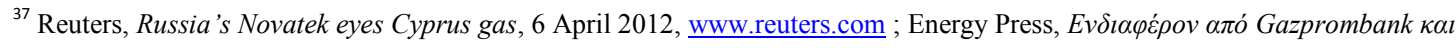

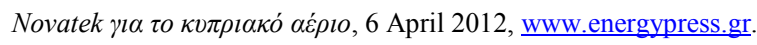

${ }^{38}$ Asterisk denotes operator. More details in Upstream Online, Players' warn response to Cyprus license round, 17 May 2012,

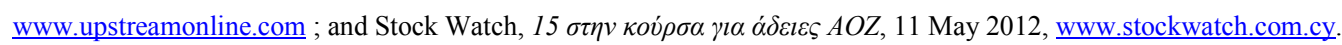


4. Total * // Novatek // Gazprom Bank

5. Premier Oil *// Vitol

6. Premier Oil *// Vitol // Petronas

7. Edison * // Delek Drilling // Avner Oil // Enel // Woodside Energy

8. ENI // Kogas

9. C.O. Cyprus Opportunity Energy // AGR Energy *

10. OAK Delta NG Exploration

11. Capricorn Oil (Cairn) // Marathon Oil // Oranje Nassau // CC Energy (CCC)

12. Winevia Holdings

13. RX-DRILL Energy Cyprus

14. PT Energi Mega Persada // Frastico Holdings

15. Emmanuelle Geo Global Rosario

This group of companies has a wide spread of financial capacities, business strategies and priorities, and technical/commercial skill-sets. For example, some boast strong experience in deepwater operations; subsea pipelines; liquefaction development (and even operatorship); and LNG trading and gas market access, while other bidders may have fewer competitive advantages to offer. Still, the participation of all these players, and certainly of the most competitive amongst them, suggests that there will probably be sufficient skills and financial strength in aggregate to realise the upstream and monetisation/export potential of Cyprus.

Russian companies in the form of Novatek and Gazprom Bank participated in the tender, even though it seems that they have decided to take a non-operating interest behind partner Total, with whom they co-operate respectively on the Yamal and Shtokman LNG projects in Russia. But the strategy of these companies, and Gazprom in particular, still remains rather unclear. 
International expansion is generally perceived positively in Moscow, and in June 2012 it emerged Gazprom is keen to participate in the development of Israeli offshore gas reserves. Earlier in March 2012 though, Gazprom Marketing \& Trading had entered into non-exclusive negotiations with the Tamar partners in Israel for a long-term SPA for up to $3 \mathrm{mmtpa}$ of LNG with no upstream farm-in and/or liquefaction equity, suggesting the company may in reality hesitate to allocate scarce capital away from the priority development areas within Russia, notably in the declining Nadym-Pur-Taz (NPT) and the difficult Yamal upstream regions. ${ }^{39}$

Moreover, the discussed participation of CNOOC in the bidding did not materialise, possibly due to other priorities, limited deepwater experience, and perhaps even a lack of information. Similarly, and in contrast to partner Delek Group, Block 12 license holder Noble Energy did not submit any bids in the second round. This was probably a corollary of the company's need to manage its very substantial exposure to the East Mediterranean region (Cyprus and Israel), and to optimise allocation of available capital.

Finally, some IOCs, including supermajors with regional assets and a probable strategic fit on both the upstream and even the natural gas monetisation level, were notable for their absence. For example, BP and GDF Suez did not submit any bids despite their: a) deepwater expertise; b) regional presence (including Egypt, with its challenging supply and demand balances); and c) potential to benefit significantly from possible greenfield LNG developments in Cyprus, due to their own relatively limited alternative opportunities at liquefaction growth, at least compared to some of the other IOCs which have numerous liquefaction projects under way. Other major players with LNG interests, deepwater expertise, and even regional positioning which were similarly absent include Shell, ExxonMobil, Chevron, Statoil, and BG Group. However, it is always possible these and other individual companies simply did not identify sufficient prospectivity to justify a bid, and/or this did not fit with their business strategies.

Blocks 2 and 9 were the most successful of the second licensing round of Cyprus, receiving the most bids of all offered acreage; in contrast blocks 1,4, and 13 failed to receive any bids. It is possible that this reflects both their geological potential, as well as regional political risk.

\footnotetext{
${ }^{39}$ For more details see Upstream Online, Gazprom 'eyes E\&P role' offshore Israel, 27 June 2012, www.upstreamonline.com ; Upstream Online, Gazprom in 'Tamar LNG sales talk', 22 March 2012, www.upstreamonline.com ; and also Upstream Online, Noble in Tanin gas strike, 6 February 2012, www.upstreamonline.com.
} 
Nicosia aims at completing preliminary screening by the end 2012; and to conclude relevant negotiations and accordingly to award second round upstream licences by the end of $2013 .{ }^{40}$ However, the institutional capacity of Cyprus to evaluate these bids remains relatively limited and could be strained even further by its assumption of the 6-month rotating presidency of the EU as of July 2012, which could render the envisaged timetable above an optimistic one. These problems are examined in chapter 5 below in more detail.

\section{Map 3: Exploration blocks in the Republic of Cyprus}

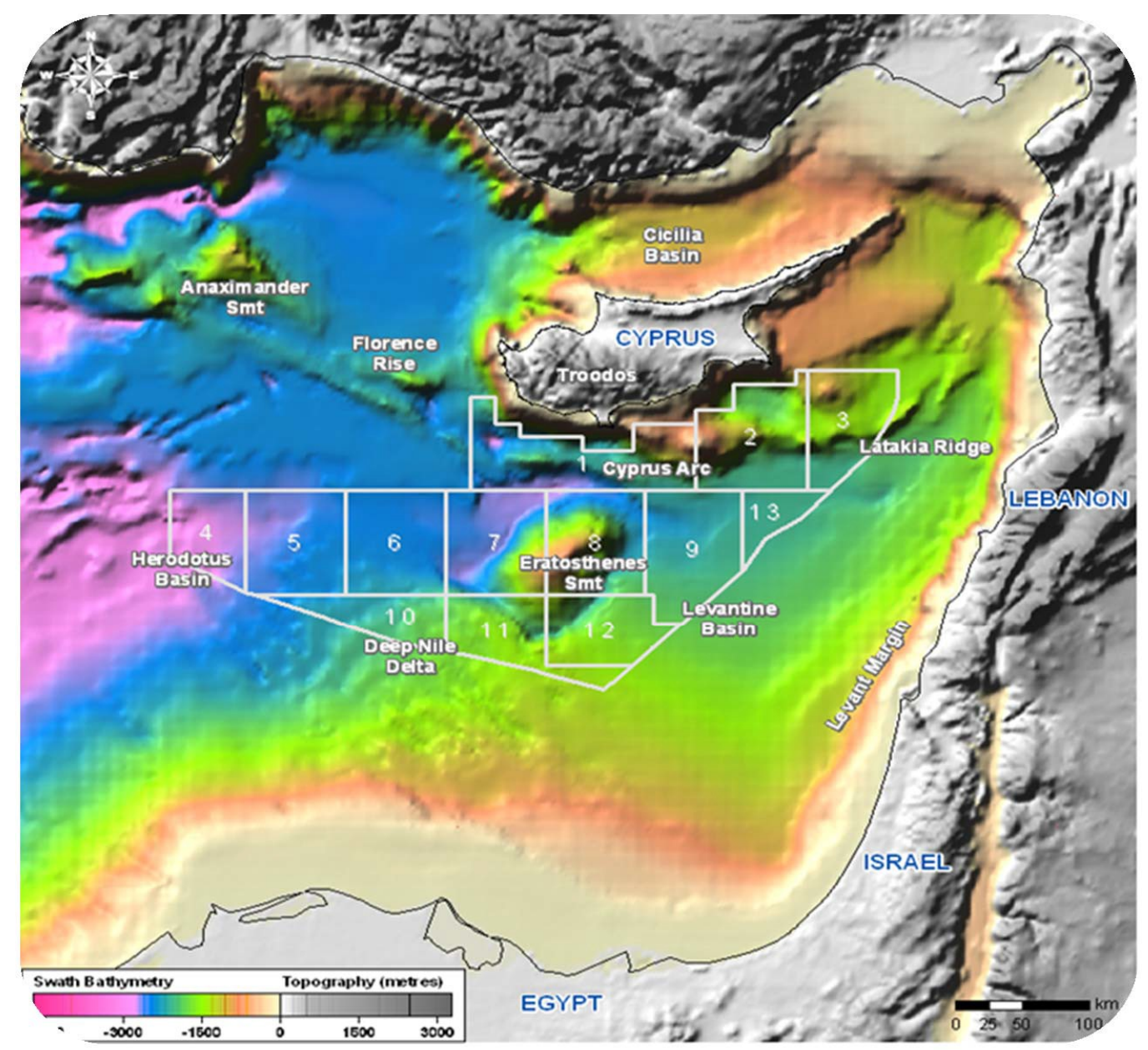

Source: Ministry of Commerce, Industry, and Tourism of the Republic of Cyprus

\footnotetext{
${ }^{40}$ Upstream Online, Players' warn response to Cyprus license round, 17 May 2012, www.upstreamonline.com.
} 


\subsection{The role of Turkey and other actors}

\subsubsection{Turkey and the international community}

Ankara has responded extremely negatively to E\&P developments in the Republic of Cyprus, which it does not recognise, and in September 2011 Prime Minister Recep Tayyip Erdoğan cautioned IOCs they would be excluded from energy projects in Turkey if they invested in Cyprus upstream. This threat was reiterated by the Turkish Ministry of Foreign Affairs in May 2012, when Nicosia publicised the list of the bidders in its second licensing round. ${ }^{41}$ Even though of course there has been no talk of expropriation of such existing investments, this still represents a significant risk for IOCs, given Turkey's growing downstream market (including anticipated domestic gas price liberalisation) and also midstream opportunities; where, among others, major IOCs such as Shell, BP, and GDF Suez have invested.

Moreover, Turkey's upstream is now becoming increasingly attractive to IOCs. For example, the Turkish state-owned upstream operator Türkiye Petrolleri Anonim Ortaklığı (TPAO) is planning to move forward with IOC involvement in offshore E\&P operations in south/southeast Turkey, namely in the Antalya, Mersin, and Iskenderun regions (Map 4). According to TPAO, some $10,000 \mathrm{~km}$ of $2 \mathrm{D}$ and $1,000 \mathrm{~km}$ of $3 \mathrm{D}$ data has already been gathered and related farm-out commenced in the first quarter of 2011 with reference to the Gulf of Antalya. In November 2011 TPAO and Shell signed cooperation agreements, covering seismic research in offshore Antalya as well as exploratory drilling there after 2014. The two companies will share production in Antalya (and also in Diyarbakir) on an equal $50 / 50$ footing, if commercially viable oil and/or gas reserves are indeed found in these areas. ${ }^{42}$

According to local media, there is preliminary interest in the establishment of similar JVs with TPAO in Turkey from other major international companies too, including ExxonMobil and Chevron which have already invested in the Turkish upstream sector in the Black Sea. TPAO also claims that ExxonMobil is interested in the Turkish unconventional potential, which is estimated at approximately 15 tcf. Even though little concrete progress has so far

\footnotetext{
${ }^{41}$ See Upstream Online, Turkey warns it will not deal with Cyprus bidders, 18 May 2012, www.upstreamonline.com ; and also International Crisis Group, Aphrodite's gift: can Cypriot gas power a new dialogue, Europe Report No 216, 2 April 2012, www.crisisgroup.org.

${ }^{42}$ TPAO, Farm out activities in the Mediterranean, accessed 6 February 2012, www.tpao.gov.tr ; Kathimerini Cyprus, E$\mu \pi \lambda \dot{\kappa} \kappa \varepsilon l$

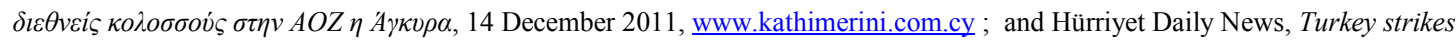
oil, gas deal with Shell, 23 November 2011, www.hurriyetdailynews.com.
} 
been reported, such a move would arguably be in line with the supermajor's overall strategy, in the aftermath of its multibillion acquisition of XTO in the US and a growing strategic focus on unconventional E\&P across the globe, including in Europe. ${ }^{43}$

\section{Map 4: Request for Proposals by TPAO for Iskenderun Basin}

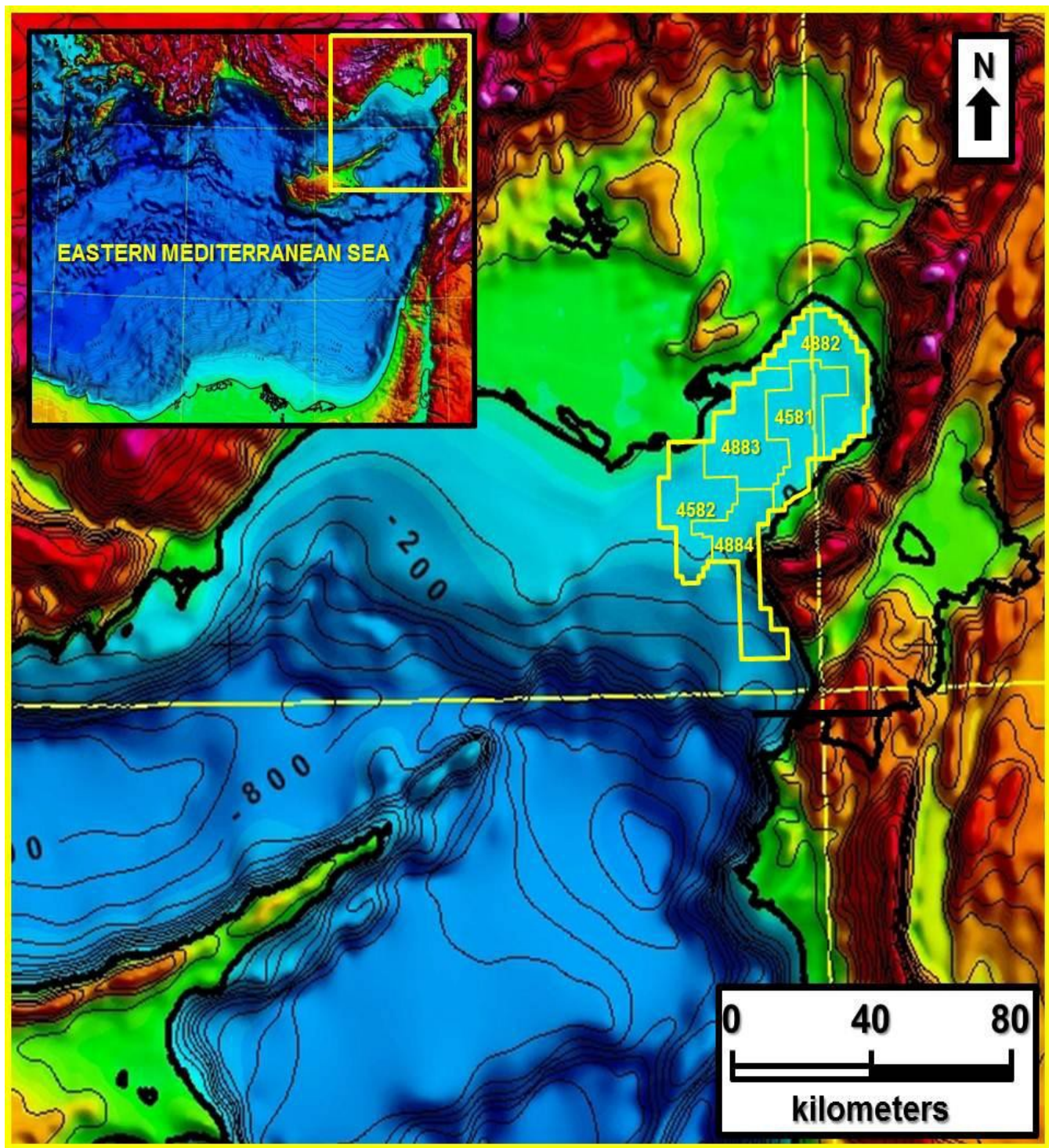

Source: TPAO

\footnotetext{
${ }^{43}$ Reuters, Exxon eyeing Turkish shale gas prospects: TPAO CEO, 12 March 2012, www.reuters.com.
} 
Turkish arguments against hydrocarbons exploration (and future exploitation) operations in Cyprus revolve around four main - and partially conflicting - axes. Specifically:

1. The Republic of Cyprus is obliged to share any future profits from hydrocarbon activities with the Turkish Cypriots;

2. The Republic of Cyprus does not represent the Turkish Cypriots and lacks authority to negotiate $\mathrm{E} \& \mathrm{P}$ agreements, even for areas under government control in the south;

3. The recent EEZ delimitations of the Republic of Cyprus to its west and southwest are incorrect and encroach on the Turkish continental shelf; and

4. The rights of the so-called TRNC are violated.

Concerning the first two points, Ankara has made clear that any proceeds from monetisation of Cypriot hydrocarbons should be shared on an equal footing with the Turkish Cypriots; while in February 2012 the Turkish Ministry of Foreign Affairs issued a statement describing the second licensing round as a unilateral step of the "Greek Cypriot Administration", which completely fails to take into account the rights of the Turkish Cypriots, and undermines the UN-led peace process. However, President Christofias has already stated his agreement in principle with sharing hydrocarbon revenues with the island's Turkish Cypriot community, a statement received favourably by the UK government, a Guarantor Power, as well as others. At the same time though, Turkey has argued that the government of the Republic of Cyprus not only lacks the necessary authority to negotiate E\&P agreements on behalf of the whole of the island, but cannot do this even for territories under government control in the south. ${ }^{44}$

With regard to point "3" on EEZ delimitations, the Turkish position is that relevant provisions of UNCLOS cannot apply in the case of Cyprus due to the latter's small size and island status, and also the geography of the Mediterranean, which Turkey sees as relatively self-enclosed. As a result, the Turkish government claims Cyprus's reach to its west (i.e. south of Turkey) cannot exceed 12 nautical miles off the Cypriot coast. In fact, Ankara is operating under an assumed demarcation with Egypt along the median line between the two countries which, however, is not recognised by Cairo and is also refuted by the EEZ delimitation agreement of 2003 between Cyprus and Egypt. The latter is already in force.

\footnotetext{
${ }^{44}$ UK House of Lords, Cyprus EU Presidency, HL Deb, 9 November 2011, www.theyworkforyou.com ; Kathimerini Cyprus,

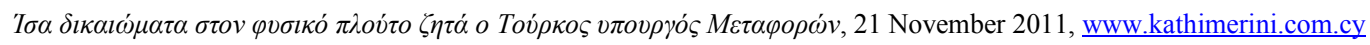


Furthermore, shortly after Cyprus announced the launching of its second round in February 2012, the Turkish Ministry of Foreign Affairs issued a strongly-worded statement asserting that the offshore blocks $1,4,5,6$, and 7 overlapped with the continental shelf of Turkey (Ankara has very serious reservations concerning the applicability of EEZ in this region). Accordingly, it warned it will under no circumstances allow foreign companies to proceed with "unauthorised oil/natural gas exploration and exploitation" in these "overlapping areas" (Map 5 below). This was reiterated when the list of bidders was publicised in May 2012. ${ }^{45}$ Moreover, the Turkish government did not stop there and, on 26 April 2012, it approved TPAO E\&P licenses for a total six offshore blocks which overlap with Cypriot Blocks 1, 4, 5, 6, and 7. One of these six blocks even lies close to the Greek island of Rhodes in the south east Aegean Sea, potentially encroaching on that country's continental shelf too. ${ }^{46}$

It should be noted that the Turkish position regarding blocks $1,4,5,6$, and 7 , namely that these fall within its own continental shelf, is qualitatively very different from the initial Turkish focus, which only questioned the authority of the Republic of Cyprus to negotiate E\&P agreements on behalf of the whole of Cyprus, given the ongoing divisions in the island. It remains to be seen whether the Turkish government is willing to escalate matters along these lines, or instead if this is merely a means of increasing the perception of political risk related to upstream operations, hence discouraging E\&P operations under the second round. ${ }^{47}$

\footnotetext{
${ }^{45}$ More details in Upstream Online, Turkey warns it will not deal with Cyprus bidders, 18 May 2012, www.upstreamonline.com; International Crisis Group, Aphrodite's gift: can Cypriot gas power a new dialogue, Europe Report No 216, 2 April 2012, www.crisisgroup.org ; Turkish Ministry of Foreign Affairs, Press release regarding the second international tender for offshore hydrocarbon exploration called by the Greek Cypriot Administration (GCA), No. 43, 15 February 2012, www.mfa.gov.tr ${ }^{46}$ See Middle East Economic Survey, TPAO begins drilling well in northern Cyprus, Vol. LV No 19, 7 May 2012,

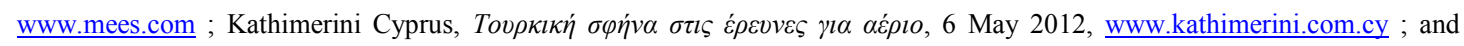
Upstream Online, Turkey to explore offshore Cyprus, 1 May 2012, www.upstreamonline.com.

${ }^{47}$ Notwithstanding the validity or not of the Turkish legal arguments in this framework, and its willingness to resort to force (and/or to other active obstructionism), Turkey could also invoke UNCLOS Articles 74 and 83 which limit E\&P rights in disputed areas. At the same time though, there is an explicit obligation placed on parties to work together in good faith towards reaching an agreement, with the latter including making "every effort to enter into provisional agreements of a practical nature". The fact that Turkey is not a signatory of UNCLOS and even refuses to engage directly with the Republic of Cyprus weakens credibility and undermines the effectiveness of its arguments. For more information on this matter see International Crisis Group, Aphrodite's gift: can Cypriot gas power a new dialogue, Europe Report No 216, 2 April 2012, www.crisisgroup.org .
} 


\section{Map 5: Turkish claims on offshore blocks of the Republic of Cyprus}

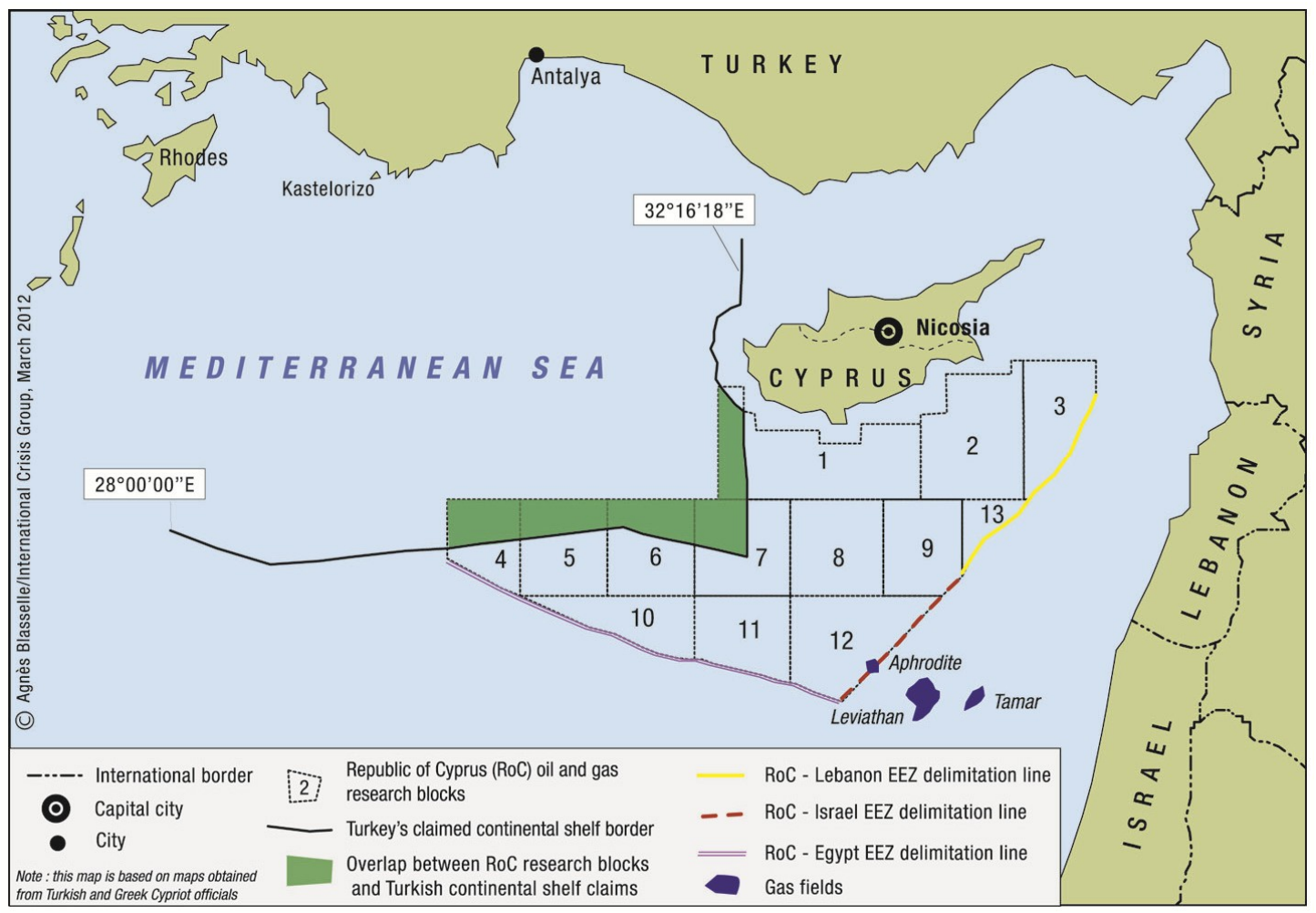

Source: International Crisis Group

Nicosia has utterly rejected Turkish allegations, claiming it is acting well within its sovereign rights as stipulated under international law. Moreover, authorities in Cyprus already have significant experience in dealing with what they regard as active Turkish obstructionism, which manifested itself in the form of military exercises during the first licensing round. ${ }^{48}$ Importantly, just before the commencement of the drilling activities in Block 12 and with mounting pressure from Turkey which included the mobilisation of its naval and air forces, ${ }^{49}$ in November 2011 the Deputy Foreign Minister of Israel, Danny Ayalon, visited Athens, where he stated that Israel was ready to protect drilling activities in Cyprus. In January 2012 Demetris Eliades became the first Cypriot Defence Minister ever to visit Israel officially, signalling the increasing strategic alignment, including energy interests, of the two countries.

\footnotetext{
${ }^{48}$ See International Crisis Group, Aphrodite's gift: can Cypriot gas power a new dialogue, Europe Report № 216, 2 April 2012,

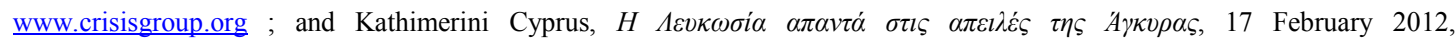
www.kathimerini.com.cy

49 More details in Bloomberg, Erdogan's fighter jets challenge Cypriot gas exploration in Mediterranean, 10 October 2011, www.bloomberg.com ; Today's Zaman, Turkish warships head towards Cyprus in oil exploration dispute, 21 September 2011, $\underline{\text { www.todayszaman.com }}$
} 
In February 2012, Benjamin Netanyahu in turn became the first Israeli PM to visit Cyprus and discussed co-operation between the two countries on a number of levels, including energy. The Turkish press offered extensive coverage of Netanyahu's visit to the island and its significance with regard to Turkish foreign and security policy in the eastern Mediterranean, while also reporting that Nicosia might grant the Israeli air force access to its airbases. ${ }^{50}$

Moreover, Turkish comments have generally been out of tune on this matter with the position of the US, Russia, and the EU, which have lent political support to the Republic of Cyprus. ${ }^{51}$ For example, in September 2011 Baroness Ashton, speaking through a spokesman in her capacity as the High Representative of the Union for Foreign Affairs and Security Policy and Vice-President of the European Commission, openly urged Ankara to refrain from any threat, friction, or action which could negatively affect good neighbourly relations and the peaceful settlement of border disputes. And similarly, in December 2011 the European People's Party, which represents centre-right parties in the EU Parliament, supported the right of Cyprus to proceed with exploratory drilling; it condemned the military threats and escalation of Turkey; and it called for the "involvement of the EU in the efforts to develop hydrocarbon resources in the Eastern Mediterranean." 52

The fact that blocks 1 and 4 did not receive any bids in the second licensing round may reflect limited geological potential but also political risk; in other words potential investors may have

\footnotetext{
${ }^{50}$ Cyprus and Israel have said that access will be granted for peaceful purposes only and does not have any military aspects attached to it. For more details on the growing relationship between the two countries see for example Hürriyet Daily News, Israel and Greek Cyprus gas push disturbs Turkey, 17 February 2012, www.hurriyetdailynews.com ; Haaretz, In Cyprus, Netanyahu stresses cooperation in natural gas, 17 February 2012, www.haaretz.com ; Reuters, Netanyahu discusses energy

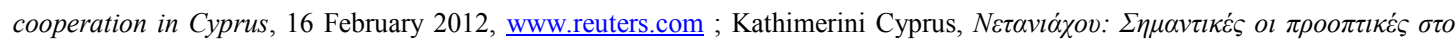

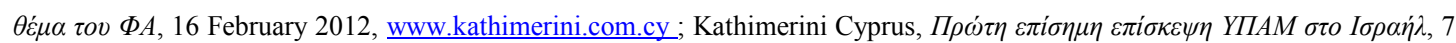
January 2012, www.kathimerini.com.cy; and, finally, the Jewish Journal, Ayalon: Israel will defend Greek oil drilling in Cyprus, 23 November 2011, www.jewishjournal.com.

51 ANSA Med, Cyprus: Russian navy nears gas drilling zone, 25 November 2011, www.ansamed.info ; Kathimerini Cyprus,

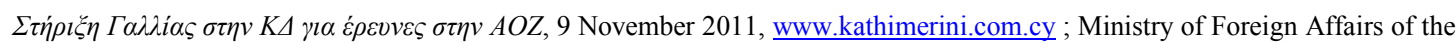
Republic of Cyprus, Statements by the Minister of Foreign Affairs Dr Erato Kozakou-Marcoullis and the British Foreign

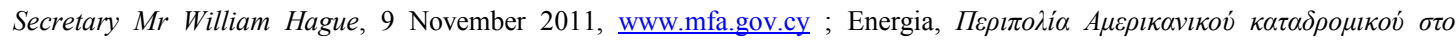
Oıкó $\varepsilon \delta o ~ 12,8$ November 2011, www.energia.gr ; Hürriyet Daily News, Deal with north Cyprus, top minister tells the EU, 30 September 2011, www.hurriyetdailynews.com ; Bloomberg, Cyprus drilling must stay within UN-Law, Russia's Lavrov says, 21 September 2011, www.bloomberg.com ; Hürriyet Daily News, US backs up Greek Cyprus in gas-drilling row, 12 August 2011, www.hurriyetdailynews.com

${ }^{52}$ See the Emergency Resolution adopted at the EPP Congress, Marseille (France), 7th-8th December 2011, http://epp2011.eu ; and Oil \& Gas Journal, EU reprimands Turkey over threats to drilling offshore Cyprus, 20 September 2011, www.ogj.com.
} 
stayed away due to the Turkish claims on them. However, equally disputed blocks 5, 6, and 7 seem to have been successful in attracting bids. If these bids actually include offers by some of the larger IOCs involved in the second round, that would probably mean the political backing that has been offered to Cyprus from the international community has proved enough to neutralise Turkish opposition; and, as a result, the Turkish position on this matter could be eroded further in the future. However, such interest from large IOCs for these blocks has not yet been confirmed and their licensing under the second round cannot be taken for granted. ${ }^{53}$

The international support that Nicosia has so far enjoyed on this important matter is related primarily to economic considerations, but may also include some geopolitical calculations. Specifically, potential significant gas production in member-state Cyprus could support supply diversification in the EU, which is seeing its own indigenous gas production decline. The emergence of Cyprus as a viable supply option could also ease the continent's increasing dependence on Turkey for transit of all of its non-Russian gas inflows from the Caspian region; even though this is not yet necessarily perceived as a potential threat by EU countries. Israel seems to be equally positively inclined for co-operation with Nicosia, especially after the recent fallout with Ankara and its desire to establish direct energy links with Europe, arguably for both economic and political reasons. ${ }^{54}$

\subsubsection{Turkey and the TRNC}

With reference to point "4" of 3.4.1 above, in September 2011 Turkey and TRNC signed a continental shelf agreement which extends beyond territories under Turkish control in north Cyprus and well into areas under the control of the government of the Republic of Cyprus (which Ankara does not recognise). Their agreement demarcated boundaries between them in Turkey's favour (i.e. it did not follow the median line principle), probably as a means of supporting the broader Turkish position regarding the maritime boundaries of Cyprus. ${ }^{55}$

Following up on the aforementioned continental shelf agreement, in November 2011 TPAO and authorities in the north signed a "Petroleum Services and Production Sharing Contract", under which TPAO is granted access to both onshore and offshore blocks and assumes $100 \%$

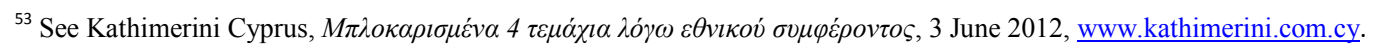

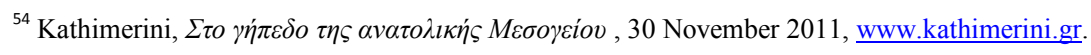

${ }^{55}$ International Crisis Group, Aphrodite's gift: can Cypriot gas power a new dialogue, Europe Report No 216, 2 April 2012, www.crisisgroup.org ; Today's Zaman, KKTC continental shelf agreement extends to Greek Cyprus areas, 16 December 2011, www.todayszaman.com.
} 
of relevant development costs. Importantly though, licensing by the TRNC, which remains unrecognised by the international community except Turkey, overlaps with offshore blocks in areas which are still under the control of the government of the Republic of Cyprus; specifically, with blocks 1 (claimed also by Turkey), 2, 3, 8, 9, 12, and 13 (see Map 6).

Furthermore, in a ceremony attended by Turkish-Cypriot leader Derviş Eroğlu and Turkish Energy Minister Taner Yildiz, on 26 April 2012 the Turkish upstream operator commenced exploratory drilling onshore Cyprus in the area of Trikomo, that lies northwest of Famagusta, a city in northern Cyprus which remains partially deserted since the Turkish invasion of 1974. The Turkyuduru- 1 well in Trikomo has a target depth of approximately 3,000 metres and is expected to take several months to complete; while the Turkish plan is also to commence extensive seismic surveys by the end of 2012 in various onshore areas starting with Morphou; as well as to expand into the disputed blocks offshore Famagusta as soon as possible. ${ }^{56}$

The fact that the TPAO-TRNC agreement encroaches on offshore blocks that actually form part of the second licensing round of the Republic of Cyprus appears to be politically aligned with the recent statements of the Turkish Ministry of Foreign Affairs, which asserted that Cypriot offshore blocks $1,4,5,6$, and 7 in reality overlap with Turkey's continental shelf. This could be a policy of deliberately increasing the perceived political risk in Cyprus, therefore discouraging bidders from proceeding with E\&P operations under the second round. However, the fact that Turkey has signed a continental shelf agreement with an unrecognised entity such as TRNC which, moreover, is clearly in violation of the continental shelf of areas which are under government control in the south of the island, undermines Turkish claims.

Indeed, offshore blocks 2 and 9 of the second licensing round were the most successful ones; while blocks 3,8 , and 9 were also able to attract bids. This seems to suggest that interested

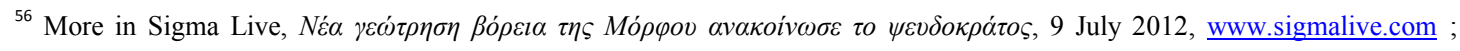
Middle East Economic Survey, TPAO begins drilling well in northern Cyprus, Vol. LV No 19, 7 May 2012, www.mees.com ; Upstream Online, Turkey 'starts drilling off Cyprus', 26 April 2012, www.upstreamonline.com ; Upstream Online, TPAO: Cyprus drilling “in days”, 12 March 2012, www.upstreamonline.com; Argus Media, Turkey TPAO to start drilling onshore Cyprus, 12 March 2012, www.argusmedia.com ; TPAO, TPAO and Ministry of Economy and Energy of TRNC Partnership for Petroleum Services and Production S [sic], accessed 6 February 2012, www.tpao.gov.tr ; Energy Press, Kí $\pi \rho o \varsigma: \Delta \imath \dot{\alpha} \beta \eta \mu \alpha \sigma \tau o v$

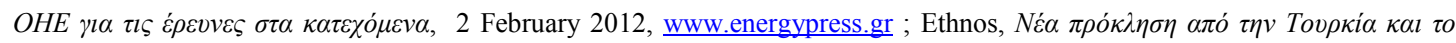

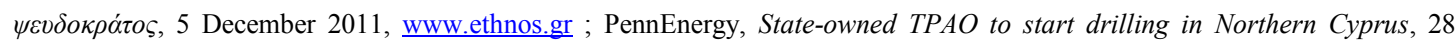

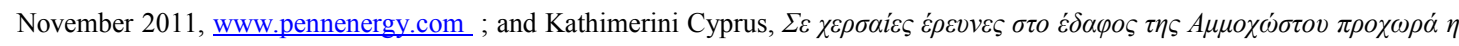
Tovркía, 28 November 2011, www.kathimerini.com.cy.
} 
parties were not particularly concerned and / or discouraged by the relevant Turkish claims; and that the difficulties with block 13 may have more to do with its size and depth.

Chapters 4 and 5 below respectively examine available monetisation options for the natural gas reserves of Cyprus, including the interplay between the political and commercial levels; as well as the emerging institutional framework in Cyprus and its capacity to cope with the task at hand, notably with bid evaluation and monetisation negotiations.

\section{Map 6: Contextualisation of E\&P blocks "licensed to TPAO by TRNC"}

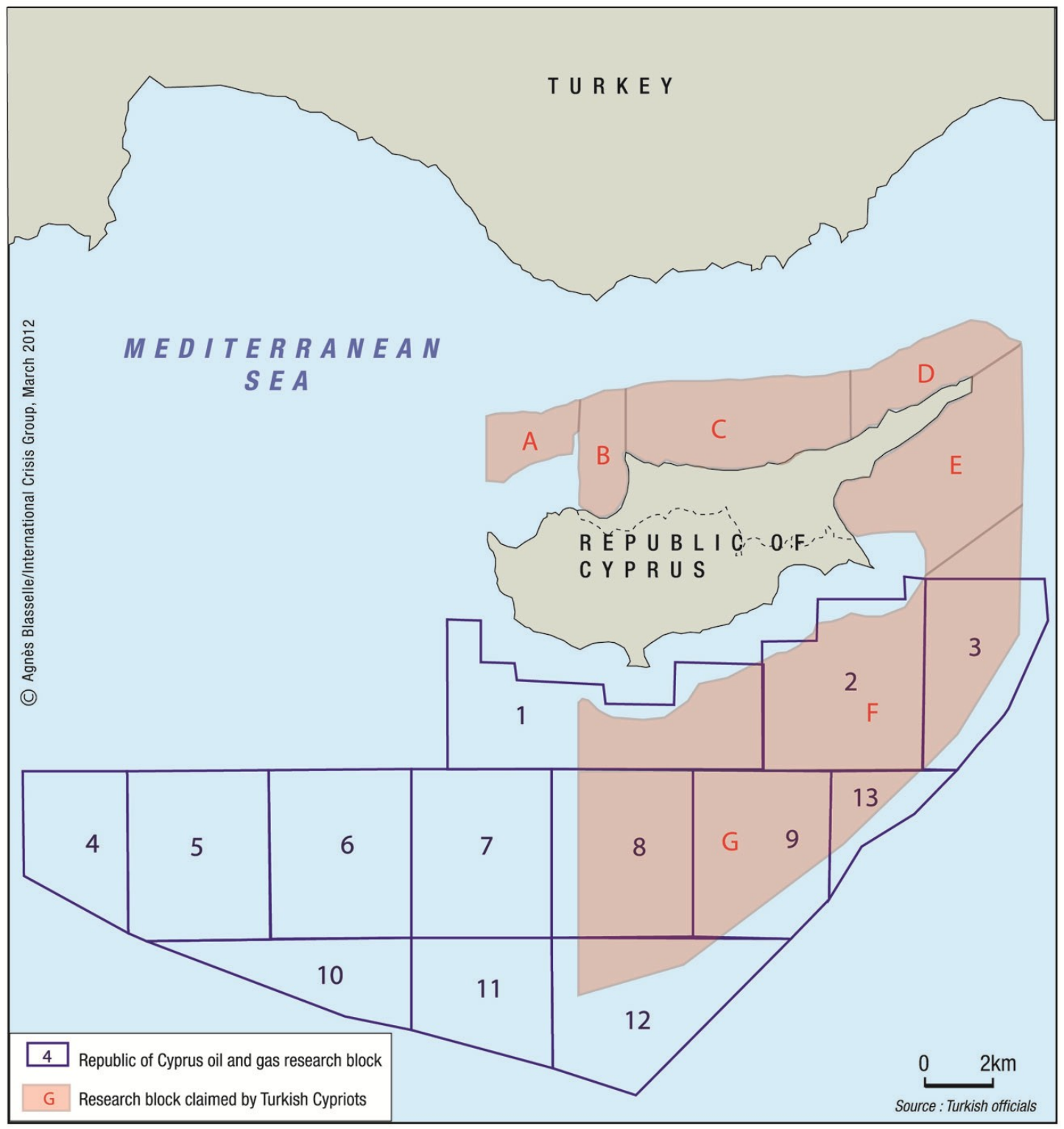

Source: International Crisis Group 


\section{Monetisation}

\subsection{General background}

The Republic of Cyprus has already expressed its interest in becoming a natural gas exporter, as soon as its own domestic needs for gas-fired power generation have been satisfied; while Noble Energy has commenced preliminary technical studies which are aimed at construction of what most probably will be an early production system, as well as a $200-\mathrm{km}$ subsea gas pipeline from the Aphrodite field to the onshore Vasilikos industrial area (see Map 7). Construction of this scheme is expected to be completed and natural gas therefore to become available in Cyprus around 2017/2018, at projected costs which could reach Euros 2 billion; with full field development and exports commencing some two years later, in 2019/2020. ${ }^{57}$ However, this may be an optimistic timetable, even excluding other technical complications.

Despite infrastructure development costs incurred by the contractor up to the delivery point being reimbursed through a cost recovery mechanism under the terms of the PSC agreement ("Cost Hydrocarbons"), deliveries to onshore Cyprus most probably require the installation of some form of offshore gas production facility, which may not prove viable. ${ }^{58}$ If we assume availability and usage at that time of some 1,080 MW of gas-fired power generation capacity, i.e. all currently oil-fired units at the Vasilikos power station, as well as oil-fired units which are considered relatively easily convertible to natural gas at the Moni and Dhekelia plants, the maximum gas consumption for Cyprus is less than 0.9 bcma.

It is therefore more likely that Noble Energy will insist that supply of natural gas to Cyprus would have to be part of a full scale development plan for its offshore discovery, including agreement on a viable gas export plan based on full field development with the government (the approval of the latter of the contractor's development and production plan is necessary). This could in turn delay the envisaged gasification of the power generation sector of Cyprus,

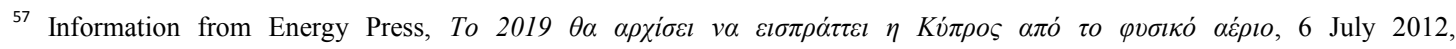

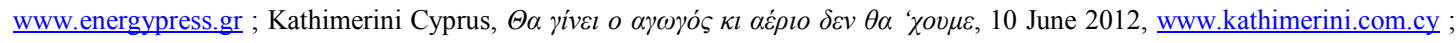

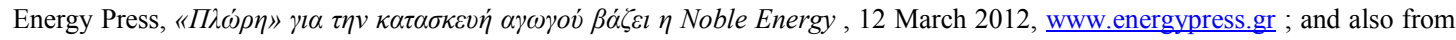
the interview of Dr Titos Christofides, Under Secretary to the President of the Republic of Cyprus to Kathimerini Cyprus,

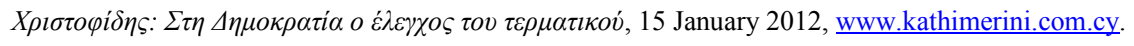

${ }^{58}$ However, international media have quoted unnamed industry sources who are claiming that the adjacent Leviathan gas field in Israel's EEZ has no need for such compression equipment, because reservoir pressure is sufficient to drive gas to Israel's shore. For more information see Upstream, New floater to kick-start Leviathan development, 1 June 2012, Vol. 17, Week 22.
} 
to the detriment of local consumers who will therefore continue to be exposed to oil prices. ${ }^{59}$ At any rate, the fact that the longer-term domestic gas requirement in Cyprus is fairly small and will probably be lower than the 1.7 bcma reference scenario for 2025 (see Chapter 2) means that the bulk of any indigenous natural gas production will be monetised primarily by accessing foreign markets.

There seem to be five broad options for monetisation of Cypriot natural gas reserves, namely:

\section{Constructing an export gas pipeline to Europe via Greece;}

2. Constructing an export gas pipeline to Turkey;

3. Constructing a liquefaction facility alone;

4. Developing joint liquefaction capacities with Israel; or

5. Developing a floating liquefaction plant (FLNG), alone or with Israel.

It is possible that monetisation will depend heavily also on geopolitical calculations and will be affected by the evolution (or lack thereof) of the relationship between Nicosia and Ankara; and also the level of engagement and specific role of Israel in the whole monetisation process. These issues are examined below in more detail. Ultimately though, the monetisation solution

\footnotetext{
${ }^{59}$ The Republic of Cyprus is now examining alternatives aimed at offsetting delays incurred before gas production commences. One of the solutions discussed is using gas from the adjacent Israeli Tamar field as an interim solution. However, it is very difficult to imagine how getting gas from Tamar to Cyprus might be easier (and faster) compared to getting gas from Aphrodite; especially if this does not form part of a broader joint monetisation/export agreement with Israel.

Meanwhile, the discussed alternative of CNG imports from Israel ignores the fact that, despite the existence of many CNG carrier concepts (some of them with preliminary approvals by class societies), there is still no commercial application of this technology. Moreover, were this to move forward, it could still require some 2.5 years from signing a contract to starting relevant operations. Additionally, the economics of CNG marine transportation seem to be favourable in certain cases when it forms part of a broader integrated project that includes floating CNG (as opposed to floating LNG) operations. This means that commercialisation of CNG is more likely at the hands of an integrated player, rather than at the hands of Cyprus pursuing it as a short-term solution; and that, therefore, the only realistic alternative for Nicosia may be deployment of a floating regasification unit (FSRU). However, the economics of the FSRU option too, including the ability of Cyprus to sign a medium term LNG supply contract, will have to be assessed thoroughly before commissioning.

More details on the Cypriot interest in an interim solution with the collaboration of Israel until domestic gas becomes available, as well as some technical information and state of progress with reference to marine CNG transportation can be found in Politis,

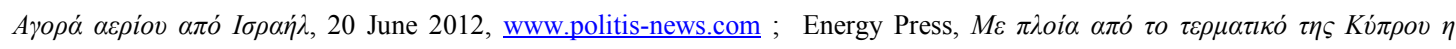

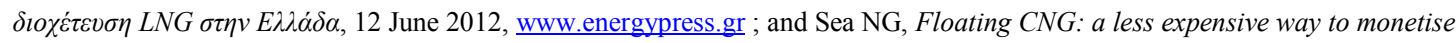
offshore gas, Presented at the Eastern Mediterranean and North Africa Forum, 28 February 2012, www.emnagasforum.com.
} 
which proceeds to completion will be the one providing the best returns for the IOC investors. And should political preferences rule out such an option, the result is likely to be project delay and, in extremis, cancellation.

\section{Map 7: Potential route for connection of Block 12 with Cyprus}

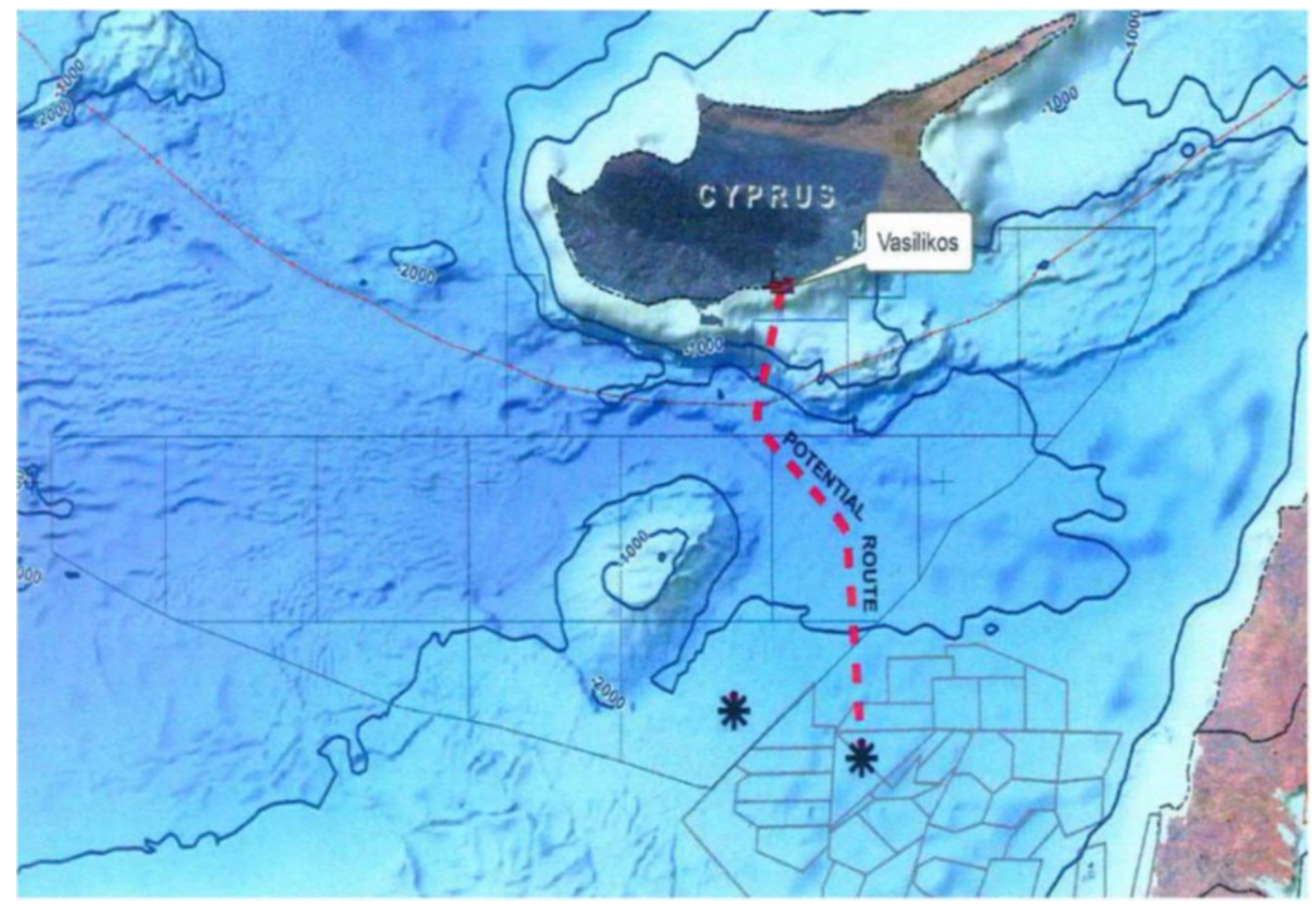

Source: Ministry of Commerce, Industry, and Tourism of the Republic of Cyprus 


\subsection{Pipeline options}

\subsubsection{Pipeline to Greece}

The Republic of Cyprus could monetise its upstream reserves via a natural gas export pipeline that would ultimately reach natural gas markets in Europe, through either Greece or Turkey. The first option could be realised by construction of a subsea pipeline of roughly $700-\mathrm{km}$ to the Greek island of Crete; continuing for approximately $200-\mathrm{km}$ along or onshore Crete for gasification of local power generation (currently oil-fired) and cost-reduction purposes; and returning to its subsea route for an additional $\sim 200-\mathrm{km}$ from western Crete to the Peloponnese in mainland Greece (south Greece), with the aim of connecting to the Greek grid (Map 8). Athens and the country's Public Gas Corporation DEPA have been pushing in that direction, while preliminary independent studies commissioned by DEPA suggest that such a pipeline, with a transportation capacity of around $8 \mathrm{bcma}$, is technically and economically feasible. ${ }^{60}$

\section{Map 8: Potential route of proposed East Med - Greece gas pipeline}

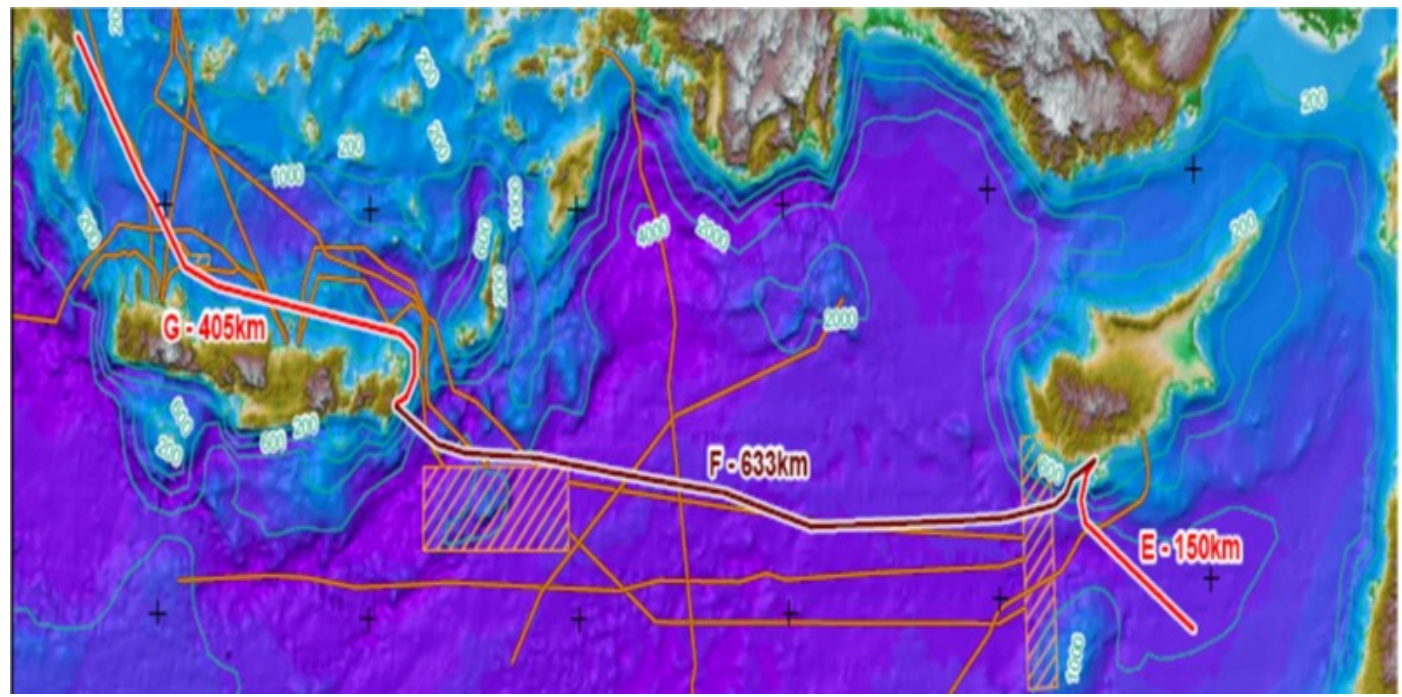

Source: DEPA

\footnotetext{
${ }^{60}$ More information is available in Konstantinos Karayannakos, East Mediterranean gas: Greece - the gateway to Europe, Presented at the $1^{\text {st }}$ Academy of Athens Hydrocarbons Conference, 20 April 2012, www.academyofathens.gr ; Harry Sachinis, The role of the ITGI System: New opportunities and synergies rise from the East Mediterranean, Presented at the $1^{\text {st }}$ Cyprus

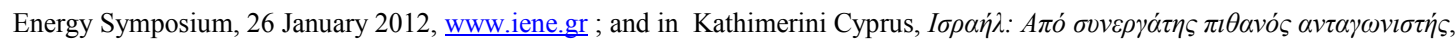
27 November 2011, www.kathimerini.com.cy.
} 
The commercial rationale for a pipeline to Greece is that Cypriot (and even Israeli) gas could access a market with relatively high gas import prices, despite current economic difficulties; as well as capture regional synergies with both existing and planned natural gas infrastructure in Greece and the wider region, including the Trans Adriatic Pipeline; DEPA's and Edison's Interconnector Turkey-Greece-Italy (ITGI) and the Interconnector Greece-Bulgaria (IGB); and also various bilateral gas interconnectors in South Eastern Europe and beyond (Map 9). This means that East Mediterranean volumes reaching Greece could flow westwards to large European markets such as Italy; and northwards to South Eastern and even Central Europe.

Additionally, there are hopes that markets in South East Europe in particular could offer opportunities for increased natural gas imports from new sources in the coming years due to: a) growing overall energy demand, as a result of low current levels and macroeconomic gains; b) declining indigenous gas production, which will need to be complemented by new supply; c) substitution of other inefficient and polluting fuels, in line with EU rules and regulations; ${ }^{61}$ d) and a desire to diversify their present gas import mix with new (non-Russian) supplies. Moreover, the contractual framework for the supply of natural gas to buyers in South Eastern Europe remains relatively firmly anchored to long-term oil-indexed gas pricing mechanisms. This is in direct contrast to the more liberalised and interconnected natural gas markets of Western Europe, where buyers are pushing their suppliers for shorter-term, hub-indexed gas. In the present market context, hub-indexation results in lower procurement prices for buyers; and, thereby to reduced profit margins for the natural gas producers supplying them. ${ }^{62,63}$

\footnotetext{
${ }^{61}$ For example, electricity in South Eastern Europe, which is currently inefficiently used for water and space heating purposes, could be gradually replaced by the direct use of natural gas; by the same token, wasteful heat-only boilers in old district heating systems could be substituted with either the direct use of gas or more efficient gas-fired Combined Cycle Gas Turbines (CCGTs). For more information on this matter see Aleksandar Kovacevic, The potential contribution of natural gas to sustainable development to South Eastern Europe, March 2007, Oxford Institute for Energy Studies, www.oxfordenergy.org.

${ }^{62}$ See for example Bloomberg, Europe may buy most gas at spot prices by 2014, SocGen says, 6 Mar11 June 2012 , www.bloomberg.com; for more details on the increasing influence of traded hubs on European pricing mechanisms and their significance see Patrick Heather, Continental European gas hubs: are they fit for purpose, Oxford Institute for Energy Studies, June 2012, www.oxfordenergy.org; Jonathan Stern and Howard Rogers, The transition to hub-based gas pricing in continental Europe, Oxford Institute for Energy Studies, March 2011, www.oxfordenergy.org ; and also Jonathan Stern, Continental European long-term gas contracts: is a transition away from oil product linked-pricing inevitable and imminent, Oxford Institute for Energy Studies, September 2009, www.oxfordenergy.org.

${ }^{63}$ For more details on regional gas demand potential, supply options, and infrastructure development see Anastasios Giamouridis and Spiros Paleoyannis, Security of gas supply in South Eastern Europe: potential contribution of planned pipelines, LNG, and storage, Oxford Institute for Energy Studies, July 2011, www.oxfordenergy.org ; and also Anastasios Giamouridis, Natural gas
} 
DEPA estimates that pipeline tariffs will be very competitive compared to the LNG option with regard to gas deliveries to Greece, as well as across South Eastern Europe and even Italy; specifically that East Mediterranean gas could be delivered to Greece at nearly one third of the cost of equivalent LNG deliveries; and at less than two thirds for deliveries to Italy. ${ }^{64,65}$

in Greece and Albania: supply and demand prospects to 2015, Oxford Institute for Energy Studies, December 2009, www.oxfordenergy.org.

${ }^{64}$ See Konstantinos Karayannakos, East Mediterranean gas: Greece - the gateway to Europe, Presented at the $1^{\text {st }}$ Academy of Athens Hydrocarbons Conference, 20 April 2012, www.academyofathens.gr.

${ }^{65}$ There has also been speculation and hopes in Greece that a direct pipeline link with East Mediterranean gas fields could form part of a broader regional supply nexus, which at a later stage might also include domestic supply from offshore blocks in the area south of Crete. Noble Energy has already shown some preliminary interest in the upstream potential in Greece, but this has yet to materialise on any practical level, despite the regional synergies that the company could achieve there. Moreover, it is too early at this point to assess the commercial potential of Greek upstream; and even more so to try and factor it into the ongoing negotiation and decision-making process with reference to the monetisation of East Mediterranean gas reserves.

This is of course a direct corollary of the fact that, according to publicly available information, at the moment there are no adequate seismic - let alone exploratory drilling - data for these areas. Athens is actively pushing forward with exploring the Greek upstream potential and in March 2012 it announced that eight international companies had submitted binding offers in a relevant tender to shoot offshore seismic in the Ionian Sea and south of Crete. However, the long lead times associated with moving forward from seismic to E\&P operations; to exploratory drilling; and to actual confirmation of hydrocarbons reserves; means this will probably fail to have any real impact on the current debate about the monetisation of East Mediterranean gas.

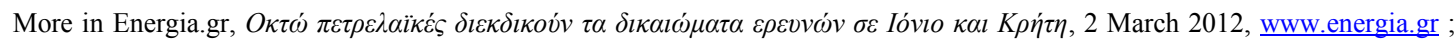

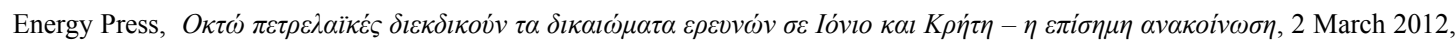

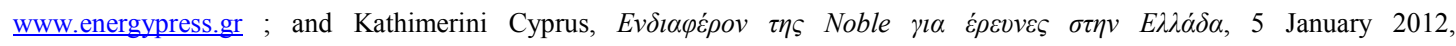
www.kathimerini.com.cy. 


\section{Map 9: Synergies with planned infrastructure in SE Europe}

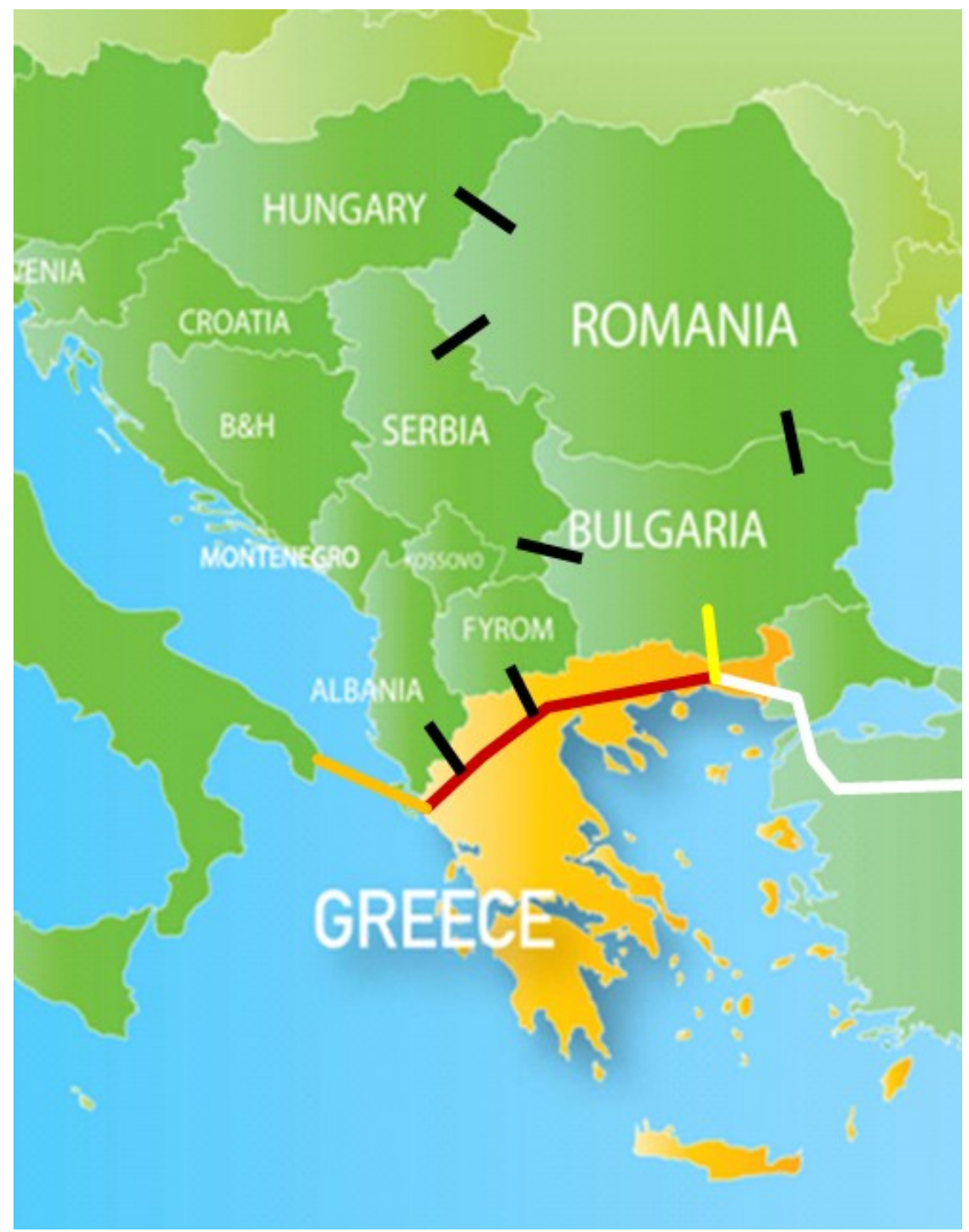

Source: DEPA

There might even be a political rationale to support construction of such a pipeline to Greece, given that at the moment Nicosia has very limited political leverage and would ideally like to see that increased, so as to be able to achieve its foreign policy imperatives; while Israel may similarly be interested in improving both its regional as well as its European political ties, including with Greece and European countries farther afield, for its own security reasons. Against this backdrop, the construction of a pipeline that would unlock a fifth energy corridor for the supply of Europe with gas while inevitably also committing all capacity to European buyers (rather than just a part as would likely be the case under the flexible LNG option) could be a political gesture towards supply security and economic competitiveness in the EU; and it could also greatly benefit South Eastern Europe, one of the most vulnerable European 
regions in terms of supply disruptions, as demonstrably shown in the context of the 2009 Russo-Ukrainian crisis which heavily affected it. ${ }^{66}$

All this would in fact be strongly confluent with EU policy on the matter, especially given the lowered expectations of the flow of substantial gas volumes to Europe via Southern Corridor, (which is now scheduled to transport only $\sim 10 \mathrm{bcma}$, out of originally envisaged $\sim 30 \mathrm{bcma}$ ); thereby boosting the diplomatic and political capital of the contributing parties in EU circles. Various Cypriot officials have at times spoken very warmly of this prospect; albeit they are not providing project funding to that end. ${ }^{67}$

However, there is still relatively little consensus on the commercial viability of this project. First, there are concerns about the potential technical complexity of the proposed gas pipeline, stemming from its significant length as well as sea depths in which it will need to be laid. ${ }^{68}$ Second, even if in fact viable, the project is dependent on successful completion of other downstream infrastructure projects to allow it to reach its full export potential beyond Greece, including both upgrades in the Greek natural gas system and new regional interconnectors. Third, even if these technical/economic obstacles are successfully overcome, the project still locks suppliers into a relatively limited number of regional natural gas markets, compared to the inherently more flexible LNG option, which offers the seller access to global markets. Fourth, there are important uncertainties in connection with anticipated market opportunities

\footnotetext{
${ }^{66}$ For the impact of this crisis on South Eastern Europe and some planned remedial action on the gas infrastructure level see Anastasios Giamouridis and Spiros Paleoyannis, Security of gas supply in South Eastern Europe: potential contribution of planned pipelines, LNG, and storage, Oxford Institute for Energy Studies, July 2011, www.oxfordenergy.org .

${ }^{67}$ See for example the interview of the Minister of Commerce, Industry, and Tourism of the Republic of Cyprus to G. Lakes of the Middle East Economic Survey, Vol. LV No 18, 30 April 2012 (Cyprus targets roles as regional energy center), www.mees.com.
}

${ }^{68}$ For example, in March 2012 Israel, Cyprus, and Greece agreed to proceed with a feasibility study concerning potential construction and commercial operations of a 2,000-MW subsea power cable which is to link their respective electricity grids, dubbed the Euro-Asia Interconnector. The ambitious Interconnector will consist of three offshore sections, namely Israel-Cyprus, Cyprus-Crete, and Crete-Peloponnese, the combined length of which will exceed 1,000-km, rendering it the longest in the world. However, the fact that even the connection of the Peloponnese in mainland Greece with the Greek island of Crete has not moved forward, despite Crete offering a relatively large energy demand centre which remains isolated from the country's national grid; as well as its substantial Renewable Energy Sources potential (RES) and continuing dependency on expensive oil-fired power generation for its needs, merely illustrates the complexity and inherent difficulties of this project. If anything, the proposed CretePeloponnese link would be the shortest of the aforementioned three sections, with an estimated length of roughly $120-\mathrm{km}$.

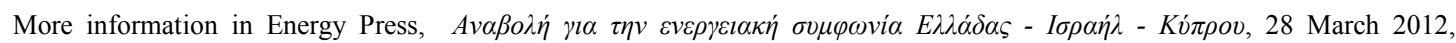

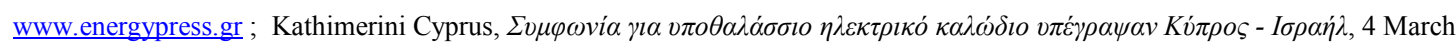
2012, www.kathimerini.com.cy ; Reuters, Cyprus group plans Greece-Israel electricity link, 23 January 2012, www.reutes.com. 
in South East Europe, notably around the realisation of their demand potential and pricing. ${ }^{69}$ And fifth, pipeline exports to South Eastern Europe (and even to Central Europe and Italy) will have to compete not only with the existing long term contracted pipeline supplies from the Russian Federation, but also with new Azeri pipeline gas from Shah Deniz Phase 2 and other pipeline sources such as South Stream; as well as with longer-term gas supply prospects including Turkmenistan and also indigenous Black Sea and unconventional gas reserves.

The alternative of developing a pipeline to Greece and beyond as a complement to rather than a substitute for liquefaction looks attractive, by theoretically offering the best of both worlds. However, it fails to take into account the importance of brownfield economics and economies of scale in the context of costly infrastructure development such as that of liquefaction plants. LNG projects tend to improve significantly their profitability as they expand beyond their first greenfield phase and capture cross-train synergies and the ensuing cost efficiencies; thereby reducing their applicable unit costs by some $15 \%$ to $35 \%$ (or, minus USD 1 to $1.5 / \mathrm{mmbtu}$ ) ${ }^{70}$ enhancing their access and terms vis-à-vis capital markets; and even ameliorating sales terms, including in the context of both their contractual as well as flexible spot sales. ${ }^{71}$

\footnotetext{
${ }^{69}$ Indeed, uncertainties in South East Europe as to the realisation of its natural gas demand potential are high, as this will likely be defined both by the strength of the region's economic recovery, as well as political (including institutional) considerations. On the political / institutional level, support for gasification in the broader region, even though strong, is far from unconditional, due to the persistence of (not unreasonable) funding and pricing concerns. Importantly, gas demand in South Eastern Europe in the past two decades suggests a non-linear correlation with GDP, reflecting the region's turbulent political and economic history, as shaped in the aftermath of the regime collapse and conflicts of the 1990s; and of the economic recession which started in 2008. Pricing of energy products - i.e. of natural gas, power, and heating - on both the import as well as the local distribution level is a real concern in essentially all South East European countries, and will inescapably impact on their attractiveness as markets. Large sections of the population in this region are relatively poor and, therefore, unable to bear the burden of high energy prices. If energy prices remain low, these countries will be less attractive markets to suppliers (unless gas import prices are subsidised). If, on the other hand, domestic natural gas, electricity, and heating prices in these countries were to increase to cost-reflective levels without any protective mechanisms for the local energy consumer, gas demand destruction could be a logical consequence. This is particularly true in a region such as South Eastern Europe, where substitution with oil products and also with other domestically-procured alternatives such as biomass continues to be very relevant. Finally, the current prevalence of profitable (for sellers) oil-indexation in the region could be undermined in the coming years as South Eastern Europe increases its natural gas supply options thanks to a modernisation of its relevant regulatory framework and the development of new bilateral interconnectors, LNG infrastructure, and storage.

${ }^{70}$ Wood Mackenzie, www.woodmacresearch.com

71 The failure of Shtokman to monetise by a combination of pipeline and liquefaction despite its much more substantial gas reserves and experienced players (Gazprom, Total, Statoil) serves as a useful warning of the pitfalls of this particular approach. See for example Upstream Online, Shtokman revamp could center on LNG, 23 April 2012, www.upstreamonline.com ; Upstream Online, Statoil 'backs LNG bid' on Shtokman, 11 April 2012, www.upstreamonline.com
} 
Against this backdrop, the Cypriot government seems to have remained unconvinced as to the merits of constructing a long subsea gas pipeline link from the East Mediterranean to Greece; and its officials have in fact stated very clearly on various occasions that they see LNG as the only viable monetisation option for their gas. Moreover, in June 2012 the Cypriot government decided to take all necessary steps towards development of liquefaction facilities in Cyprus. ${ }^{72}$ In contrast, the government of Israel has shown itself to be more open to discuss closer energy cooperation with both Greece and Cyprus, including with reference to gas pipeline options; possibly as a means of strengthening regional ties and shunning export dependency on Turkey especially after the Mavi Marmara incident of 2010 and the ensuing diplomatic fallout. ${ }^{73}$

Given the very clear risk for regional players that Cyprus (and/or Israel) will move towards the liquefaction monetisation option, rather than for their own natural gas pipeline proposals, there is value for them in adopting a much more flexible commercial position in this context; potentially following the successful example of leading Asian buyers like Kogas, Osaka Gas, Tokyo Gas and others, which often seek small equity stakes in liquefaction, and sometimes also upstream, as a means of adding value to their portfolios by capturing attractive margins; while at the same time benefiting from securing better terms in the SPAs they sign with them (on top of equity gas offtake). Indeed, their involvement early on in the development process means that they are often able to sign long-term gas supply agreements on favourable terms, as operators need such firm contracts in order to boost bankability and secure their financing.

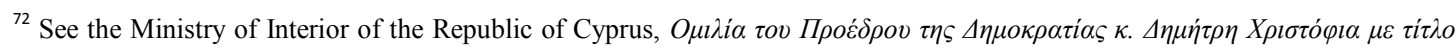

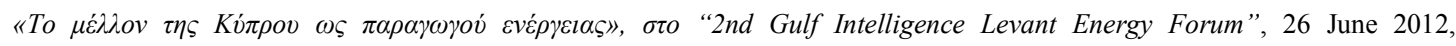

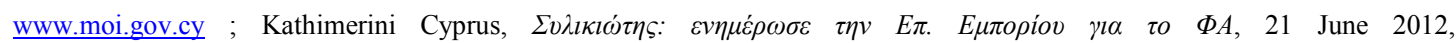

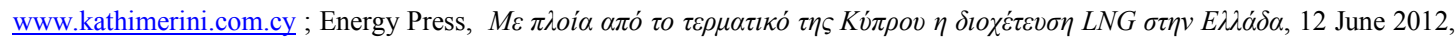

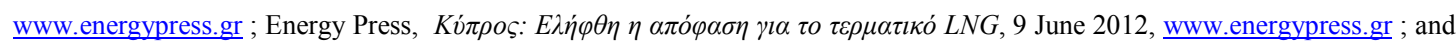

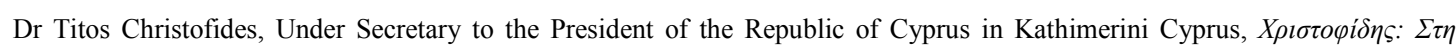

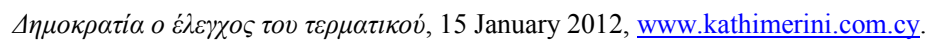

${ }^{73}$ The Mavi Marmara sailed towards the Gaza Strip with the aim of breaking an Israeli blockade and delivering humanitarian aid. It was intercepted in international waters on 31 May 2010 by the Israeli navy, and nine Turkish activists were killed after Israeli troops boarded the ship. Turkey condemned strongly the incident and demanded a formal apology, which Israel refused to offer. This has caused serious diplomatic tensions between the two counties, which previously enjoyed quite close cooperation, including harsh statements from both sides; the withdrawal of the Turkish ambassador from Israel; the expulsion of Israel's ambassador in Turkey; and the recent charges against four senior Israeli military commanders by Turkish courts. For more information see BBC News, Mavi Marmara: Israeli officers face Turkish trial, 28 May 2012, www.bbc.com ; and also BBC News, Turkey suspends Israel defence ties over Gaza aid raid, 6 September 2011, www.bbc.com.
} 
Adoption of such a strategy by regional companies could therefore arguably allow them to capture more of the value that is to be generated by recent gas discoveries in their periphery. However, this presupposes that they have the financial capacity to participate as investors; moreover, even though these players may benefit from such a hedge along the value chain, they will likely have to charge high prices for the resulting volumes in their domestic and/or targeted downstream gas markets which, may prove challenging under present circumstances.

At any rate, early involvement and negotiation for firm and potentially also favourably-priced LNG supply contracts (with or without equity) would also buttress the project rationale for the development of 'gateway' regasification terminals targeting markets in South East Europe, one of the most vulnerable regions in terms of their security of natural gas supply in Europe, for example DEPA's planned Aegean FSRU in northern Greece. ${ }^{74}$

\subsubsection{Pipeline to Turkey}

Meanwhile, Ankara through state-owned company TPAO has argued that development of greenfield liquefaction in the East Mediterranean would not be a suitable commercial option, as a result of (what TPAO claims to be) a saturated regional LNG market due to the existence of significant liquefaction capacity in the broader MENA, notably Qatar, Egypt, and Algeria. According to this view, monetisation of the Cypriot natural gas reserves can be successful only by means of a pipeline to Turkey; with Cypriot volumes transiting to European markets. The Turkish side has also invoked the potential political benefits of building such a pipeline, with Turkish Energy Minister Taner Yildiz stating in December 2011 that energy cooperation between Turkey and Cyprus including monetisation of indigenous reserves through Turkey could follow the successful negotiation of a settlement in the Cyprus dispute. ${ }^{75}$

On the commercial level, the Turkish position on the presumed unsuitability of liquefaction as a suitable monetisation option with regard to East Mediterranean natural gas seems to ignore LNG market fundamentals (to be examined in more detail in the next section "liquefaction"). Still, depending of course on the agreed price formation mechanism, sales of Cypriot gas to

\footnotetext{
${ }^{74}$ More information on Aegean FSRU and other LNG projects can be found in Anastasios Giamouridis and Spiros Paleoyannis, Security of gas supply in South Eastern Europe: potential contribution of planned pipelines, LNG, and storage, Oxford Institute for Energy Studies, July 2011, www.oxfordenergy.org .

${ }^{75}$ Aksam, Akdeniz'deki gaz düğümünün çözümü Türkiye'den geçiyor, 31 January 2012, www.aksam.com.tr ; Kathimerini Cyprus,

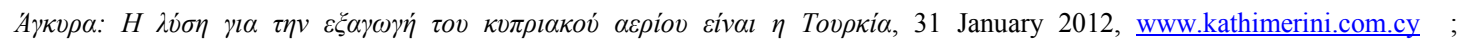

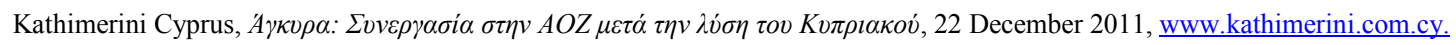


Turkey via pipeline would probably offer good returns, due to the latter's proximity to Cyprus (see Map 10) and the relatively small investment and transportation costs that would need to be incurred in order to link the Cypriot upstream with the Turkish downstream gas market; combined with attractive import prices and expected domestic price liberalisation in Turkey.

However, if a part of these volumes were to continue onwards to EU gas markets to achieve diversification, as has indeed been proposed and would be a prudent commercial strategy, this project could face some of the same challenges confronting the proposed pipeline to Greece. Specifically, it would be dependent on the successful completion of regional interconnectors, and could even require upgrades in the Turkish system; and would inevitably also increase transportation costs, thus diluting realised profit margins in each of its proposed end markets. Furthermore, even if all of these challenges were to be successfully overcome, the very nature of monetisation by pipeline would lock Cypriot natural gas volumes to Turkey and a limited number of other natural gas markets with important uncertainties as to their future potential, as well as expose it to possibly strong competition from other gas pipeline supply projects; compared to the inherently more flexible LNG option, which offers access to global markets.

On the political level, committing to a gas pipeline to Turkey, or to Europe through Turkey, looks unlikely before the two sides can agree on a solution in the ongoing Cyprus dispute, given that Ankara does not recognise (or even engage directly with) the Republic of Cyprus. Moreover, it is difficult to envisage the Greek Cypriot side agreeing to long-term dependency on Turkey as a market and/or transit, even after a negotiated solution to the Cyprus problem (and it is conceivable that even the EU would in the first instance not choose dependency on Turkish transit for all its non-Russian inflows, i.e. from the Caspian and East Mediterranean). This prospect has already stirred up considerable controversy and in December 2011 the government was forced to a formal statement denying President Christofias had committed to a Cyprus-Turkey gas pipeline, as earlier claimed by Turkish-Cypriot leader Derviş Eroğlu. ${ }^{76}$

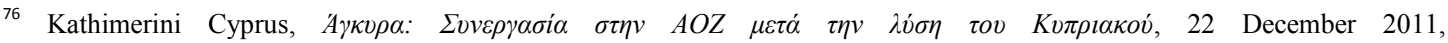

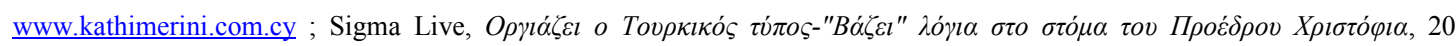
December 2011, www.sigmalive.com.
} 
Map 10: Proximity of Cyprus to Turkey

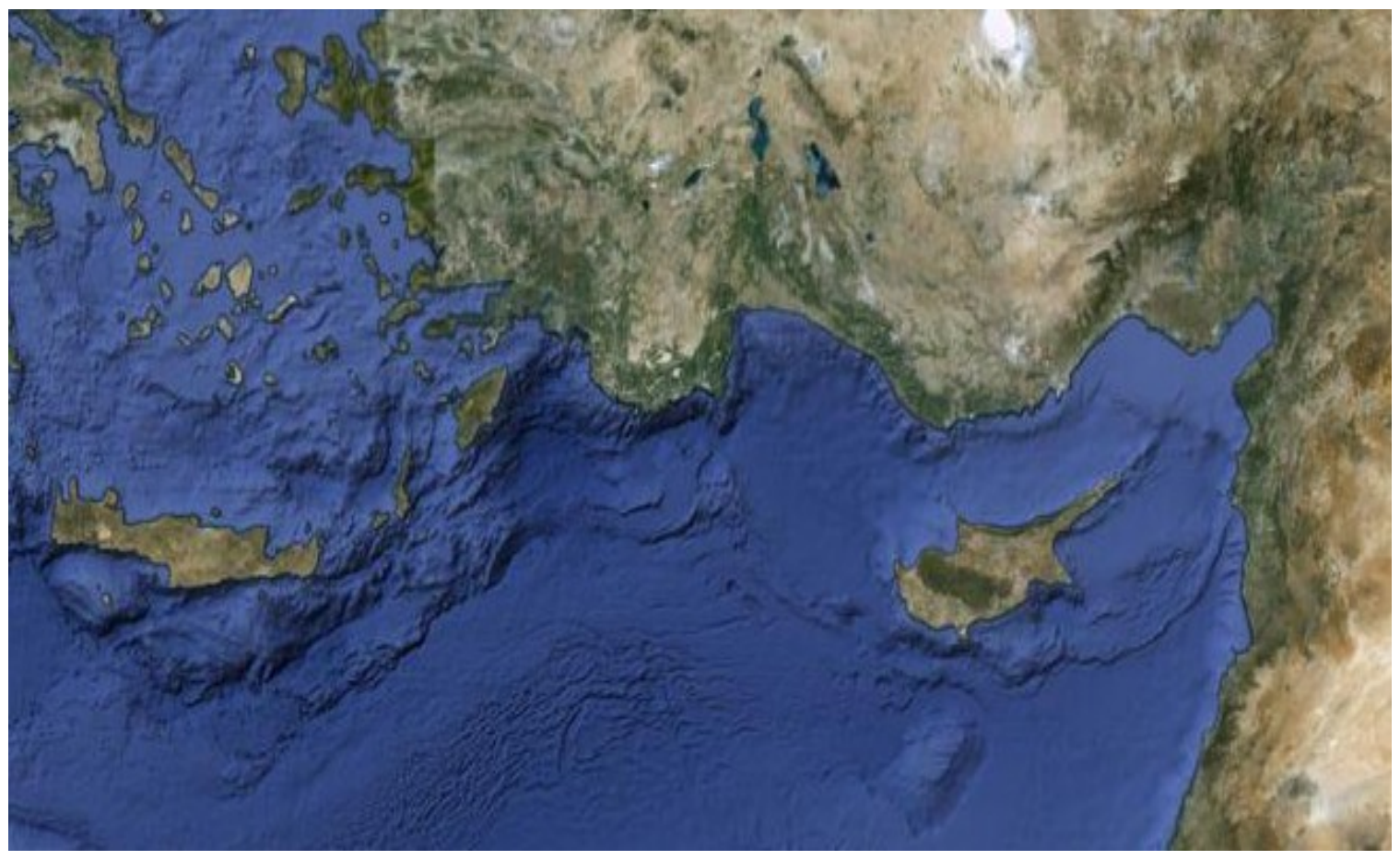

Source: Google maps 


\subsection{Liquefaction}

\subsubsection{The global LNG market}

The Turkish assertion that new liquefaction in the Eastern Mediterranean is redundant due to market fundamentals is dubious to say the least, given the strong demand potential for LNG, including diversions from this region to premium gas markets in Asia, as well as the relative dearth of realistic prospects for substantial greenfield and/or expansion liquefaction capacity projects in the broader Atlantic Basin and the Middle East during the course of this decade. This is especially so as some of the existing LNG plants in Egypt and Algeria are performing below design, due to their burgeoning domestic natural gas demand at low subsidised prices; this problematic situation is not expected to improve significantly in the coming years. ${ }^{77}$

Hence, it is not at all obvious why Cyprus or other Eastern Mediterranean liquefaction plants would find it hard to secure demand outlets for their cargoes under contractual or spot terms. ${ }^{78}$ Turkish assertions in this framework seem to be premised more on political concerns related to the Cyprus dispute, and also to Turkey's ambition to become the key transit hub for diversified (non-Russian) natural gas flows from the Caspian and other regions to Europe, rather than an objective commercial assessment of available options and market context. ${ }^{79}$

The natural gas industry's "rule-of-thumb" assumption is that LNG is the more economical alternative compared with a pipeline for distances that are in excess of 3,000 to $5,000 \mathrm{~km}$. This is obviously a very rough guide as a number of diverse factors affect actual economics and - more importantly - viability of specific monetisation projects, including commodities and shipping costs, and even ultimate gas market access allowed under each export option.

\footnotetext{
${ }^{77}$ For more information see Bassam Fattouh and Jonathan Stern (eds.), Natural gas markets in the Middle East and North Africa, Oxford Institute for Energy Studies, 2011, www.oxfordenergy.org.

${ }^{78}$ This is of course quite different from saying (and it is indeed not argued here) that there is no inescapable risk for liquefaction as a gas commercialisation option. Related risks stem primarily from the uncertainty over the evolution of supply and demand balances in the Atlantic and globally, which are bound to affect profitability and even viability of such infrastructure (see below).

${ }^{79}$ Furthermore, some Turkish analysts have expressed fears that E\&P in the Republic of Cyprus shifts the balance of power in favour of the Greek Cypriot side, aggravating a trend which in their view commenced with accession of the Republic of Cyprus to the EU, without a prior solution to the island's political division. For more information on this matter see Kathimerini Cyprus,

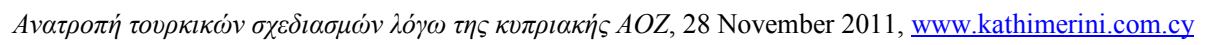


What is certain though is that the liquefaction option offers inherent destination flexibility, thus providing sellers with easier reach to premium markets, irrespective of their location. ${ }^{80}$

In practical terms and under the present industry framework, this translates into direct access into natural gas markets in the Asia-Pacific region, where LNG sellers enjoy more opportunities to sign long-term, oil-indexed supply contracts with slopes close to oil parity; compared to considerably less favourable slopes in Europe and even an increasing push by European buyers to break away from oil-indexation and to be priced directly off traded hubs, which reflect market fundamentals and are better aligned with their own downstream markets. Furthermore, when LNG's inherent flexibility is embedded also in pertinent sales contracts, as for example in the case of Qatar, and in the portfolios of key IOCs like BG Group and BP, then that also leaves room for profitable arbitrage between the Atlantic and Pacific Basins. ${ }^{81}$

Additionally, the LNG market is very dynamic and has grown rapidly since inception in 1964 , with no reversals into negative demand growth except a brief 2-year hiatus in the early 1980s. This has been the result of fast demand growth for natural gas in the Asian economies, increased offtakes from other existing LNG customers, and also an ever increasing number of countries developing import/regasification capacities and entering the LNG market as buyers. There are currently 26 countries importing LNG from only 11 in 2000; with the past four years alone seeing the addition of countries such as Canada, Argentina, Brazil, Chile, Kuwait, and Thailand in the expanding importers' list; while in the past decade, global demand for LNG more than doubled, from some 100 million tonnes per annum (mmtpa) to $241 \mathrm{mmtpa}$. This represents a very favourable Compound Annual Growth Rate (CAGR) of about $8.4 \%$, compared to the wider gas industry's $2.6 \%$, in terms of total dry gas consumption (Figure 11); and it is in fact higher compared to liquefaction growth seen in the same period (Figure 12). Importantly, demand growth is forecast to remain strong in the medium term, with Israel,

\footnotetext{
${ }^{80}$ For a background in Atlantic basin and global LNG trading including some details on project economics see Howard Rogers, LNG trade-flows in the Atlantic basin: trends and discontinuities, Oxford Institute for Energy Studies, March 2010, www.oxfordenergy.org.

${ }^{81}$ However, contractual flexibility is usually the prerogative of later liquefaction trains which are less in need of firm contracts to underpin financing needs; and could thus probably be relevant in the Republic of Cyprus only beyond the Aphrodite discovery. For more information on the increasing influence of traded gas hubs on European pricing mechanisms and their significance see Patrick Heather, Continental European gas hubs: are they fit for purpose, Oxford Institute for Energy Studies, June 2012, www.oxfordenergy.org; Jonathan Stern and Howard Rogers, The transition to hub-based gas pricing in continental Europe, Oxford Institute for Energy Studies, March 2011, www.oxfordenergy.org ; and Jonathan Stern, Continental European long-term gas contracts: is a transition away from oil product linked-pricing inevitable and imminent, Oxford Institute for Energy Studies, September 2009, www.oxfordenergy.org.
} 
Malaysia, Indonesia, Singapore and Pakistan likely to start importing LNG over the next 2-3 years. This will offer sellers new marketing opportunities and improve price floors. ${ }^{82}$

\section{Figure 11: Global LNG Vs total gas demand growth 2000-2010}

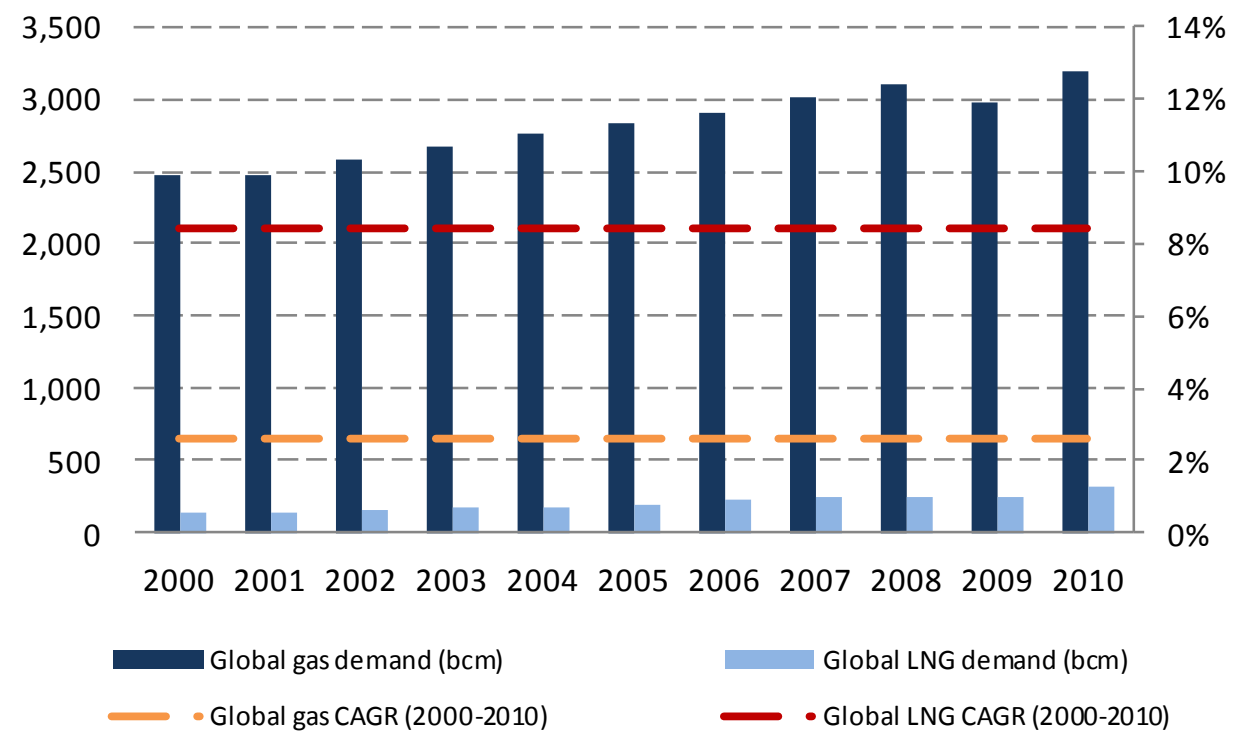

Figure 12: Global LNG demand Vs liquefaction growth 2000-2010

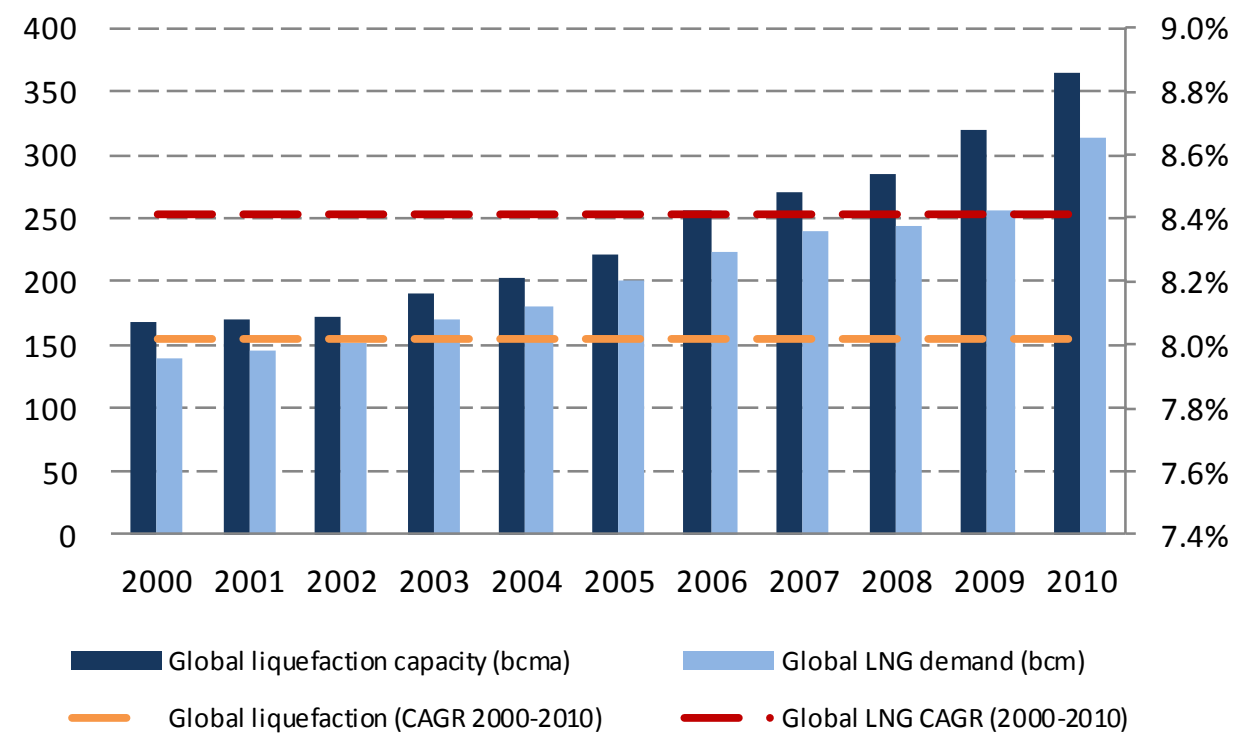

Sources: PFC Energy, EIA, BP statistical Review

\footnotetext{
${ }^{82}$ Information from PFC Energy, Global LNG Service, accessed 1 April 2012, www.pfcenergy.com ; and also from the US Energy Information Administration (EIA), International Energy Statistics, accessed 1 April 2012, www.eia.gov.
} 


\subsubsection{Contextualisation of East Mediterranean LNG}

Cyprus's location suggests it could access a wide range of LNG markets at affordable cost, as exhibited also by the global marketing reach of the adjacent Egyptian liquefaction plants. In 2011 alone, the latter delivered cargoes to a total 16 countries across Europe, Asia-Pacific, Middle East, and the Americas, including emerging markets in South America (Figure 13).

\section{Figure 13: Egyptian LNG exports in 2011 by country and region}
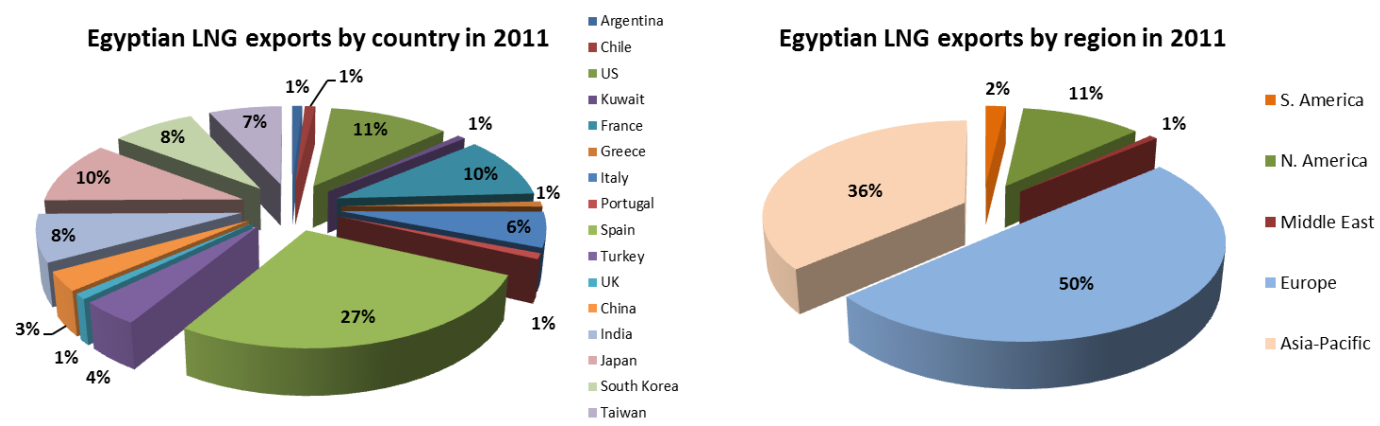

Source: PFC Energy, Global LNG Service

Based on estimates for Egypt, in March 2012 Cypriot LNG transportation costs would have stood at USD $\sim 3.2 / \mathrm{mmbtu}$ for Japan and South Korea; and as low as $1.5 / \mathrm{mmbtu}$ for India. Despite somewhat or even significantly lower transport costs for some European destinations (up to USD 1.2/mmbtu with reference to deliveries of LNG cargoes to France and the UK), substantial regional price differences mean Cyprus could at the time have realised a much better netback (i.e. landed price minus shipping) of roughly USD $12.5 / \mathrm{mmbtu}$ in the spot market for all aforementioned sales to Asia, compared to only USD 8/mmbtu for UK sales. Similarly, potential sales of LNG cargoes from Cyprus to other European markets at the time would still have failed to match, or even come close, to the Asian premium, with the French and Spanish netback standing at less than USD 9.2/mmbtu and USD 9.6/mmbtu respectively. Furthermore, Cyprus could have realised a very favourable netback of USD $11.3 / \mathrm{mmbtu}$ (with a transportation cost of roughly USD 2.8/mmbtu) for deliveries at the Bahia Bianca regasification terminal in Argentina, which represents a promising demand growth region. ${ }^{83}$

\footnotetext{
${ }^{83}$ The fact that in April 2012 the Argentinean government expropriated the 51\% of YFP owned by Repsol could raise the country's LNG requirements, if it fails to raise the necessary capital and get know-how to make the most of its unconventional resources. More details in Upstream Online, Repsol warns it could sue YFP investors, 23 April 2012, www.upstreamonline.com; and BBC News, Spain's Repsol urges talks in Argentina YPF oil tension, 16 April 2012, www.upstreamonline.com.
} 
The above prices and costs therefore indicate favourable netback differentials which stand between USD 1.7/mmbtu (Spain vs. Argentina), and USD 4.5/mmbtu (UK vs. South Korea). Overall, differentials in spot prices between Japan/Korea and Spain in the same month stood at USD 5.25/mmbtu; and as high as USD $6.4 / \mathrm{mmbtu}$ between Japan/Korea and the NBP. These substantial premia are inaccessible without the LNG option (details in Figure 14). ${ }^{84}$

Furthermore, Cyprus as an LNG producer could potentially also benefit from any significant inroads the fuel may be able to achieve in the 2020s and beyond in the global bunker market. Whilst there is only a handful of such vessels today, classification society Det Norske Veritas (DNV) believes the bulk of new ships ordered in 2020 will be capable of operating on LNG. ${ }^{85}$ Realisation for Cyprus in particular of this important potential could be facilitated by active involvement of international traders with relevant experience and expertise in this context; for example, Vitol has been increasing its presence on the island and is pushing forward with construction of oil storage at Vasilikos through 50\% subsidiary VTTI, aimed at benefitting from the very favourable geography of Cyprus at the intersection of MENA and Europe; while it also participated along with Premier Oil and Petronas in the second licensing round (see 3.3.2 above for more details on Vitol's upstream bids). ${ }^{86}$

\section{Figure 14: Snapshot of LNG landed prices, freight rates, and Egyptian netback}
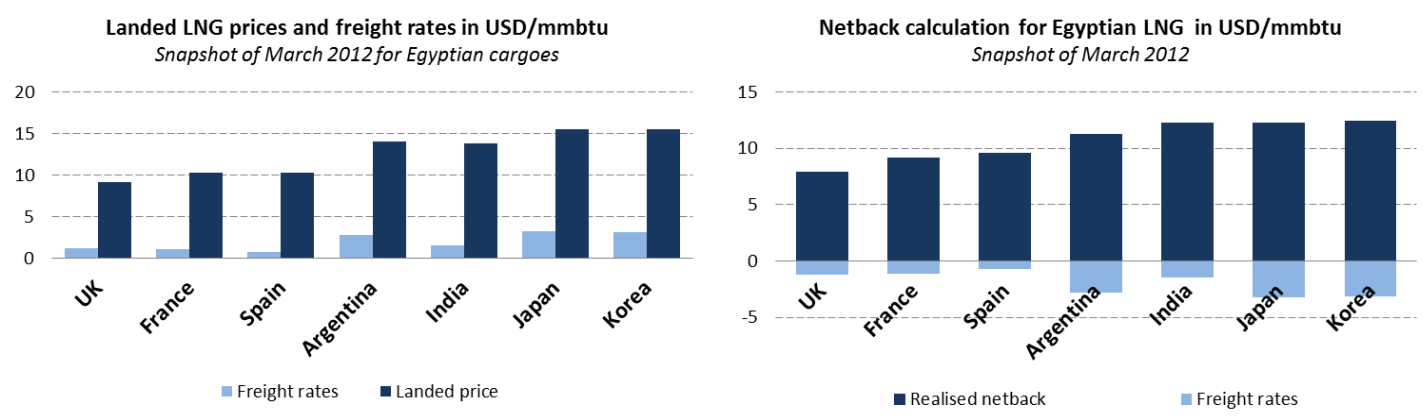

Source: Waterborne, European LNG Report, 9 March 2012

\footnotetext{
${ }^{84}$ Price calculation based on information from Waterborne, European LNG report, 9 March 2012, www.waterborneenergy.com.

${ }^{85}$ Det Norske Veritas, Annual report 2011, www.dnv.com.

${ }^{86}$ VTTI is to develop a total of 34 oil storage tanks with a combined capacity of 643,000 cubic metres in two phases at Vasilikos. Phase 1 will include 357,000 cubic metres and completion is envisaged in early 2014; while the remainder storage capacity will come online with Phase 2 a few months later in the same year. Total investment costs are estimated at some Euros 220 million. More information is available in VTTI, Terminals \& pipelines: overview VTT Vasilikos, accessed 6 July 2012, www.vtti.com ;

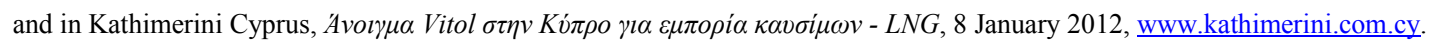


There is of course no guarantee that recent price differentials will persist (see Figure 15), and/or that they will always point towards non-European markets as the preferred destination. Indeed, the aforementioned advantages and market flexibility offered by monetisation through LNG will have to be assessed against a number of risk factors that can erode its advantages. First, the high unit costs of liquefaction, which for a single-train plant are now estimated at between USD 4.5 and 6/mmbtu (excluding upstream costs) ${ }^{87}$ Second, the high shipping rates. Third, that this strong demand for gas in Asia cannot be assumed to endure indefinitely. Fourth, that whilst Asian LNG prices under long-term contracts linked to crude oil prices presently stand at above USD $15 / \mathrm{mmbtu}$, they are subject to downside risk from crude oil price volatility. And fifth, that the continued appetite for such price formation mechanisms on the part of Asian buyers cannot - and should not - be taken for granted. For example Japan, the largest global buyer of LNG, is already seeking to introduce some Henry-Hub priced LNG volumes to its portfolio, as it is trying to cope with costly inputs into its power generation sector in the aftermath of the triple Fukushima disaster of March $2011 ;^{88}$ and China could in the future become less willing to pay high LNG prices as its gas pipeline import options grow. Another factor to consider in this framework is also the scale of the new LNG projects which are set to come on-stream in the course of the coming decade; primarily Australian projects, but there could be potentially large LNG exports from North America and East Africa too.

However, even in a possible reversal of the existing market context, LNG sellers will still retain flexibility to market to premium destinations at the time, irrespective of their location. Moreover, the abovementioned relatively high unit costs of USD $4.5-6 / \mathrm{mmbtu}$ for greenfield liquefaction facilities can be partially offset by expansion projects, which enjoy brownfield economics and can have their breakeven thereby reduced to between USD 3 and 5/mmbtu. ${ }^{89}$

\footnotetext{
${ }^{87}$ Information on prices from Wood Mackenzie, www.woodmacresearch.com. Some preliminary estimates cited recently in Cyprus referring to a price tag of roughly USD 10 billion with reference to a single-train 5 mmtpa LNG plant would, if realised, bring breakeven levels at above USD 7/mmbtu. However, this may include other costs too, i.e. over and above pure liquefaction.

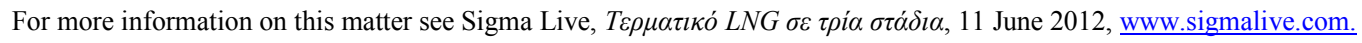

${ }^{88}$ See for example Platts, Japan seeking US LNG, to ask for US waiver during Kuwait meeting, 13 March 2012, www.platts.com.

${ }^{89}$ Prices from Wood Mackenzie, www.woodmacresearch.com. A cost of USD 8 billion for construction of a second 5 mmtpa train, and USD 6 billion for a third mentioned recently in Cyprus, would bring their breakeven at USD 5.7/mmbtu and USD $4.3 / \mathrm{mmbtu}$ respectively. The average breakeven cost of the expanded 3-train liquefaction plant would then stand at approximately USD 5.7/mmbtu. As mentioned above though, this could be inflating the applicable liquefaction breakeven by

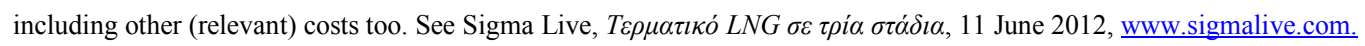


This suggests that any subsea natural gas pipeline of the scale and complexity required in this framework could have difficulty competing with an expandable liquefaction project, even in some of the more limited regional gas markets that the pipeline proposes to access. Furthermore, the fact that freight rates are currently at historically record levels suggests that LNG exports to premium - yet remote - destinations could become more appealing / easier to reach in the future in real terms, as new-build LNG carriers already in the industry's order book come online in the next few years and help rationalise applicable transportation costs.

Figure 15: Historical import price differentials in European and Asian markets*

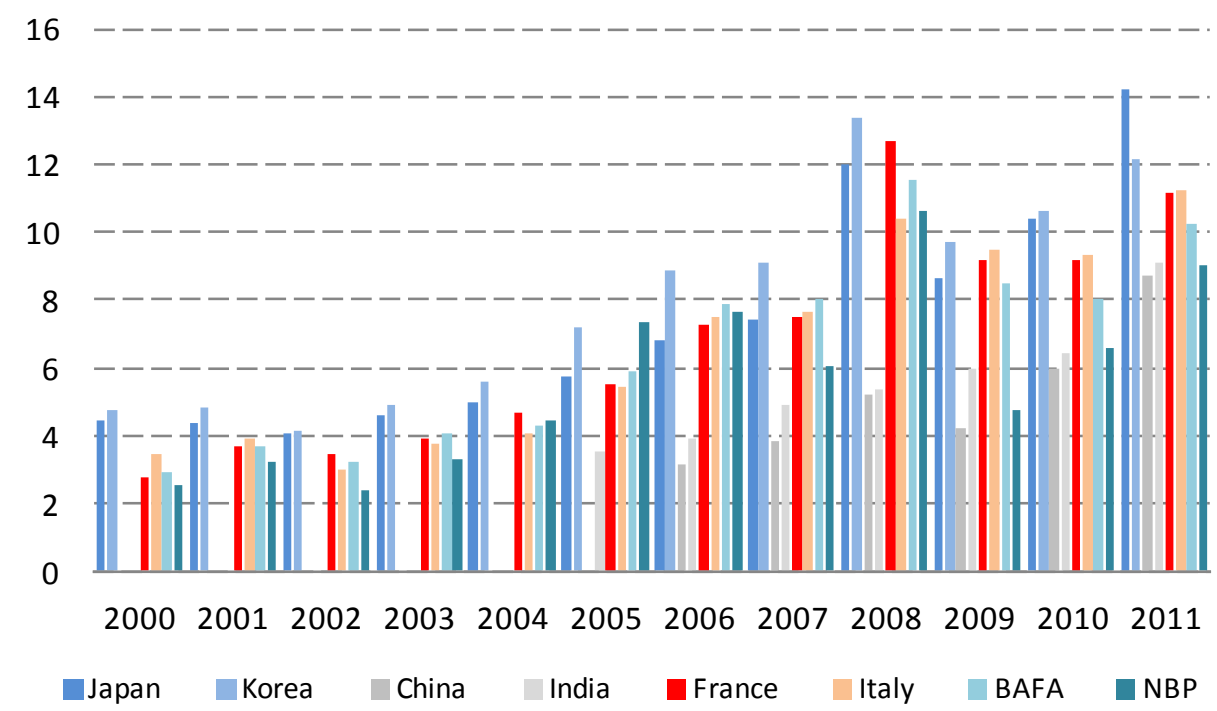

* Prices in USD/mmbtu

Source: German Federal Office of Economics and Export Control (BAFA); PFC Energy, Global LNG Service

Concerning the potential value of LNG in the political dimension for the Republic of Cyprus, assuming commercial loss from not selling to higher priced Asian markets can be ignored, then there is no practical reason why LNG could not be used to serve the same political objectives as pipeline gas; and to support EU gas supply security by committing part or all of its output to specific European gas buyers under firm long-term contracts, including through Balkan gateway regasification terminals such as the planned Aegean FSRU in north Greece; or, as a compromise between the political and the commercial, to commit volumes to flexible European IOCs which can deliver their offtake to the highest bidder irrespective of location, and share some part of this commercial upside with Cyprus. 
Against this backdrop, in an interview with the Middle East Economic Survey in April 2012 Neoklis Sylikiotis, the (then new) Minister of Commerce, Industry, and Tourism, confirmed the political nature and strategic priority ascribed to European sales of Cypriot gas, stating: "Our priority for the export of LNG is not necessarily the price - although we know the market in the Far East offers high prices - for Cyprus, the priority is to make some contribution towards Europe's security of supply." 90

\subsubsection{The floating liquefaction option (FLNG)}

Liquefaction plants have traditionally been designed and constructed as onshore terminals, albeit the FLNG option is now being promoted as a suitable means for the monetisation of gas reserves which are far from the shore and / or in cases where land availability is an issue. FLNG technology is not yet operational, but is expected to become available on a commercial basis before the end of this decade as, in May 2011, Royal Dutch Shell reached its Final Investment Decision (FID) for the pioneer $3.6 \mathrm{mmtpa}$ Prelude floating liquefaction project. Prelude FLNG will be constructed in Korean shipyards and based in Australia's Browse Basin, at a reported/unofficial cost of up to USD 12.6 billion. Various players including Shell are also pushing forward with FLNG projects in locations such as Australia, Brazil, Nigeria, Iraq, Indonesia, Malaysia, and Timor-Leste; while Shell is also working towards development of other FLNG versions better suited to higher production rates and to dry natural gas wells. ${ }^{91}$ However, significant technical complexity and high development costs for the FLNG option suggest partners will have to overcome major challenges before completing these projects. ${ }^{92}$

The Prelude FLNG project is expected to be completed by 2017, which bodes well for the envisaged full field development and lead times for liquefaction in the Eastern Mediterranean. Nevertheless, until now there has been very limited discussion concerning FLNGs in Cyprus, which seems to be relatively well-placed in terms of land availability in the Vasilikos area. Indeed, according to local sources, the latter is able to accommodate three to five liquefaction trains of 5 mmtpa each, thereby possibly rendering FLNG a less necessary option for Cyprus,

\footnotetext{
${ }^{90}$ See the interview of Neoklis Sylikiotis, Minister of Commerce, Industry, and Tourism to Gary Lakes of the Middle East Economic Survey, Vol. LV No 18, 30 April 2012 (Cyprus targets roles as regional energy center), www.mees.com

${ }^{91}$ Specifically, Shell is working on its FLNG Lean concept that could produce 6 mmtpa and would be suitable for dry gas wells, reducing unit costs. Upstream Online, Shell in global hunt to deploy FLNG lean unit, 7 June 2012, www.upstreamonline.com.

${ }^{92}$ See Reuters, Shell gives nod to world's first floating LNG project, 20 May 2011, www.reuters.com ; and PFC Energy’s liquefaction projects database at its Global LNG Service, www.pfcenergy.com.
} 
while politics of an onshore terminal on national soil and job creation could also play a role. ${ }^{93}$ In contrast, it is being considered in Israel as an option for the monetisation of the Myra and Sarah, Shimshon, and Tamar fields (three projects) albeit with no supermajor's involvement. ${ }^{94}$ This lack of support from a major IOC with relevant experience undermines confidence in the ability to execute these demanding projects and, unless land requirements prove to be an insurmountable obstacle in Cyprus, renders FLNG a rather less credible option at the moment.

\subsubsection{Cooperation with Israel and Noble Energy}

The geographic proximity of Cypriot and Israeli upstream fields renders unitisation agreements and joint monetisation through liquefaction an attractive proposition for very practical reasons for both countries, with commercial cooperation between them inevitably spilling over onto the political level too. The Israeli government has thus lent its political (suggesting possibly also military) support to drilling activities in Cyprus, while Israeli company Delek has successfully farmed-in to Noble Energy's Block 12; and both Delek and a number of other Israeli players have submitted bids in the second licensing round of Cyprus. Moreover, potential monetisation of Cypriot and Israeli gas via joint liquefaction in Cyprus could allow Nicosia to benefit from the Israeli diplomatic and military security umbrella, which might be necessary to counter the ongoing Turkish political risk. Importantly though, joint development and unitisation agreements too represent significant technical/commercial instruments that tend to bind partners strongly together in political terms as well.

On the commercial level, such joint reserve monetisation with Israel would allow Cyprus to reach the critical mass needed to achieve economies of scale and underpin project economics, thereby also improving margins and profitability for their joint LNG export infrastructure; without having to wait for an extra 3-4 years to prove up new reserves from its second round. This could allow realisation of government revenue from hydrocarbon activities much earlier, a welcome prospect in the present context of increasing pressures on the Cypriot economy. ${ }^{95}$

\footnotetext{
${ }^{93}$ Information from author's discussions with regional government and industry officials, April and June 2012.

${ }^{94}$ Operator Noble Energy is also set to launch a pre-qualification exercise for a Floating Production and Storage and Offloading (FPSO) at its Leviathan field in Israel's EEZ; whilst, at the same time looking to bring in a partner with suitable LNG experience. At the moment, it still remains unclear how this FPSO may progress and/or fit with an export scheme for the relevant reserves. For more details on these issues see Upstream, New floater to kick-start Leviathan development, 1 June 2012, Vol. 17, Week 22; and PFC Energy, Global LNG Service, www.pfcenergy.com.

${ }^{95}$ Including the recent relatively small Tanin discovery offshore Israel, Noble has discovered gross gas mean resources of some 35 tcf in the Levant basin. More information is available at Upstream Online, Noble in Tanin gas strike, 6 February 2012,
} 
It should be noted though that if considerable liquid content (condensates and/or deep oil) were also proved-up in Aphrodite under Noble's appraisal drilling by end-2012 / early 2013, this could enhance dramatically its economics and allow it to proceed as a stand-alone project, without the need to consider wider economies of scale and cost reduction.

However, and despite the aforementioned commercial and political benefits for Nicosia, cooperation between Cyprus and Israel on hydrocarbon exploitation, including monetisation, is neither risk-free nor an option that may be exercised at will by either of these two parties. For example, cooperation of Israel with Cyprus could prove impossible in cases of:

1. A decision by Israel not to export gas, to enhance its own long-term supply security; ${ }^{96}$

2. A decision by Israel to export some gas, but retain infrastructure within its territory;

3. A decision by Israel to export gas, but with facilities in a country other than Cyprus;

4. A decision by Israel not to become involved with the Cyprus dispute if its foreign policy imperatives, including its diplomatic relations with Turkey, dictate so.

Some of these potential reservations were reflected in the non-binding recommendations of Israel's Tzemach committee which is in favour of relatively limited gas exports from Israel, but under the explicit provision that any export infrastructure with reference to Israeli natural gas will have to be under Israeli control and also to be located within Israeli territory. ${ }^{97}$ Similarly, and looking at such co-operation from the Cypriot point of view, if ownership and

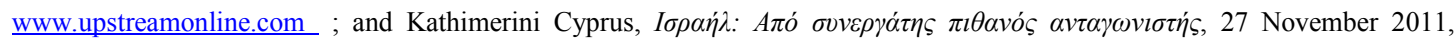
www.kathimerini.com.cy.

${ }^{96}$ Israeli concerns are not alleviated by difficult diplomatic relations with some neighbouring countries, or by the problematic supply from Egypt since the overthrow of Hosni Mubarak in February 2011. Indeed, the export pipeline linking Egypt with Israel was bombed at least 14 times between February 2011 and April 2012, when the Egyptian Natural Gas Holding Company (EGAS) claimed breach of contract due to missed payments and scrapped its deal with the East Mediterranean Gas Company (EMG); thus terminating supply to Israel (see BBC News, Egypt scraps Israel gas supply deal, 23 April 2012, www.bbc.com).

${ }^{97}$ The Tzemach Committee sees four priorities with regard to local gas: a) assured long-term gas supply in the domestic market; b) boosting gas market competition; c) ensuring low gas prices for local consumers; and d) increasing government revenue. Inherent tensions between these principles have manifested in a reported disagreement between the Finance Ministry of Israel, which prefers to maximise export quantities to increase government revenue; the Tzemach Committee which has recommended that approximately $400 \mathrm{bcm}$ (roughly half of current discoveries) stay in Israel to cover envisaged local needs for gas to 2040; and the Environmental Protection Ministry and others who want an even larger share to be kept in Israel for security purposes. For more information see Haaretz, State to allow export of 50\% of gas reserves, 6 April 2012, www.haaretz.com ; and also Globes, Tzemach committee to recommend allowing gas exports, 20 March 2012, www.globes.co.il. 
other applicable structures in the proposed joint liquefaction plant reflected shares of feedstock natural gas volumes (i.e. as it has reportedly been requested by the Israeli side), ${ }^{98}$ then that could undermine the declared goal of Nicosia to retain control of all strategic energy infrastructure that is to be developed on the island, including liquefaction infrastructure. ${ }^{99}$ Excessive reliance on Israeli gas fields in early phases of development could undermine monetisation of any new Cypriot finds and render Cyprus a mere liquefaction service provider to Israel, if the bulk of the available land at the Vasilikos area for three to five liquefaction trains of $5 \mathrm{mmtpa}$ each is taken up by units that would be dedicated to Israeli fields instead. While this might still earn significant revenue and provide skilled employment opportunities, it does not appear to fit well with the strategic aspirations of Nicosia. ${ }^{100}$

Furthermore, the discussed joint monetisation of gas reserves between Israel and Cyprus would represent the first arrangement in the world whereby volumes from one country are transported for liquefaction to another, and are then exported as LNG from that latter country. This will in all probability present the governments and commercial partners on both sides with a number of serious legal, political, and commercial complications to overcome. ${ }^{101}$

There is also a threat that close cooperation with Israel including joint asset development could discourage possibly interested IOCs from investing in gas export facilities in Cyprus, as a necessary and in reality inescapable means of protecting their present good relationships with (as well as also positioning in) MENA countries that may be hostile to the state of Israel. This could deprive Cyprus of potentially valuable partners with needed financial capabilities, project experience, and relevant operations across the LNG value chain; and consequently

\footnotetext{
${ }^{98}$ This position has not been officially confirmed though and could theoretically be overcome by other relevant arrangements, e.g. with Israel booking medium-term capacity as needed rather than actually owning equity. However, the recommendations of the Tzemach committee suggest that real long-term control over export infrastructure will likely be a key Israeli objective.

${ }^{99}$ More information in Upstream Online, Cyprus looks for possible LNG partners, 28 March 2012, www.upstreamonline.com ; also in the interview of Neoklis Sylikiotis, the current Minister of Commerce, Industry, and Tourism to Kathimerini Cyprus,

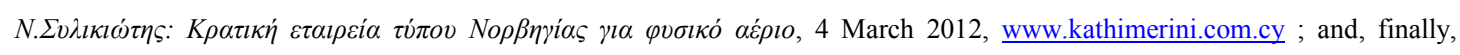

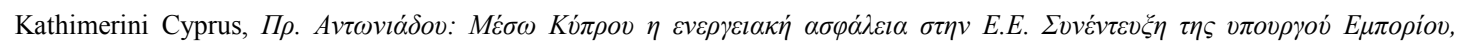

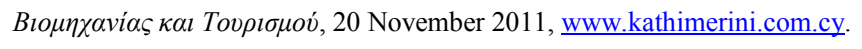

${ }^{100}$ Map 11 below offers an overview of the designated area at the Vasilikos industrial area, as the latter currently stands.

${ }^{101}$ PFC Energy, www.pfcenergy.com
} 
also of their ability both to contribute towards the implementation of this liquefaction project, as well as to improve associated project economics and to enhance its global market access. ${ }^{102}$

If the Cypriot government moves forward immediately and under the existing commercial arrangements with the development of a 5 mmtpa expandable liquefaction plant at Vasilikos, as it has been proposed by Noble and was in fact accepted by the government in June 2012, then this would present Nicosia with another set of important challenges to overcome, i.e. accepting project economics as they currently stand without achieving economies of scale ${ }^{103}$ and relying exclusively for this costly and complex development, commercial arrangements, and consequent profit margins, on a partner with a relatively limited capital programme (around USD 3.5 billion globally in 2012); and with little liquefaction and trading experience. Indeed, the experience of Noble Energy in the LNG context remains limited to its upstream operations in Equatorial Guinea, where it supplies a local methanol plant and an LPG processing plant, as well as the Marathon-operated Equatorial Guinea liquefaction plant. ${ }^{104}$

Against this background, the company recently hired Citibank to help it find partners with LNG expertise and financial strength, to join its operations in the East Mediterranean. Nevertheless, given the substantial involvement of Noble Energy in E\&P operations in Israel, it remains to be seen exactly how successful the company may be in attracting experienced IOCs, which could also enjoy strong links to energy-rich MENA countries hostile to Israel. ${ }^{105}$

At any rate, Noble Energy and the Cypriot authorities have been assessing the liquefaction option in some detail and have held preliminary discussions on the commercial aspects of the

\footnotetext{
${ }^{102}$ Still, the Republic of Cyprus is bound to face difficulties of this kind with companies that have already invested - or are planning to proceed with such investments - in the growing Turkish upstream, midstream, and downstream energy market. Meanwhile, close LNG cooperation with Israel would probably be less of a problem for potential Sales and Purchase Agreements (SPAs) which will involve no upstream and/or liquefaction equity; as regional utilities and even IOCs seeking to boost their LNG portfolios for global trading purposes would likely find this position significantly less invasive and, therefore, easier to maintain vis-à-vis their MENA and/or Turkish upstream and downstream investment links. Importantly, the potential signing of such SPAs with IOCs with flexible portfolios and active trading departments could offer Cyprus and/or Israel opportunities to benefit from the commercial upside of marketing operations (provided of course that the applicable SPAs are appropriately structured), by relying on substantial IOC experience and related expertise for capturing profitable arbitrage opportunities.

${ }^{103}$ Unless proving-up substantial liquids content in Aphrodite with Noble's planned appraisal drilling by end-2012/early 2013; and, hence, overcoming this by radically improving project economics.

${ }^{104}$ Information from Noble Energy's website under sections Fact Sheet and Operations, both of them accessed on 9 April 2012, available online at www.noblenergyinc.com.

${ }^{105}$ More in Upstream Online, Noble starts Leviathan partner hunt, 20 April 2012, www.upstreamonline.com.
} 
proposed LNG plant at Vasilikos - in other words, whether Cyprus LNG should move forward as an integrated project, as a tolling facility, or even as a merchant liquefaction plant. Tolling arrangements are seen as better geared to ensure third-party access to the plant. ${ }^{106}$

\footnotetext{
${ }^{106}$ Information from author's discussions with regional government and industry officials, April and June 2012.
} 
Map 11: Vasilikos industrial area

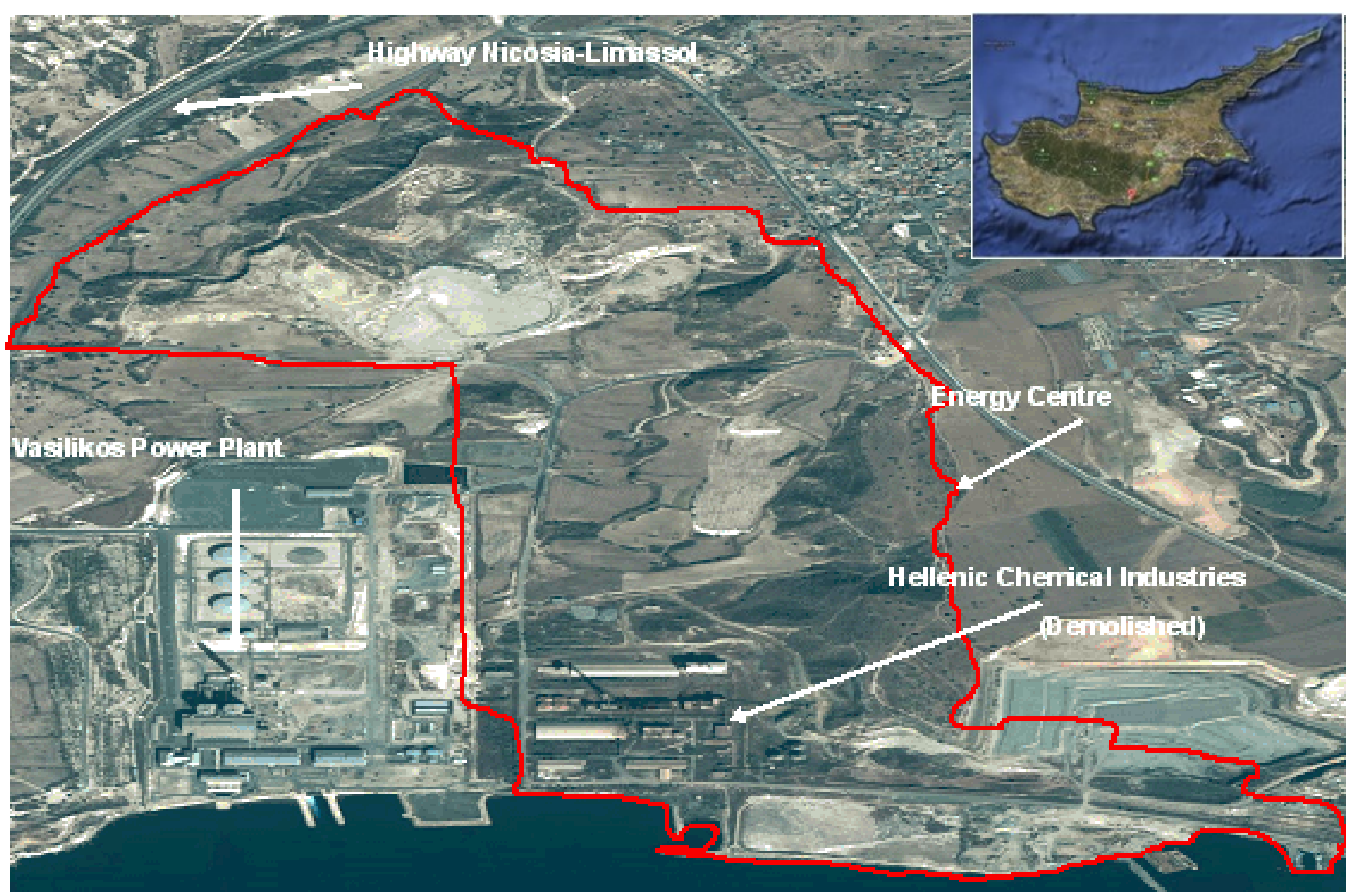

Source: Ministry of Commerce, Industry, and Tourism of the Republic of Cyprus 


\section{National hydrocarbons strategy and institutional capacity}

The Republic of Cyprus is expected to evolve in a relatively short period from a status whereby it is not even an importer of gas, to one where it participates across its value chain; including production of gas; its transportation and use in the local market; liquefaction; and marketing of available export volumes internationally, alone or in collaboration with Israel. This is causing an understandable, yet still entirely unwelcome, strain on its institutional capacity and relatively limited available skilled human resources, which could discourage investment and/or efficient development of its hydrocarbon potential.

For example, shortly after taking over as Minister of Commerce, Industry and Tourism in August 2011, Praxoula Antoniadou clashed with Solon Kassinis, the Director of the Ministry's Energy Service, instigating a disciplinary hearing against him for speaking to media without prior permission; while in October 2011, new Minister Antoniadou revoked the authorisation of Kassinis and his team to oversee Noble's operations as per PSC terms. Against this background, and following approximately five months of relevant deliberations, in late February 2012 the Cypriot parliament, in which the ruling AKEL has lost its majority, amended with cross-party support (except AKEL) the Hydrocarbons Law of 2007 and repatriated operational oversight of upstream licence holders to the Energy Service Director (and also to the Ministry's Director General), this time assigning them responsibility on that level, rather than merely reinstating earlier ministerial authorisations to that end. ${ }^{107}$

Moreover, the amendment scrapped a previous Advisory Committee which consisted of the Director General of the Ministry of Commerce, Industry and Tourism; the Attorney General; the Director General of the Ministry of Foreign Affairs; the Director General of the Ministry of Finance; the Director General of the Ministry of Agriculture, Natural Resources and Environment; the Director of the Geological Survey; and the Director of the Energy Service. Under the Law of 2007, this Advisory Committee was tasked with evaluating upstream bids and making relevant recommendations to the Minister of Commerce, Industry and Tourism. The 2012 amendment replaces it with a Technical Committee with the same composition plus the Accountant General; and the Auditor General who participates in meetings as an observer. However, the most significant departure compared to that basic Law of 2007 (as now termed)

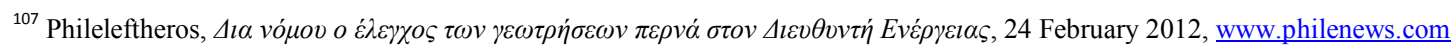


is with reference to the committee's actual responsibilities, which now expand to include, besides the evaluation of upstream bids, also contract negotiation with the selected bidders. ${ }^{108}$

The Cypriot government in the form of its Council of Ministers still needs to approve bidders, both initially and after the completion of negotiations (and may even ask for renegotiation). Furthermore, the government retains the right to proceed with direct assignments of upstream licenses in cases of overriding national security and / or of public interest considerations. However, under normal circumstances, neither the Council collectively, nor individually the Minister of Commerce, Industry and Tourism, can engage directly with contract negotiations. These provisions have been very strongly criticised and opposed by the AKEL administration, which has expressed fears that non-elected officials will control core strategic state affairs. Against this backdrop, and following a failed referral of the amended Law back to Parliament by President Christofias in March 2012, in April 2012 he referred the case to the country's Supreme Court, asking for an opinion on the constitutionality of these and other amendments. The Supreme Court has yet to issue its opinion on this important matter. ${ }^{109}$

Furthermore, in March 2012, Minister Antoniadou was replaced by then Interior Minister Neoklis Sylikiotis, with Antoniadou going so far as to accuse her former government and AKEL party colleagues of deliberately undermining her work as the Minister for Commerce, Industry and Tourism, notably with reference to her responsibilities in the energy sector. Moreover in April 2012 the former Minister lodged an appeal with the Supreme Court against President Demetris Christofias, on procedural flaws in her dismissal as Minister in March. Should the Court rule in favour of Antoniadou, then all decisions of new Minister Sylikiotis (including in the hydrocarbons area) could be considered null and void. ${ }^{110}$

The regulatory environment is further complicated by the relative lack of clarity concerning the responsibilities of the various state and independent bodies/organisations which have been

\footnotetext{
${ }^{108}$ Ibid. ; and also Ashurst, Energy briefing: the oil and gas regime in the Republic of Cyprus, March 2012, www.ashurst.com ;

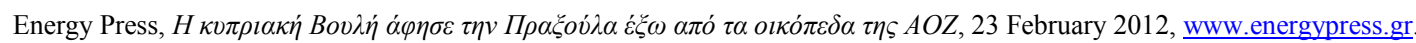

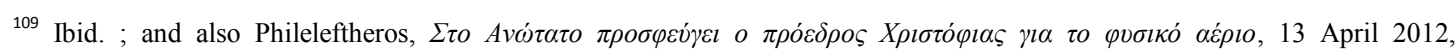

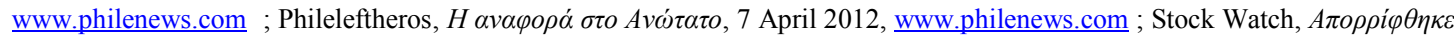

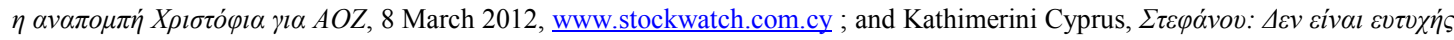

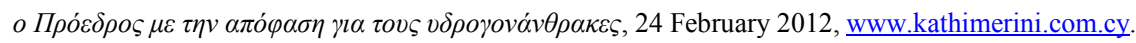

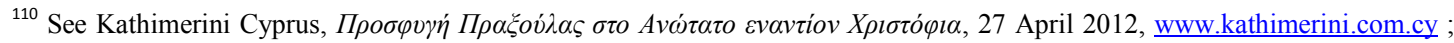

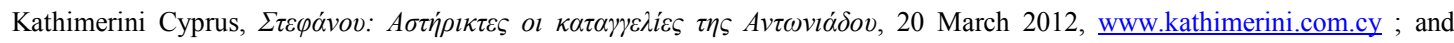

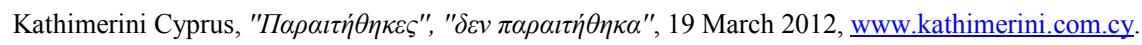


set up in the emerging framework for gas (and hydrocarbons more generally). For example, in March 2012 Parliament granted the Public Gas Corporation DEFA a monopoly status over imports and marketing of natural gas, including of LNG, into the domestic Cypriot market (i.e. besides DEFA's role as owner of the transmission and distribution systems) for as long as Cyprus remains an isolated energy system under EU rules/regulations. However, AKEL voted against these provisions due to unresolved legal issues which were flagged by the Law Office. Moreover, in April 2012 President Christofias referred this case as well to the Supreme Court, for an opinion on its constitutionality. ${ }^{111}$

Other complications in this framework stem from the interest of certain state-owned market participants such as EAC in a direct stake in potential liquefaction infrastructure in Cyprus, due to it being the largest potential domestic consumer. However, and even though it is unlikely EAC could acquire any substantial such stake given the high capital requirements, its option for a $44 \%$ stake in DEFA may complicate matters. ${ }^{112}$ In the same vote of March, Parliament also confirmed that the Cyprus Energy Regulatory Authority (CERA/RAEK) would play a role in gas exports; while it will possibly also be tasked with granting third-party exemptions to Noble Energy for the pipeline that will link Aphrodite with onshore Cyprus. The regulator is also invited and attends meetings on relevant matters with Noble Energy. ${ }^{113}$

Earlier, in November 2011, the government had set up a "Wise Men Committee" comprising members with substantial upstream and midstream experience with the IOCs BP and Shell; with engineering companies Schlumberger and KBR; as well as with international academia, to offer advice on technical and commercial matters pertaining to monetisation of Aphrodite and long-term strategic planning with regard to hydrocarbons exploitation more generally. ${ }^{114}$

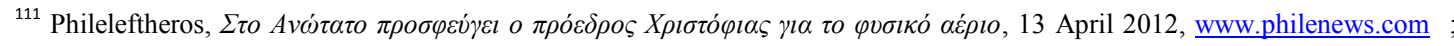

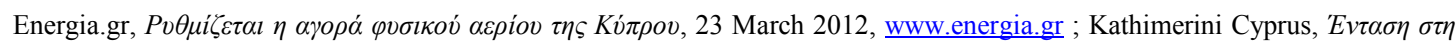

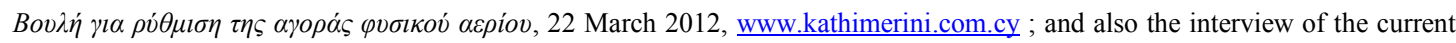

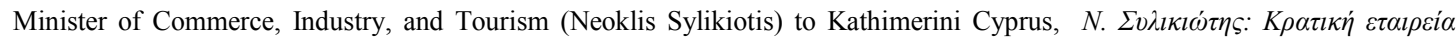

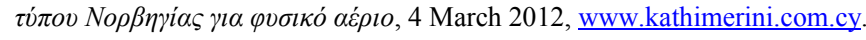

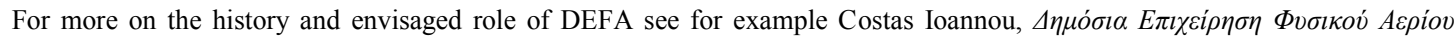
$(\triangle E \Phi A)$, Presented at the $1^{\text {st }}$ Cyprus Energy Symposium, 26 January 2012, www.iene.gr.

${ }^{112}$ Information from author's discussions with regional government and industry officials, April and June 2012; and also from Kathimerini Cyprus, $\Lambda \alpha \nu \theta \alpha \sigma \mu \varepsilon \dot{v o \varsigma}$ o $\delta \imath \alpha \chi \omega \rho \imath \sigma \mu o ́ \varsigma \tau \eta \varsigma \kappa v \pi \rho \imath \alpha \kappa \eta ́ \varsigma A O Z, 11$ December 2011, www.kathimerini.com.cy ; and

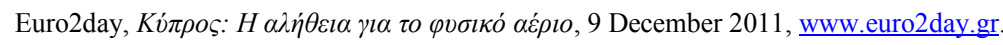

${ }^{113}$ Ibid.

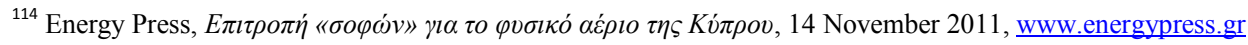


Furthermore, in June 2012 the government appointed a small team consisting of the Deputy Accountant General Andreas Zachariades, Energy Service Director Solon Kassinis, Wise Men Committee member Theo Kontou, and a representative of the Law Office, with the aim of negotiating monetisation of the Aphrodite offshore gas discovery with Noble Energy, including both the arrival of gas onshore Cyprus and the development of LNG infrastructure, apparently with an emphasis on third-party access. ${ }^{115}$

Exactly how all relevant arrangements will be complemented and/or superseded by the planned establishment of a dedicated new state-owned upstream operator and marketer of local hydrocarbons, based on the Norwegian model of Petoro and Statoil, is still rather vague. According to Minister Sylikiotis, the company is to be established soon and participate across the value chain, including in new PSCs and E\&P operations under the second licensing round; while it will also participate in any export infrastructure that is to be developed with the aim of monetising local gas reserves; as well as in the marketing of profit hydrocarbons. ${ }^{116}$

Finally, it is not yet clear specifically how and to what extent all these bodies will be able to develop expertise and work together in a way that maximises local hydrocarbons potential; or how pending referrals to the Supreme Court and other legal proceedings may stall progress. The fact that a presidential election is to take place and as a result the government may be changed in less than a year (February 2013) adds even more to this regulatory uncertainty. Importantly, the institutional capacity of Cyprus to deal with all these issues will be tested in the forthcoming evaluation of bids which were submitted under its second licensing round; and even more so in highly complex (technically/commercially) negotiations on monetisation. While in terms of timing, the 6-month rotating EU presidency taken over by Nicosia on $1^{\text {st }}$ July 2012 is expected to stress even more the, already relatively thin, resources of the country. If current institutional arrangements in Cyprus prove inadequate to deal with the task at hand, this may lead to significant delays and undermine realisation of the local hydrocarbon potential, to the detriment of the Republic of Cyprus, local consumers, and foreign investors.

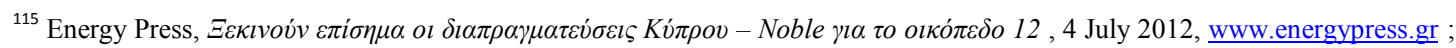

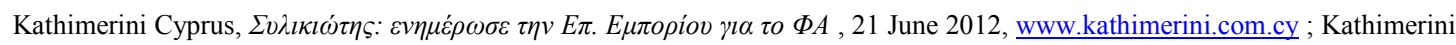

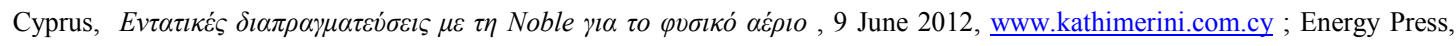

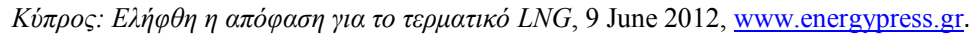

${ }^{116}$ Cypriot authorities are also considering the establishment of a sovereign wealth fund, again based on the Norwegian model. See the interview of N. Sylikiotis, Minister of Commerce, Industry, and Tourism to Kathimerini Cyprus, $\Sigma v \lambda \imath \kappa \iota \omega ́ \tau \eta \varsigma \sigma \tau \eta v ~ « K »$ :

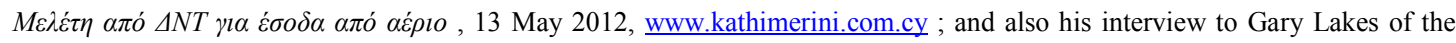
Middle East Economic Survey, LV No 18, 30 April 2012 (Cyprus targets roles as regional energy center), www.mees.com.
} 


\section{Conclusions}

\subsection{Export potential and political risk}

Subject to confirmation of a commercially viable development plan for the existing discovery and also encouraging results from the second drilling round to underpin an export strategy, gasification in Cyprus is expected to move forward relatively quickly as a means of removing dependency on expensive oil product imports, and hence reducing its overall energy bill. Power generation and also parts of the stationary sector would probably gasify relatively swiftly following production start-up, which is at the moment expected around 2017/2018; with full field development and exports commencing some two years later, in 2019/2020. However, this may prove an optimistic timetable, as the envisaged modest requirements in the local market (probably below 0.9 bcma by $2017 / 2018$ and 1.7 bcma by 2025) mean Noble will probably insist this is part of a full scale development plan for its 5-8 tcf Aphrodite discovery. At the same time however, this small domestic requirement for gas lends credence to the emergence of Cyprus as a new export source, even if based just on the Aphrodite field.

However, this significant potential may be threatened by political risk related to the continuing Cyprus dispute and wider. Turkish warnings to the IOCs not to invest in Cyprus are significant, given the increasing investment opportunities offered in its energy sector. Some IOCs - including supermajors with regional assets and a potential strategic fit in the upstream, mid, and downstream sectors - were notable for their absence from bidding in the second licensing round, while the fact that blocks 1 and 4 did not receive any bids may in reality reflect both geological potential but also political risk from the opposition of Turkey, as Ankara claims that certain parts of these blocks fall within its own continental shelf.

Still, the range of companies and consortia including integrated IOCs, upstream independents, gas buyers and traders, and regional companies that did submit bids in the second round suggests there will probably be sufficient skills and financial strength in aggregate to realise the upstream and monetisation potential; even though these players are characterised by wide disparities in financial capacities, business strategies; and technical/commercial skill-sets. Moreover, equally disputed blocks 5, 6, and 7 seem to have been successful in attracting bids; while the high demand for 2 and 9, coupled also with the success of 3 and 8 in attracting bids, suggests interested parties were not particularly concerned or discouraged by the - always problematic - continental shelf and upstream agreements recently signed in northern Cyprus. 


\subsection{Monetisation options}

In June 2012, Nicosia decided to take all necessary steps towards development of liquefaction facilities in Cyprus, in line with the preference of Block 12 licence holder, Noble Energy. Liquefaction and hence export via LNG offers important advantages which for the most part remain inaccessible with other export options. First, the LNG market is more dynamic than the gas market, which it outpaces by a wide margin (CAGRs of $8.4 \%$ vs. $2.6 \%$ in $2000-2010$ ). While driven in the main part by the fast demand growth for natural gas in Asian economies, this is also the result of increased offtakes from other existing customers and a rising number of countries entering the LNG market, which helps to improve price floors for LNG sellers. Moreover, LNG demand is to remain strong (and may even penetrate the bunker sector too).

Second, LNG's inherent flexibility enables it to reach premium markets irrespective of their location. In the present framework, this translates into access to markets in the Asia-Pacific, where sellers enjoy more opportunities to sign long-term, oil-indexed supply contracts with slopes close to oil parity; compared to considerably less favourable slopes in Europe and even a push by European buyers to break away from oil-indexation and be priced off traded hubs. And third, provided this flexibility is embedded in applicable SPAs, there is also room for potentially very profitable arbitrage opportunities between the Atlantic and Pacific Basins; albeit this is usually the prerogative of later trains, less in need of firm contracts to underpin their bankability; and could thus probably only be realised for trains subsequent to Aphrodite.

The geographic location of Cyprus suggests it could access a very wide range of gas markets at affordable costs, as exhibited by the global marketing reach of the adjacent Egyptian plants, which in 2011 accessed 16 countries in Europe, Asia, the Middle East, and the Americas. Indicatively, differentials in spot gas prices between Japan/Korea and Spain in March 2012 stood at USD 5.25/mmbtu; and as high as USD 6.4/mmbtu between Japan/Korea and the UK. However, these competitive advantages and market flexibility offered by LNG monetisation will have to be to be assessed against a number of factors working in the opposite direction. First, the high unit costs of liquefaction, which for a single-train plant are estimated at USD 4.5-6/mmbtu (excluding upstream costs). Second, the currently high LNG shipping rates. Third, the fact that strong demand for gas in Asia cannot be assumed to endure indefinitely. Fourth, the downside risks stemming from the exposure of LNG to oil price volatility. And, fifth, that the continued appetite for such price formation should not be taken for granted. Another factor to consider in this framework is also the scale of the new liquefaction projects which are set to come on-stream in the coming decade; primarily Australian greenfield plants, but there could also be potentially large LNG exports from North America and East Africa. 
Monetisation via gas pipeline to Greece, or even to Turkey, could offer access to promising markets with relatively high oil-indexed prices, and regional synergies with existing and planned infrastructure, including the Southern Corridor and some smaller interconnectors. This means that East Mediterranean gas could flow westwards to large European markets such as Italy; and northwards to natural gas markets in South East and even Central Europe. Furthermore, there are hopes South East Europe could offer opportunities for increased gas imports from new sources in the coming years, due to growing energy needs in general; declining indigenous gas production; substitution of inefficient and polluting fuels with gas; and a desire to diversify their current natural gas import mix with new (non-Russian) supplies.

There might even be a strong political rationale to support construction of such a gas pipeline, as its development would unlock a fifth corridor for the supply of Europe, while inevitably also committing all capacity to European buyers (rather than just a part as with flexible LNG). This could be a political gesture towards EU supply security and economic competitiveness; and it could also benefit greatly South East Europe, one of the most vulnerable European regions in terms of supply disruptions, as demonstrated in the 2009 Russo-Ukrainian crisis. All this would in fact be strongly confluent with EU policy, especially given the lowered expectations of substantial volumes of natural gas to Europe via its Southern Corridor project; thereby boosting the diplomatic and political capital of the contributing parties in EU circles. Greece seems a more probable partner for this project as, each for different sets of reasons, Cyprus, Israel, and even the EU would want to avoid full transit dependency on Turkey.

However, there is still relatively little consensus on the commercial viability of this project. First, there are concerns about the potential technical complexity of the proposed gas pipeline, which stem from its significant length and the sea depths in which it will need to be laid. Second, even if in fact viable, the project is dependent on successful completion of other downstream infrastructure projects to allow it to reach its full export potential beyond Greece, including both upgrades in the Greek natural gas system and new regional interconnectors. Third, even if these technical/economic obstacles are successfully overcome, the pipeline still locks suppliers into a relatively limited number of regional gas markets, compared to LNG. Fourth, there are important uncertainties in connection with anticipated market opportunities in South East Europe, notably concerning realisation of their demand potential and pricing. And fifth, exports by pipeline to South East Europe (and even to Central Europe and Italy) will have to compete not only with the existing long term contracted supplies from Russia, but also new Azeri gas from Shah Deniz 2 and other pipeline sources such as South Stream; and in the longer-term with Turkmenistan and indigenous Black Sea and unconventional gas. 
The alternative of developing a pipeline to Greece and beyond as a complement to rather than a substitute for liquefaction looks attractive, by theoretically offering the best of both worlds. However, it fails to take into account the importance of brownfield economics and economies of scale in the context of costly infrastructure development such as liquefaction. LNG projects tend to improve their profitability significantly as they expand beyond their first greenfield phase and capture cross-train synergies and the ensuing cost efficiencies, thereby reducing their applicable unit costs by between $15 \%$ and $35 \%$ (or, minus USD 1 to $1.5 / \mathrm{mmbtu}$ ); enhancing their access and terms vis-à-vis capital markets; and even ameliorating sales terms, including in the framework of both their contractual as well as spot sales.

Given the very clear risk for regional players that Cyprus (and/or Israel) will move towards the liquefaction monetisation option, rather than for their own natural gas pipeline proposals, there is value for them in adopting a much more flexible commercial position in this context; potentially seeking small equity stakes in liquefaction, or in the upstream to capture margins. At the same time, thanks to their involvement early on in the relevant development process, they might even be able to benefit from securing better terms in possible SPAs they will sign. The above are of course contingent on players having adequate access to capital and markets. Still, early involvement and negotiation for firm and potentially also favourably-priced LNG supply contracts (with or without equity) would also buttress the project rationale for the development of gateway regasification terminals targeting markets in South East Europe.

At any rate, the decision on the preferred export strategy for the offshore natural gas discovery in Cyprus is a fundamental one, and directly affects the plan for field development. Against this backdrop, it requires early structured studies on the part of the key stakeholders; but, in practical terms, resourced and driven by those IOCs which will ultimately invest in it. These studies will need to include both scoping and costing of all field development options, and market feasibility including discussions with potential customers for the given volumes, whether to be delivered by pipeline or as LNG; and in the case of monetisation by pipeline, discussions also with infrastructure owners and operators including potential transit countries. Only after such work is successfully completed can a rational assessment and decision on a the preferred monetisation/export option for Cypriot gas reserves be made.

It is possible local reserve monetisation will depend heavily also on geopolitical calculations. Ultimately though, the solution which proceeds to completion will be the one providing the best returns for the IOC investors. And should political preferences rule out such an option, the result is likely to be project delay and, in extremis, cancellation. 


\subsection{Co-operation with Israel and Noble Energy}

Assuming Israel would commit on a firm basis to co-operation with Cyprus; and that joint monetisation is able to overcome all the legal, political, and commercial challenges posed by being the first arrangement in the world whereby gas from one country is liquefied and exported through another, Cyprus would benefit on both the commercial and political levels.

First, joint monetisation of gas from the Aphrodite discovery - the only discovered resource in Cyprus at the moment - with natural gas reserves from Israel would allow Cyprus to reach an early critical mass to underpin project economics and achieve economies of scale, without having to wait for an extra 3-4 years to prove up new reserves from its second round. However, existence of considerable liquid content in Aphrodite could dramatically enhance its economics and allow it to move as a stand-alone project without need for wider synergies; thus Noble's planned appraisal drilling in late 2012/early 2013 could be very important. Second, Nicosia could benefit substantially from the Israeli diplomatic and military security umbrella, which might in fact be necessary in order to counter the Turkish political risk. Importantly though, joint development and unitisation agreements too represent significant technical/commercial instruments, which tend to bind partners strongly together in political terms as well. It is therefore likely that such an agreement with Israel could offer enough alignment and political backing to Cyprus, without having to proceed with joint liquefaction.

In connection to this latter point, a heavy reliance on Israeli gas as feedstock of a joint plant, particularly if this is accompanied by corresponding equity, as reportedly requested by Israel, would put in jeopardy the declared goal of Nicosia to retain strategic control over these assets. And it could even undermine monetisation of new gas finds and render Cyprus a mere liquefaction service provider to Israel, if the bulk of the available land at the Vasilikos industrial area is taken up by liquefaction trains that would be dedicated to Israeli gas fields. While this might still earn significant revenue and provide skilled employment opportunities, it does not appear to fit well with the strategic aspirations of Cyprus.

Furthermore, there is a threat that such close co-operation with Israel could discourage potentially interested IOCs with MENA positions from investing in facilities in Cyprus, possibly depriving it of partners which could help with project economics and marketing. And, thus, it could also force Nicosia to rely on one, smaller, and so far inexperienced partner (in terms of large LNG projects), Noble Energy; unless the latter is successful in enlisting partners with LNG experience and financial resources (e.g. through a Block 12 farm-in), which may be difficult exactly because of its Israeli links. 


\subsection{Institutional capacity}

Cyprus is expected to evolve in a relatively short period from a status whereby it is not even an importer of natural gas, to one where it participates across its value chain from upstream to downstream, including natural gas production; transportation and use in the local market; liquefaction; and marketing of available export volumes internationally, alone or with Israel. This is causing an understandable, yet still entirely unwelcome, strain on the institutional capacity and the relatively limited available resources of Cyprus, which could discourage investment and/or efficient development of its hydrocarbon potential. It is not yet clear how, and to what extent, these various bodies and organisations set up will be able to develop expertise and work together in a way that maximises national hydrocarbons potential; or how pending referrals to the Supreme Court and other legal proceedings may stall progress. Importantly though, the institutional capacity of Cyprus to deal with these serious issues will be tested in the forthcoming evaluation of bids submitted under its second licensing round; and more so in the highly complex (technically/commercially) negotiations on monetisation. If current institutional arrangements in Cyprus prove inadequate to deal with the task at hand, this may lead to significant delays and undermine realisation of local hydrocarbon potential, to the detriment of the Republic of Cyprus, local consumers, and foreign investors.

\subsection{Impact of and on the Cyprus dispute}

Politically and commercially, it would be very challenging to monetise Cypriot natural gas via a gas pipeline to and/or through Turkey, even if as a means of solving the Cyprus dispute. In contrast, a pledge to construct a spur pipeline from territories under government control to north Cyprus as soon as practicable after gas production from Aphrodite has commenced, would represent a real and practical step towards sharing the benefits of Cypriot natural gas. A move with low cost but high symbolic value in this context could include the development of a natural gas connection between the two sides of Nicosia, the world's last divided capital.

Moreover, the very presence of commercially recoverable hydrocarbons in Cyprus and the wealth creation associated with this could become the catalyst for solving the Cyprus dispute; or conversely it could offer arguments, and in fact reinforce resistance to reunification efforts, e.g. if Greek Cypriots feel that they are not getting enough in return for sharing their wealth; or, if the Turkish Cypriots believe that they are not getting a fair and equitable share out of it. This dimension is likely to play a very important role in any decision concerning development of the Cypriot natural gas sector, with its commercial and political ramification transcending the narrow boundaries of the Republic of Cyprus and the East Mediterranean. 


\section{References}

Ashurst, Energy briefing: the oil and gas regime in the Republic of Cyprus, March 2012, www.ashurst.com

Electricity Authority of Cyprus (EAC), Tender 90/2011, Supply and delivery of heavy fuel oil for the period 1 December 2011 to 31 January 2013, www.eac.com.cy

Fattouh, Bassam and Stern, Jonathan (eds.), Natural gas markets in the Middle East and North Africa, Oxford Institute for Energy Studies, 2011, www.oxfordenergy.org

Giamouridis, Anastasios, Natural gas in Greece and Albania: supply and demand prospects to 2015, Oxford Institute for Energy Studies, December 2009, www.oxfordenergy.org

Giamouridis, Anastasios and Paleoyannis, Spiros, Security of gas supply in South Eastern Europe: potential contribution of planned pipelines, $L N G$, and storage, Oxford Institute for Energy Studies, July 2011, www.oxfordenergy.org

Heather, Patrick, Continental European gas hubs: are they fit for purpose, Oxford Institute for Energy Studies, June 2012, www.oxfordenergy.org

International Crisis Group, Aphrodite's gift: can Cypriot gas power a new dialogue, Europe Report No 216, 2 April 2012, www.crisisgroup.org

Karayannakos, Konstantinos, East Mediterranean gas: Greece - the gateway to Europe, Presented at the $1^{\text {st }}$ Academy of Athens Hydrocarbons Conference, 20 April 2012, www.academyofathens.gr

Kassinis, Solon; The status of hydrocarbon exploration in Cyprus, Presented at the Israel Business Conference, Tel Aviv, Israel, 12 December 2011, www.mcit.gov.cy

Kovacevic, Aleksandar, The potential contribution of natural gas to sustainable development to South Eastern Europe, Oxford Institute for Energy Studies, March 2007, www.oxfordenergy.org

Office of the Law Commissioner of the Republic of Cyprus, The Exclusive Economic Zone Law 2004, January 2010, www.olc.gov.cy 
Papanastasiou, Panos, The prospects for gas and oil exploration and exploitation in Cyprus, Presented at the $1^{\text {st }}$ Academy of Athens Hydrocarbons Conference, 20 April 2012, www.academyofathens.gr.

Rogers, Howard, LNG trade-flows in the Atlantic basin: trends and discontinuities, Oxford Institute for Energy Studies, March 2010, www.oxfordenergy.org.

Sachinis, Harry, The role of the ITGI System: New opportunities and synergies rise from the East Mediterranean, Presented at the $1^{\text {st }}$ Cyprus Energy Symposium, 26 January 2012, www.iene.gr

Sea NG, Floating CNG: a less expensive way to monetise offshore gas, Presented at the Eastern Mediterranean and North Africa Forum, 28 February 2012, www.emnagasforum.com

Stern, Jonathan, Continental European long-term gas contracts: is a transition away from oil product linked-pricing inevitable and imminent, Oxford Institute for Energy Studies, September 2009, www.oxfordenergy.org

Stern, Jonathan and Rogers, Howard, The transition to hub-based gas pricing in continental Europe, Oxford Institute for Energy Studies, March 2011, www.oxfordenergy.org

Tomich, John, Noble Energy: Cyprus gas discovery, Presented at the $1^{\text {st }}$ Cyprus Energy Symposium, 26 January 2012, www.iene.gr

\section{Web sites}

Academy of Athens, www.academyofathens.gr

AKEL, www.akel.org.cy

Aksam, , www.aksam.com.tr

AnsaMed, www.ansamed.info

Argus Media, www.argusmedia.com

BBC, www.bbc.co.uk

Bloomberg, www.bloomberg.com 
CIA World Factbook: www.cia.gov

CNBC News, www.cnbc.com

Cyprus Mail, www.cyprus-mail.com

Det Norske Veritas, www.dnv.com

DIKO, www.diko.org.cy

DISY, www.disy.org.cy

Energia.gr, www.energia.gr

Energy Information Administration (EIA), www.eia.gov

Energy Press, www.energypress.gr

EPP $20^{\text {th }}$ Congress, http://epp2011.eu

Ethnos, www.ethnos.gr

European Commission, http://ec.europa.eu

Euro2day, www.euro2day.gr

Federal Office of Economics and Export Control, www.bafa.de

Financial Times, www.ft.com

Globes, www.globes.co.il

Haaretz, www.haaretz.com

Hürriyet Daily News, www.hurriyetdailynews.com

Institute of Energy for South-East Europe; www.iene.gr

Jewish Journal, www.jewishjournal.com

Kathimerini Cyprus, www.kathimerini.com.cy. 
Middle East Economic Survey, www.mees.com

Ministry of Commerce, Industry and Tourism of the Republic of Cyprus, www.mcit.gov.cy

Ministry of Foreign Affairs of the Republic of Cyprus, www.mfa.gov.cy

Ministry of Foreign Affairs of the Republic of Turkey, www.mfa.gov.tr

Ministry of Interior of the Republic of Cyprus, www.moi.gov.cy

Natural Gas Europe, www.naturalgaseurope.com

New York Times, www.nytimes.com

Noble Energy, www.nobleenergyinc.com

Office of the Law Commissioner of the Republic of Cyprus,, www.olc.gov.cy

Oil \& Gas Journal, www.ogj.com

Penn Energy, www.pennenergy.com

Petrostrategies, www.petrostrategies.org

PFC Energy, www.pfcenergy.com

Phileleftheros, www.philenews.com

Platts, www.platts.com

Politis, www.politis-news.com

Reuters, www.reuters.com

Rigzone, www.rigzone.com

Sigma Live, www.sigmalive.com

Stock Watch, www.stockwatch.com.cy

They Work For You, www.theyworkforyou.com 
Today's Zaman, www.todayszaman.com

To Vima, www.tovima.gr

TPAO, www.tpao.gov.tr

UPB, www.ulusalbirlikpartisi.com

Upstream Online, www.upstreamonline.com

Waterborne, www.waterborneenergy.com

Wood Mackenzie, www.woodmacresearch.com

Zawya, www.zawya.com 